Portland State University

PDXScholar

6-11-1997

\title{
GIS Applications to Glaciology: Construction of the Mount Rainier Glacier Database
}

Jeremy Laurence Mennis

Portland State University

Follow this and additional works at: https://pdxscholar.library.pdx.edu/open_access_etds

Part of the Geography Commons

Let us know how access to this document benefits you.

\section{Recommended Citation}

Mennis, Jeremy Laurence, "GIS Applications to Glaciology: Construction of the Mount Rainier Glacier Database" (1997). Dissertations and Theses. Paper 5348.

https://doi.org/10.15760/etd.7221

This Thesis is brought to you for free and open access. It has been accepted for inclusion in Dissertations and Theses by an authorized administrator of PDXScholar. Please contact us if we can make this document more accessible: pdxscholar@pdx.edu. 


\section{THESIS APPROVAL}

The abstract and thesis of Jeremy Laurence Mennis for the Master of Science in

Geography were presented June 11, 1997, and accepted by the thesis committee and the department.

COMMITTEE APPROVALS:

Daniel M. Johnson, Chair
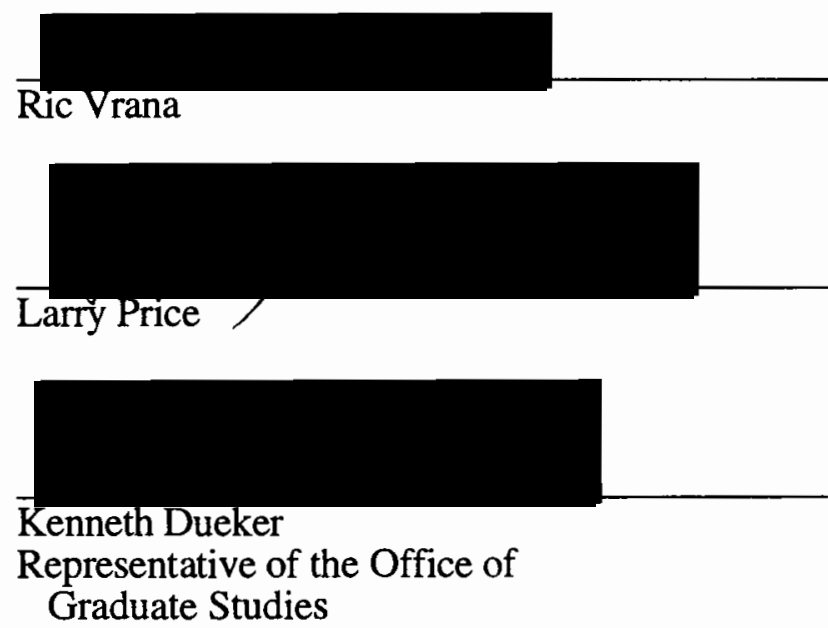

DEPARTMENT APPROVAL:

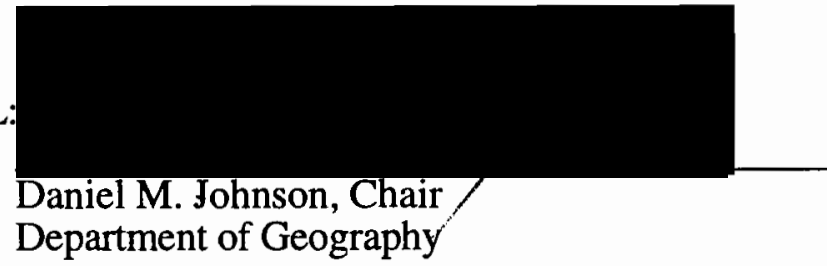

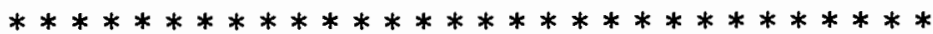

ACCEPTED FOR PORTLAND STATE UNIVERSITY BY THE LIBRARY

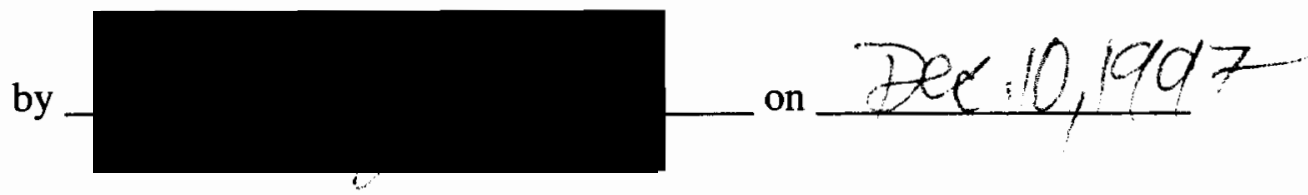




\begin{abstract}
An abstract of the thesis of Jeremy Laurence Mennis for the Master of Science in Geography presented June 11, 1997.

Title: GIS Applications to Glaciology: Construction of the Mount Rainier Glacier Database.

This thesis explores the application of Geographic Information Systems (GIS) to glaciology through the construction of a GIS database of glaciers on Mount Rainier, Washington (the Database). The volume and areal extent of these glaciers, and the temporal change to each, are calculated as a demonstration of GIS analytical capabilities.
\end{abstract}

Data for Carbon, Cowlitz, Emmons, Nisqually, Tahoma, and Winthrop glaciers for the years 1913 and 1971 are derived from historic topographic maps. The Database includes two and three-dimensional representations of glacier geometry, such as glacier extent and topography, as well as surface features, such as debris cover. A test of four interpolation techniques reveals splining as the most accurate in the creation of three-dimensional glacier surfaces from digitized contour lines. Attribute data includes glacier morphology and metadata detailing the data quality of each glacier representation. These glaciers lost approximately $13 \%$ of their planimetric area and $17 \%$ of their volume between 1913 and 1971 . Southern facing glaciers experienced significant terminus retreat while northern facing glaciers did not. 
GIS provides the computational framework and analytical tools with which diverse sources of glacier data with varying accuracies, resolutions, and projections can be compared and analyzed. However, error found within the original source data, or generated through data manipulation techniques, must be accounted for to foster analyses of known integrity. Recommendations for future development include the integration of remote sensing data; the creation of a customized user interface to facilitate query and display; and the development of spatial analysis techniques specific to glacier analysis. 


\title{
GIS APPLICATIONS TO GLACIOLOGY \\ CONSTRUCTION OF THE MOUNT RAINIER GLACIER DATABASE
}

by

JEREMY LAURENCE MENNIS

\begin{abstract}
A thesis submitted in partial fulfillment of the requirements for the degree of
\end{abstract}

\section{MASTER OF SCIENCE in GEOGRAPHY}

Portland State University

1997 


\section{ACKNOWLEDGMENTS}

This thesis is, in many ways, a collaboration between persons of different backgrounds, perspectives, and goals. However, this diversity made the experience all the more rewarding for its challenges and was ultimately a source of inspiration and learning. My thanks to Andrew Fountain: first, for the opportunity to pursue this research; second, for the great contributions to the project's direction and theoretical development; and third, for the thorough and constructive editing.

The Department of Geography at Portland State University deserves recognition for providing the education, learning environment, and resources necessary for the growth of this project. Thanks, specifically, to Ric Vrana for his teaching and insight into Geography and GIS.

This project would not have been possible without the support of the U.S. National Park Service and the U.S. Geological Survey. In particular I would like to thank the staff at Mount Rainier National Park and Carolyn Driedger of the U.S.G.S. Cascade Volcano Observatory for providing all the original data used in this study. 
TABLE OF CONTENTS

PAGE

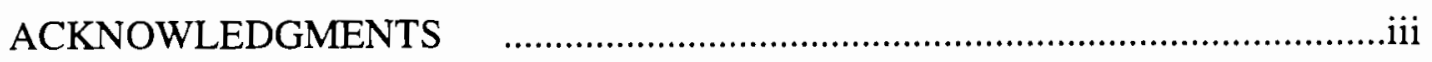

LIST OF TABLES

LIST OF FIGURES

CHAPTER

I THE INTEGRATION OF GIS AND GLACIOLOGY

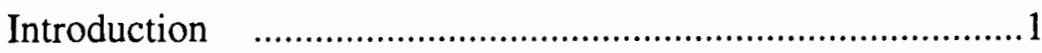

Scope and Purpose of the Project

Literature Review _....................................................14

II DISCUSSION OF DATABASE DEVELOPMENT

ISSUES

Hardware and Software Environment......................................20

Spatial Data Structures for Glacier Representation .............21

The Interpolation of Surfaces from Topographic

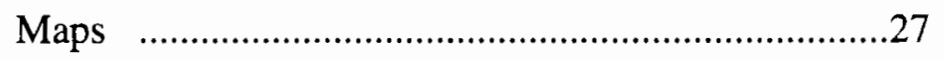

Representing Glacier Advance and Retreat .........................31

Table Relations Across Temporal and Spatial

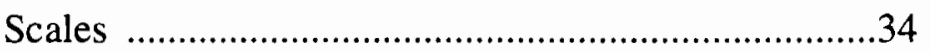


The Role of Metadata in Maintaining Data Quality 40

The Representation of Glacier Properties .44

III THE STRUCTURE AND ORGANIZATION OF THE

DATABASE 48

Database Organization: Overview .48

Spatial Data Organization $\quad$............................................50

Feature-Based Attribute Data Organization .......................57

Glacier-Based, Time-Dependent Attribute Data

Organization 59

Glacier-Based, Time-Independent Attribute Data

Organization 61

Directory Structure and Naming Conventions 62

Data Access: Query and Table Relations .66

IV METHODOLOGY FOR CONSTRUCTION OF THE

DATABASE 75

Data Acquisition 75

Data Input 77

Data Manipulation .82

Attribute Table Construction 100 
V ANALYSIS OF GLACIER AREA AND VOLUME

CHANGE

Objective and Methodology ........................................101

Results and Discussion $\quad$..........................................102

VI RECOMMENDATIONS FOR FUTURE DEVELOPMENT

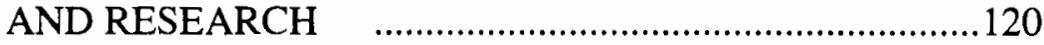

Database Development $\quad$......................................120

Application Development $\quad$...........................................124

Spatial Analysis Development $\quad$................................125

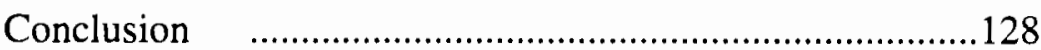

EPILOGUE

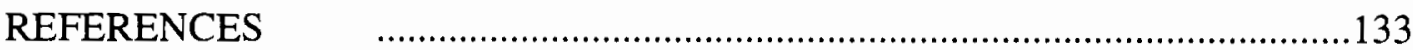




\section{LIST OF TABLES}

TABLE

PAGE

I Area and Volume of Mount Rainier Glaciers, 1913-1971 103

II Volume Error Due to Negative Cell Depth Values in Glacier

Isopach Maps 116 


\section{LIST OF FIGURES}

FIGURE

PAGE

1. Location of Mount Rainier, Washington 10

2. Glaciers on Mount Rainier that are represented in the

Database 14

3. Raster and vector data models

4. The most commonly used data structures for Digital Terrain

Models (DTMs): Digital Elevation Models (DEMs)

and Triangulated Irregular Networks (TINs) .25

5. The "wedding cake" effect 30

6. The relational database model as implemented in a GIS 36

7. Long profile of a glacier showing the zones of accumulation and ablation separated by the equilibrium line .46

8. Example vector spatial data: Glacier Extent, Debris Extent, and

Original Contour coverages .51

9. Example vector spatial data: Appended Contour, Elevation

Points, and Interpolated Contour coverages .53

10. Example vector and raster spatial data: Terminus Position coverage and Glacier Surface grid 
11. Example raster spatial data: Glacier Slope, Glacier Aspect, and Glacier Hillshade grids .56

12. Hierarchical Directory Structure for the Database by level .63

13. Table relations between feature-based and glacier-based, timedependent attribute tables 70

14. Table relations between glacier-based, time-independent and glacier-based, time-dependent attribute tables .71

15. Table relations between feature-based and glacier-based, timeindependent attribute tables .72

16. Relations between spatial data and glacier-based, timeindependent attribute tables .74

17. Interpolation method trial: trend and IDW .90

18. Interpolation method trial: kriging and spline

19. Spline interpolation parameter trial: weighting .94

20. Spline interpolation parameter trial: regularized versus tension and grid cell size .95

21. Spline interpolation parameter trial: number of search

$$
\text { points }
$$

22. Spline interpolation parameter trial: weighting with 30 search

$$
\text { points }
$$


23. Change in planimetric area of five glaciers on Mount Rainier,

$$
1913-1971
$$

24. Change in planimetric area of Nisqually Glacier,

$$
1913-1976
$$
106

25. Isopach maps of Carbon Glacier, 1913 and 1971 108

26. Isopach maps of Emmons Glacier, 1913 and 1971 109

27. Isopach maps of Nisqually Glacier, 1913 and 1971 110

28. Isopach maps of Nisqually Glacier, 1956, 1966, and 1976 111

29. Isopach maps of Tahoma Glacier, 1913 and 1971 112

30. Isopach maps of Winthrop Glacier, 1913 and 1971 113 


\section{CHAPTER I \\ THE INTEGRATION OF GIS AND GLACIOLOGY INTRODUCTION}

The recent growth of Geographic Information Systems (GIS) as a tool for spatial clata management, analysis, and display has significantly changed the nature of cartography. The digitization of spatial data allows cartographic manipulation and analysis to a degree not realized with paper maps, the historically dominant way of storing and analyzing spatial data. This shift has impacted not only the discipline of Geography but a variety of fields that are concerned with spatial data, such as Geology, Environmental Science, Biology, and Urban Planning.

Through the combination of research within these disparate disciplines, GIS technology has matured from a generic tool designed for the storage and display of spatial data to one that incorporates cartographic, mathematic, and computational models to offer a set of analytical tools that can be customized and applied to particular applications. Government organizations in particular, at a variety of bureaucratic levels, have been quick to implement GIS to manage and facilitate analysis of land use and land use change. The use of GIS has therefore grown rapidly within urban planning and natural resource management circles, fields which have a need for management of large and complex spatial data sets. 
The development of GIS applications in the Earth Sciences, however, has been slower. While technological advances in remote sensing and computational modeling have played a large role in the advancement of Earth Science throughout the last quarter of the twentieth century, these technologies have not led to the implementation of GIS for the management and analysis of spatial data. This is particularly surprising within the field of geomorphology, given the geographic nature of geomorphic inquiry (Pitty 1982) and the tradition of cartography in geomorphic data display and analysis (Vitek, Giardino, and Fitzgerald 1996). Although some work has been done in modeling hillslope processes in a GIS environment (Dikau, Cavallin, and Jager 1996), there has not been the recognition of GIS as a useful tool throughout the field. However, GIS has much to offer the study of Earth surface processes. Through the quantification and analysis of geomorphic phenomena, patterns of distribution through time and space may be revealed that promote models of geomorphic processes.

Glaciology is one such discipline with methodological traditions in cartography, quantitative analysis, and computer simulation which may benefit from the application of GIS. Glaciers and ice sheets are complex dynamic objects with varying rates of internal flow and external advance and retreat. While technology has provided the means for greater contemporary data acquisition, the potential for spatial analysis of this data has not been fully realized. In addition, the scarce historic data that does exist is in a variety of formats and locations that hinders analysis of historic glacier change. GIS provides the means for the integration of diverse historic and 
contemporary data sets and the manipulation and analytical capabilities to contribute to the construction of models of glacier process.

This paper seeks to demonstrate one application of GIS to glaciology. The purpose of this project is two-fold and can be divided between goals of a theoretical nature and goals that serve an immediate analytical application. On the theoretical side, this project explores the application of GIS techniques to glaciologic analysis through the development of database design, spatial and attribute data models, and spatial analysis techniques. The analytical application is to construct a GIS database of glaciers on Mount Rainier, Washington. An analysis of the temporal change in the volume and areal extent of these glaciers is presented as a demonstration of GIS analytical capabilities.

The Nature of Glaciologic Inquiry

The first step in examining the application of GIS to glaciology is to explore the nature of glaciologic inquiry and the scientific questions that glaciology asks. Anderson and Burt (1990) divide the nature of geomorphologic inquiry into three broad categories: form, material properties, and process. While glaciology can be considered a sub-field of geomorphology, the same divisions of investigation serve to clarify the scientific questions of both.

Form refers to the geomorphometry of glaciers. Geomorphometry includes both general geomorphometry, the measurement of large scale continuously varying properties, and specific geomorphometry, the measurement of discrete landscape 
features (Richards 1990). General geomorphometric glacier measurements include glacier elevation, slope, and aspect while specific geomorphometry in glaciology refers to measuring the location of a category of glacial features, such as crevasses. The sum of geomorphometric inquiry leads to the characterization of three dimensional glacier topography that, when coupled with temporal analysis or models of glacier dynamics, may lead to deeper understanding of the mechanisms governing glacier behavior.

Glaciologic studies that focus on geomorphometric analysis include the characterization of ice sheet topography (Joughin et al. 1996), the temporal analysis of glacial structural change (Lawson 1996), and the estimation of glacier volume (Driedger and Kennard 1986).

Material properties refer to the physical and chemical character of glacier ice and the spatial distribution of these characteristics as they vary throughout the glacier in two and three dimensions. These properties significantly influence glacier deformation and movement; when coupled with measurements of glacier geomcrphometry and numerical process models they provide improved models of glacier behavior. Studies of material properties include the spatial variability of chemical properties (Mulvaney and Wolff 1994) as well as laboratory analysis of the behavior of ice under various conditions.

Process refers to the numerical modeling of glacier dynamics. This approach emphasizes physics and mathematics in understanding the behavior of glacial systems (Paterson 1994). Dynamics may involve steady-state or time-dependent modeling of 
glacier behavior (Hutter 1983). A currently popular topic in modeling snow process is the derivation of snow stability and avalanche behavior (Brun et al. 1992; McClung and Tweedy 1994). Other studies focus on modeling the flow and deformation of glaciers and ice sheets (Budd and Jensenn 1989; Lase and MacAyeal 1989).

In addition to these three distinct branches of glaciologic inquiry is the coupling of such models to models of climate or geometric change. In this way global models of atmosphere, oceans, and ice sheets can be constructed to reveal the interrelationships that govern the evolution of the earth's environment. Much research in this area focuses on data gathered from deep ice cores (Delmas 1994; Lorius, Jouzel, and Raynaud 1992); others take a computational modeling approach.

Note also the spatial component inherent in all the branches. The study of geomorphometry is concerned with the two and/or three dimensional spatial distribution of a particular glacier characteristic, such as elevation. The empirical derivation of material properties may be aspatial, but applied research is concerned with the distribution of those properties throughout a glacier. The same is true with models of dynamic process; a numerical model predicts the behavior of the glacier throughout a space.

In addition, glacier studies are also concerned with glacier form, material properties, and process in the temporal setting -- how and why glacial change takes place. Oerlemans (1988) and Sigurdsson and Jonsson (1995) exemplify efforts to correlate historic glacier advance and retreat with historic climate data. The temporal 
comporient in glaciology can be modeled at a variety of time scales: as annual fluctuations, decadal, century, and so on. Each of these scales of temporal change in glacier character provide insight into the relationship between cryospheric and other earth processes.

One major issue of concern to glaciologic analysis is the compilation and integration of historic glacier data and the potential for merging it with data from airborne and satellite remote sensing platforms. The integration of contemporary and historic data remains necessary for the analysis of historic glacier change and the coupling of models of glacier advance and retreat to climate models.

Historic glacier data can often be found on paper maps. Some of these are topographic maps that simply include the glacier as a land cover classification, while others are created for the sole purpose of glacier monitoring. Temporal coverage for a specific glacier or a glacier group is often incomplete and/or inconsistent, leading to large gaps in the historic record. In addition, the evolution of cartography throughout the historic record, coupled with the fact that most maps are not made solely for glacier monitoring, results in a wide spectrum of data quality. For example, map scale impacts the resolution of data while survey techniques have improved dramatically throughout the past 100 years; both impact the accuracy of historic glacier information. Although these issues present obstacles to the successful integration and analysis of historic glacier data, paper maps can provide a useful source of glacier information, if made available in the proper setting. 


\section{GIS Contributions to Glaciology}

GIS can be loosely defined as, "a computer-based information system that enables capture, modeling, manipulation, retrieval, analysis and presentation of geographically referenced data" (Worboys 1995:xi). GIS includes a spatial component and a spatially referenced attribute component and has its roots in a variety of fields, such as cartography, mathematics, and computer science, that concurrently developed technologies to meet their own data management, analysis, and output goals. While GIS represents a confluence of progress within these disparate fields, research is constantly under way to customize generic GIS models for specific application purposes.

GIS can contribute to glaciologic analysis in a variety of ways. First, GIS offers the means to manage glaciologic data through data integration, storage, retrieval, and sharing. For example, historic glacier data found on maps may be digitized and geo-referenced to a common world projection and coordinate system. This allows the various temporal glacier representations to be accurately overlaid to facilitate analysis of glacier change. GIS also provides the means to transform glacier maps of varying scales and resolutions into a common spatial framework for efficient comparison. Many GIS packages also allow for the integration of remote sensing data with other types of digital data. This facilitates the comparison of contemporary glacier data with historic representations of the same glaciers. 
The digital nature of GIS data allows for efficient storage of spatial and attribute information. Because all GIS data is spatially referenced and contains attribute information defined by the user, GIS applications can facilitate the retrieval of spatial data through either spatial or attribute query. While the use of GIS itself does not necessarily imply efficient data sharing, it may play a role in facilitating the sharing of data. Since GIS provides a standardized spatial framework within which common spatial information and its attributes may be stored, databases of spatial information may be built and shared by the research community.

Second, GIS provides a setting for quantitative and qualitative data manipulation, analysis, and display. Some of these functions merely automate, and increase the efficiency of, functions already being performed manually; other functions, however, are benefits that are derived solely within a GIS environment. Most GIS packages contain automated functions that allow spatial data to be manipulated from one form to another. Since all spatial GIS data is quantified, data manipulation takes place through the application of transforming algorithms. Data manipulation can be used for data storage, display, or as a procedure in an analytical operation. Examples of data manipulation include changing the projection or coordinate system that a set of spatial data is stored in or the resampling of a raster grid.

GIS also provides qualitative and quantitative opportunities for data analysis. Through the manipulation of data, GIS allows spatial data to be displayed in various 
formats or with emphasis on certain characteristics. The visualization of the same data in different formats may reveal spatial patterns or information that can be interpreted by the user. Quantitative analysis ranges from the automated measurement of geometric character to more complex topologic operations of neighborhood or overlay analysis (Giordano et al. 1994). These techniques may be applied to the characterization of glacier geomorphometry and the correlation between glacier geomorphometry and material properties.

Most current GIS packages include a basic statistics module and are compatible with statistical software packages. While complex spatial statistics and spatial pattern recognition have not yet been fully implemented in most generic GIS packages, current research is focusing on these issues (Goodchild, Haining, and Wise 1992). Research is also continuing in the construction of data structures to model three dimensional spatial objects (Raper and Kelk 1991) and temporal change within GIS (Peuquet and Duan 1995).

\section{SCOPE AND PURPOSE OF THE PROJECT}

The purpose of the project is to construct a spatio-temporal database (hereafter, the Database) of the glaciers on Mount Rainier, Washington (Figure 1), to facilitate the analysis of glacier geometry and geometric change through time. This involves the conceptual design of the Database, implementation of the glacier data within the Database structure, and the development of a set of GIS techniques to analyze glacier geometry and glacier geometry change through time. Although the immediate purpose 


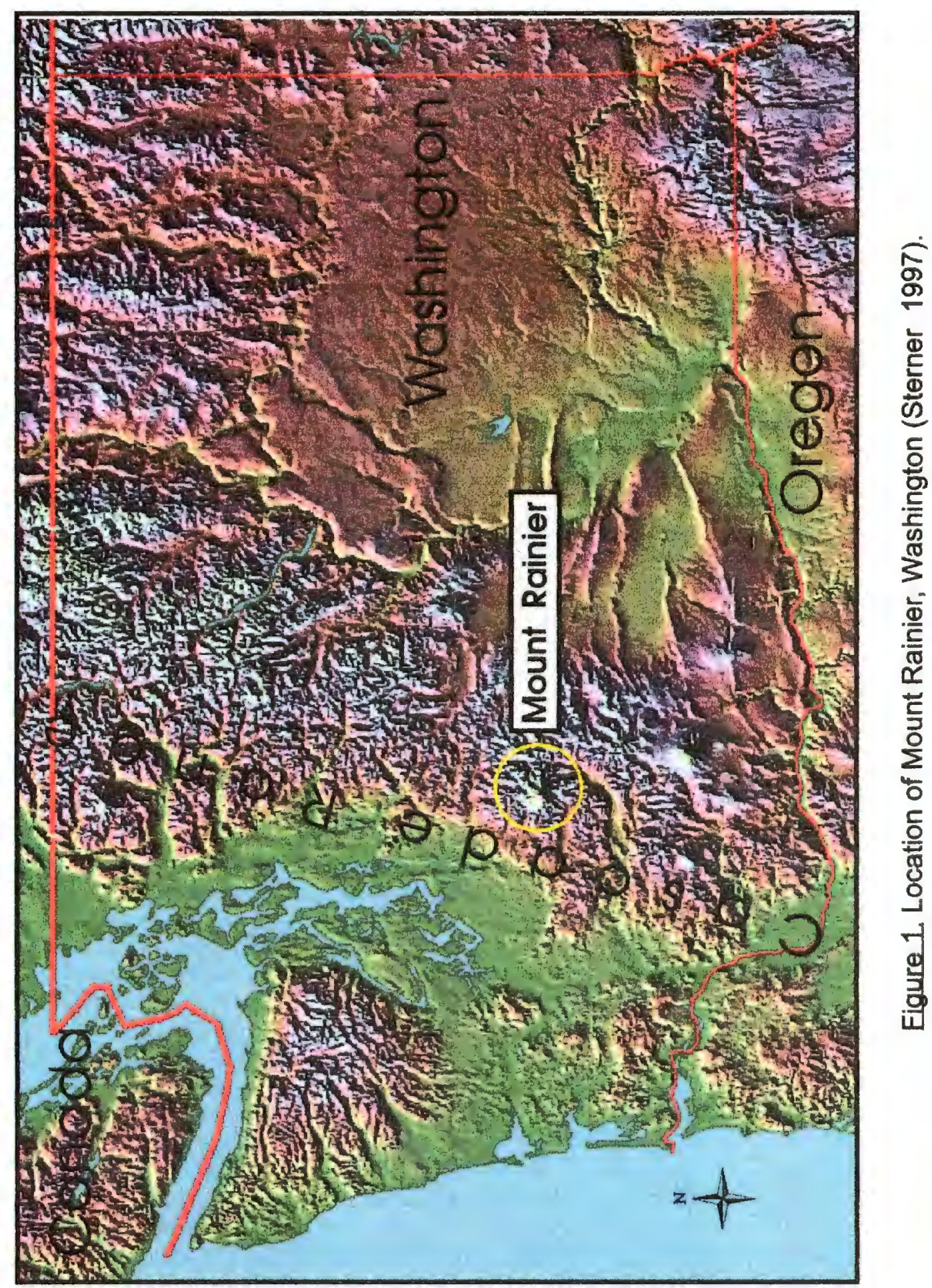


of the Database is to facilitate the analysis of glaciers on Mount Rainier, it is structured to allow any glacier to be entered into the Database through the same methodology described in this paper. In this way, the Database may act as a prototype for a world glacier clatabase that serves the data storage and analysis needs of the glaciologic research community.

\section{The Construction of the Database}

The primary goal of the Database is to provide an infrastructure that facilitates the storage, retrieval, and analysis of temporal and spatial information on alpine glaciers. The intended users of the Database are not GIS specialists but glaciologists with some GIS experience who wish to apply techniques in analytical cartography and spatial analysis to traditional glaciologic questions. While the development of a customized GIS application and graphic user interface is beyond the scope of this project. it is a natural extension to, and is defined by, the development of the Database. The Database should provide for future development by finding a balance in providing both the simplicity of infrastructure and analytical complexity that the user demands. The development of the Database in this manner will facilitate the successful implementation of the user interface to further improve access and analytical capability. The following secondary goals describe a plan to meet this criteria.

The Database should provide efficient access to spatial and temporal glacier information. The structure and attribute organization of the Database should facilitate queries based on specific location, general location, a specific year, and a range of 
years. In this way the user can approach the Database from a number of analytical angles, whether interested in the change of one glacier through time or a number of glaciers at one time. The user should also be able to quickly assess what spatial and temporal coverage the Database includes.

The Database should also provide clear and easily accessible reference information on all data sources, whether paper map, book, or journal article. While the ability of GIS to integrate diverse sources of glacial data is one of its strengths, the "scaleless" nature of GIS and the data structures used to model the glaciers themselves leave the integrity of the source data explicitly transparent to the user. The user must be able to efficiently access information on the source of all digital data for the Database to foster analyses and results of known accuracy and integrity.

Finally, the Database seeks to maximize the efficiency of operation. Efficiency implies minimization of storage space, maximization of speed of data access and analysis, and ease of maintenance and upkeep of the Database. This concerns the logical grouping of common spatial and attribute data types, normalization of all attribute data, the relation of like attribute records across tables, and the minimization of duplicate data.

Database goals concerning the spatial representation of each glacier follow the guidelines set by UNESCO/IASH (United Nations Educational, Scientific and Cultural Organization / International Association of Scientific Hydrology) (1970) to conform with the World Glacier Monitoring System (WGMS) standards in the construction of a 
world glacier index. While spatial glacier representation is limited by the data available on historic topographic maps, it includes the glacier boundary, glacier surface elevation, and the interpretation of certain surface features, such as debris cover.

'The Database attribute goals not only concern the glacier morphologic attributes as described in UNESCO/ASH (1970), but also a measure of data quality. The strategy employed here is based on the Spatial Data Transfer Standard (SDTS), part of a comprehensive plan created by the U.S. National Committee Digital Cartographic Data Standards Task Force (NCDSTF) to facilitate data sharing. The SDTS defines data quality as "fitness for use" ; therefore, data is not assigned a total quality "rating", rather the known data accuracy and sources of error are made explicit to the user who decides whether the data is suitable for a particular analytical application (Chrisman 1991).

Data on six glaciers on Mount Rainier were input into the Database: NisquallyWilson (Nisqually), Carbon-Russell (Carbon), Emmons, Winthrop, Cowlitz, and Tahoma (Figure 2). All glaciers are represented for the years 1913 and 1971, and Nisqua.lly glacier for the additional years of 1956, 1966, and 1976. In addition, glacier terminus positions for Nisqually glacier for a range of years is also incorporated into the Database. For clarity, the term "time of record" is used to refer to a glacier, or its GIS data representation, at one specific point in time. 

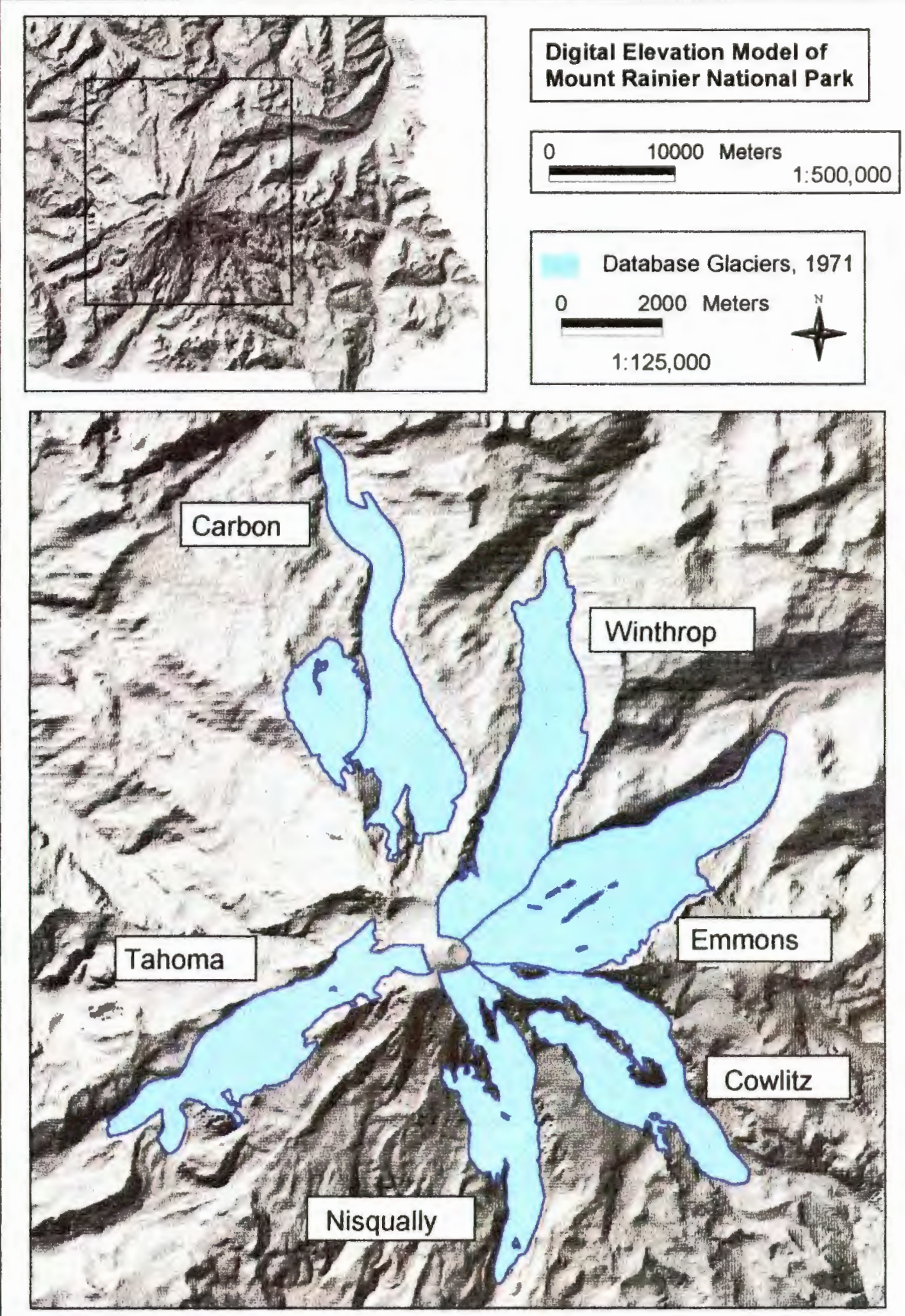

Eigure 2. Glaciers on Mount Rainier that are represented in the Database. 
Analysis of Glacier Volume and Areal Extent Change

This project reveals how analytical cartography and spatial analysis techniques can be applied to analysis of glacier geometry change. Specifically, this paper demonstrates the GIS derivation of glacier volume and areal extent, discusses other analytical applications such as spatial coincidence, and examines the strengths and limitations of the GIS approach to glaciologic modeling. To this end, each of the glaciers in the Database is analyzed to calculate glacier volume and volume change, and glacier area and area change, for the time period 1913 to 1971 . In addition, these characteristics are calculated for Nisqually glacier for all times of record contained in the Database.

\section{LITERATURE REVIEW}

A survey of the glaciologic literature reveals that GIS has been little used to date. However, a strong tradition exists for certain GIS techniques under a variety of different names. Remote sensing and automated cartography are inter-related techniques which bear a strong relationship with GIS and are prominent in glaciologic research. Because of the sheer size and inaccessibility of many glacial environments, especially the ice sheets, remote sensing of glacial environments has greatly enhanced the amount of data available to glaciologists. Remote sensing in glaciology covers the spectrum of traditional and current remote sensing technology: data from airborne, satellite, and ground-based platforms; digital and photographic data; and the use of passive and active energy sources. This data is essentially a digital map of the earth 
surface (or occasionally sub-surface) and can be directly input into a GIS for manipulation, analysis, and display.

A common and straightforward use of satellite remote sensing imagery and photogrammetry is the mapping of glacier and snow extent throughout a region. Research by Shi and Dozier (1993) and Dozier and Marks (1987) exemplify the use of certain electromagnetic bands to distinguish different types of snow cover as well as snow from rock. This technique can also be used to characterize glacier geomorphometry in variety of ways. Joughin et al. (1996) use interferometric synthetic aperture radar to construct a digital elevation model (DEM) for the West Greenland section of the Greenland ice sheet. Three dimensional topographic mapping in West Greenland is also demonstrated by Garvin and Williams (1993) through the use of an airborne laser altimeter with resolutions of about one meter. Similarly, Aniya and Naruse (1986) use aerial photography to map the structure and morphology of Soler Glacier in northern Patagonia.

Concerning other glacier surface characteristics, Lindsay and Rothrock (1993) map the spatial distribution of Arctic sea ice surface temperature and albedo from AVHRR data. Studies of ice surface radiation and albedo have been carried out by Hall et al. (1987) and Duguay (1993). Aerial photography and satellite remote sensing data also may provide for the recognition of glacial features, such as frozen lakes on the glacier surface (Winther 1993). For example, Casassa and Brecher (1993) use 
AVHRR data in the analysis of texture pattern to map and analyze the presence of ice flow stripes on Byrd Glacier, Antarctica.

While data of this nature has only existed since the advent of remote sensing satellite technology in the 1960 's, the temporal coverage of glacier data still allows for the analysis of short-term glacial change. Robinson (1993) notes that a wealth of temporal data dating to the 1960 's exists for the extent of snow in the Northern Hemisphere. He recommends the integration of these various data sources through the use of GIS to, "produce an all-weather, all-surface hemispheric snow product that includes information on snow extent, volume and the surface albedo of snow-covered regions" (Robinson 1993:370). On a somewhat smaller time-scale, Wankiewicz (1993) uses temporal satellite-based microwave data to model the annual variation of microwave brightness temperature of snowpacks.

Aside from the use of remote sensing imagery, glaciologic research that relates most closely to GIS involves the use of analytical cartography to analyze glacier topography. Most commonly, this has concerned the estimation of glacier area, and occasionally volume, from glacier mapping, and the quantitative temporal analysis of historic cartographic glacier data. For example, Driedger and Kennard (1986) use radar echo sounding to determine the sub-glacial topography of a series of glaciers in the Cascade Range, United States and determine glacier volume from cartographic glacier models. Reinhardt and Rentcsch (1986) propose a methodology by which glacier volume and elevation change can be deducted through the use of DEMs. 
Cartographic analysis of temporal glacier change is exemplified by Champoux and Ommanney (1986), who inventory the glaciers of Glacier National Park in Canada over the last 100 years through the digitization of historic maps and aerial photography. Statistical analysis of glacier change was then correlated with historic climate data from the same period to produce a model of regional climate and glacier advance and retreat.

Two articles in particular demonstrate the integration of remote sensing imagery with GIS and the use of analytical cartography for glaciologic analysis. Klein and Isaacks (1996) use Landsat TM imagery to map paleo-glacier extents in the central Andes mountains in a GIS vector environment. This derived vector data allows the researchers to model the past extent of glaciers in the region and subsequently to derive glacier volume from geomorphometric glacier models. Secondly, a proposal for the establishment of a digital database of remote sensing imagery of Antarctica is described by Steiner and Ehlers (1990). This database would provide estimates of glacier velocity through the measurement of relative movement of prominent surface features throughout a series of temporally referenced satellite images.

Based on the wealth of available digital glacier data, tradition of glacier mapping, and cartographic analysis of temporal glacier change, it appears that GIS is already integrated, in principle, into current glaciologic research methods. However, there has not been an integration of these techniques within a common computational framework nor a concerted effort to integrate the majority of remotely sensed glacier 
data with either attribute information or spatial analysis. GIS provides the framework to integrate these various established techniques so that they may be comprehensively applied to analysis of glacier change. 


\section{CHAPTER II}

\section{DISCUSSION OF DATABASE DEVELOPMENT ISSUES HARDWARE AND SOFTWARE ENVIRONMENT}

The decision of Database hardware and software environment was based foremost on availability and cost. Once the options within these two constraints were identified, the choice of one hardware and software environment over another was based on five secondary considerations. First, glacial characteristics extend in both two and three dimensions; therefore the computing environment must be able to robustly model distribution along a three dimensional, as well as a planar, surface. Second, glaciologic analysis demands complex spatial operations such as the calculation of volume, area, and the spatial coincidence of glacier attributes; therefore, a full fledged GIS, as opposed to simply a desktop mapping program, is required. Third, since a goal of the project is to develop the Database to be accessed by users with minimal GIS experience, a user friendly and easily customized graphic user interface is necessary. Fourth, due to the complex spatial and temporal variation of attributes associated with a wide range of glacier representations, the database management system must be able to efficiently relate like records across tables. This requirement ensures that the Database be implemented in a GIS, as opposed to simply a three dimensional modeling application. Finally, all other factors being equal, the 
best computing environment is the one that provides the maximum processing power with minimal processing time.

This project is carried out using a combination of $\mathrm{pcArc/Info,} \mathrm{Arc/Info,} \mathrm{and}$ Arcview 3.0 by Environmental Systems Research Institute, Incorporated (ESRI) based in Redlands, California. These interrelated GIS software packages share some common data formats that allow the strengths of each to be exploited. Digitizing is done in pcArc/Info because of availability, complex data manipulation done in Arc/Info because of analytical ability and processing speed, and the Database formatted for use in both Arcview 3.0 and Arc/Info.

This combination provides the convenience of the Arcview 3.0 user interface while also giving the user the option of using Arc/Info for more complex analytical operations. Both applications feature surface and two dimensional modeling and contain a relational database system. Because of availability, the Database is standardized to operate on the Windows 95 or WindowsNT platform.

\section{SPATIAL DATA STRUCTURES FOR GLACIER REPRESENTATION}

The primary conceptual data models for the digital representation of spatial data treat geographic phenomena as either field-based or as object-based. Field-based representation treats phenomena as varying continually across a "field" of space while object-based representation treats phenomena as distinct objects located within space (Worboys 1995). These two conceptual models of spatial representation are realized in the raster and vector data structures, respectively, upon which nearly all current GIS 
packages are based for encoding spatial data. The raster structure divides space into a regular grid in which each cell contains an attribute describing the "state" of that cell; the vector structure represents specific features as points, lines, or polygons at a coordinate location (Aranoff 1989) (Figure 3).

Different benefits and drawbacks apply to both structures. The object-based vector structure is generally more adept at representing discrete geographic phenomena composed of known boundaries at a given location in Cartesian space, such as a street network or a set of buildings. The field-based raster structure is generally better suited for representing geographic phenomena such as temperature or precipitation, whose value varies continuously as a set of real numbers across a Cartesian space and cannot be discretized into separate objects of like values (Laurini and Thompson 1992). Most geographic phenomena do not fall definitively into either of these rigidly defined conceptual categories, but can be modeled in either category with different representation and analytical results. Phenomena such as soil type, vegetation, and other "natural" features are often composed of distinct entities with common attributes but have "fuzzy" boundaries that are not well described by the vector structure. On the other hand, vector encoded street or parcel data may be converted to raster format for efficiency of representation or data manipulation. The most appropriate data structure for a given geographic phenomena is dependent on both the nature of that phenomena and analytical application (Peuquet 1984). 

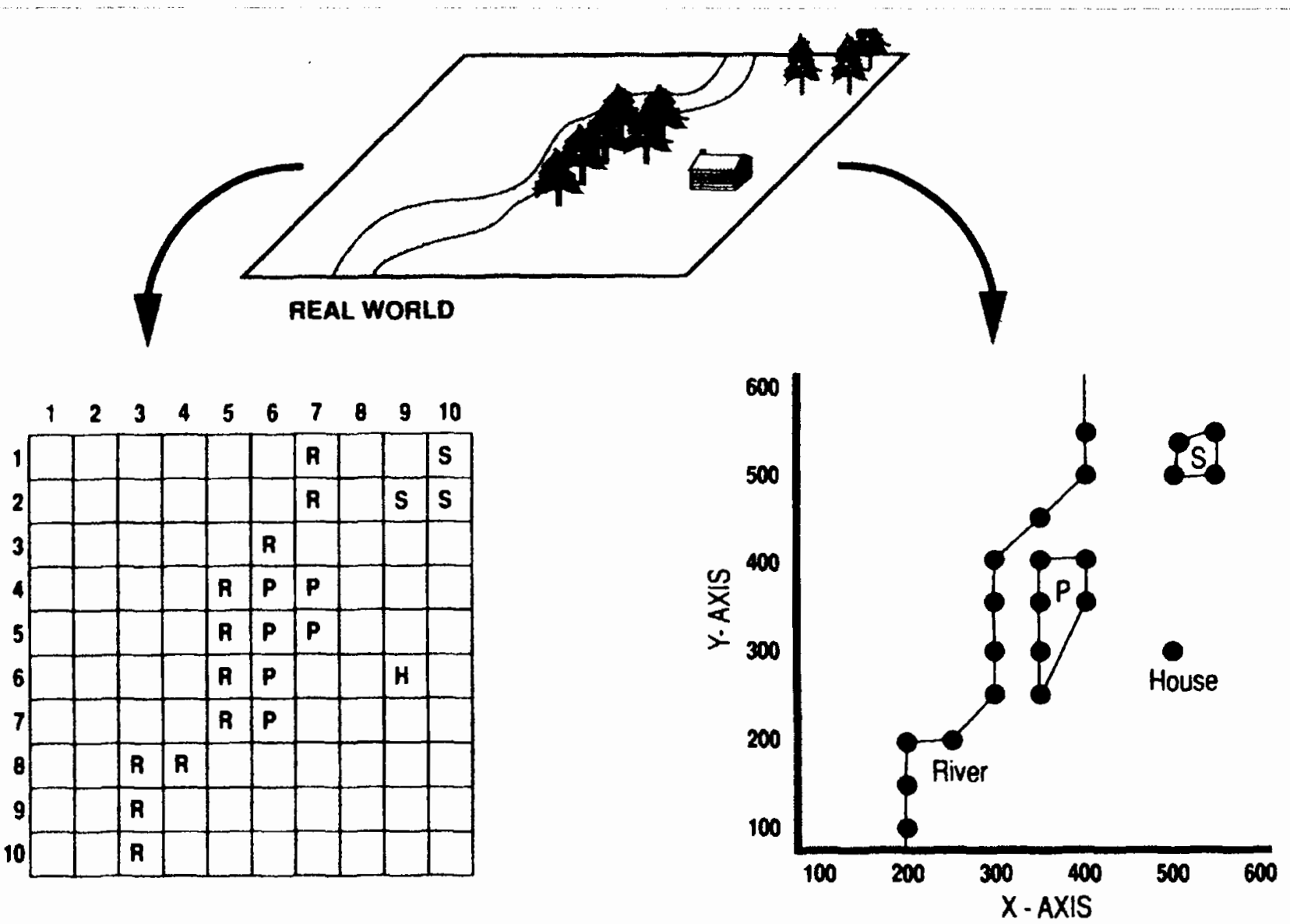

RASTER REPRESENTATION

VECTOR REPRESENTATION

Eigure 3 Raster and vector data models. The pine forest stand $(P)$ and spruce forest stand $(S)$ are area features. The river $(R)$ is a line feature and the house $(H)$ is a point feature (Aranoff 1989:164). 
Data structures describing three dimensional surfaces, known as Digital Terrain Models (DTMs), include both raster and vector approaches. Traditionally, topographic surfaces were modeled in a raster environment because of the continuously varying nature of a surface, each raster cell being assigned a " $z$ " surface value, often based on the interpolation from a set of known sample points (Burrough 1986). A DTM of this type is known as a Digital Elevation Model (DEM). Using the Triangulated Irregular Network (TIN) model, however, surfaces can be modeled as a series of vector triangular facets, derived through Delaunay triangulation of known elevation points, for which a value at a point on the surface of any facet can be interpolated (Peuker and Chrisman 1975) (Figure 4).

Research on the positive and negative characteristics of each of the surface models has revealed the strengths and limitations of each for different data sampling and terrain environments (Kumler 1994). Because the DEM model stores surface value data explicitly in a regular matrix, as opposed to the more complex vector topologic relationships in the TIN model, calculation of surface value at any point is relatively straightforward. The advantage of the complex TIN structure is the incorporation of landscape features, such as ridges and streams, within the data structure itself (Weibel and Heller 1991). However, neither model has shown a clear superiority over the other throughout a wide range of applications (Weibel and Heller 1991; Kumler 1994). 


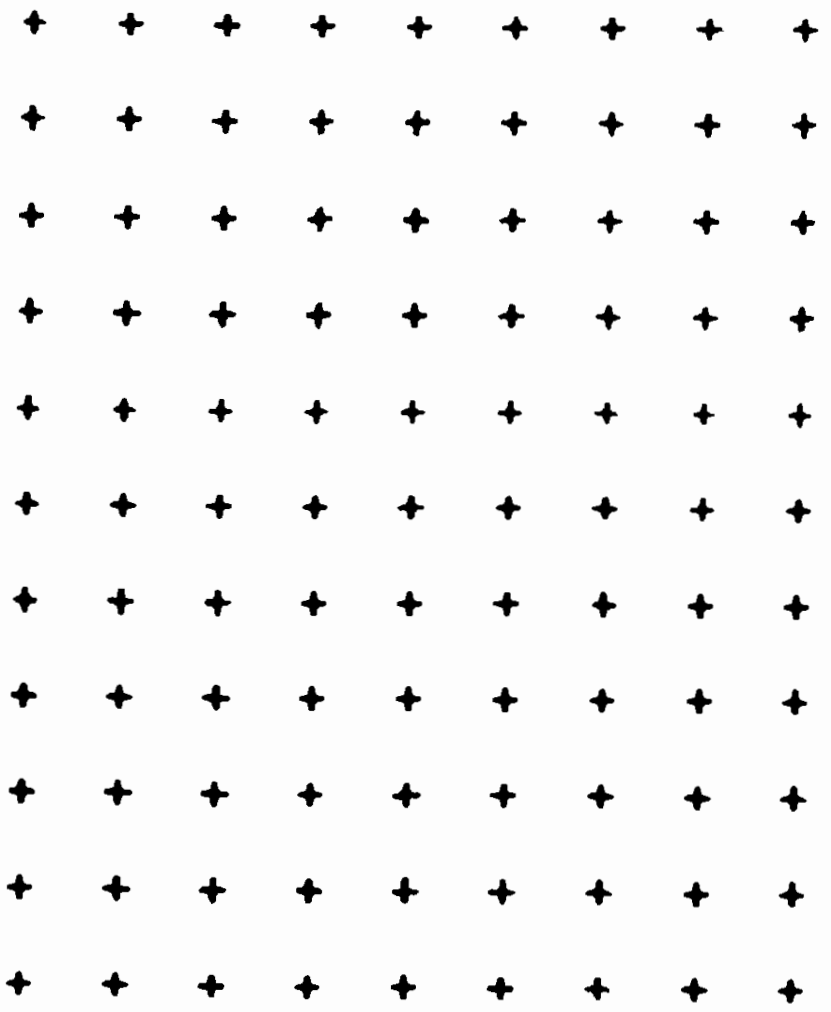

Digital Elevation Model (DEM)

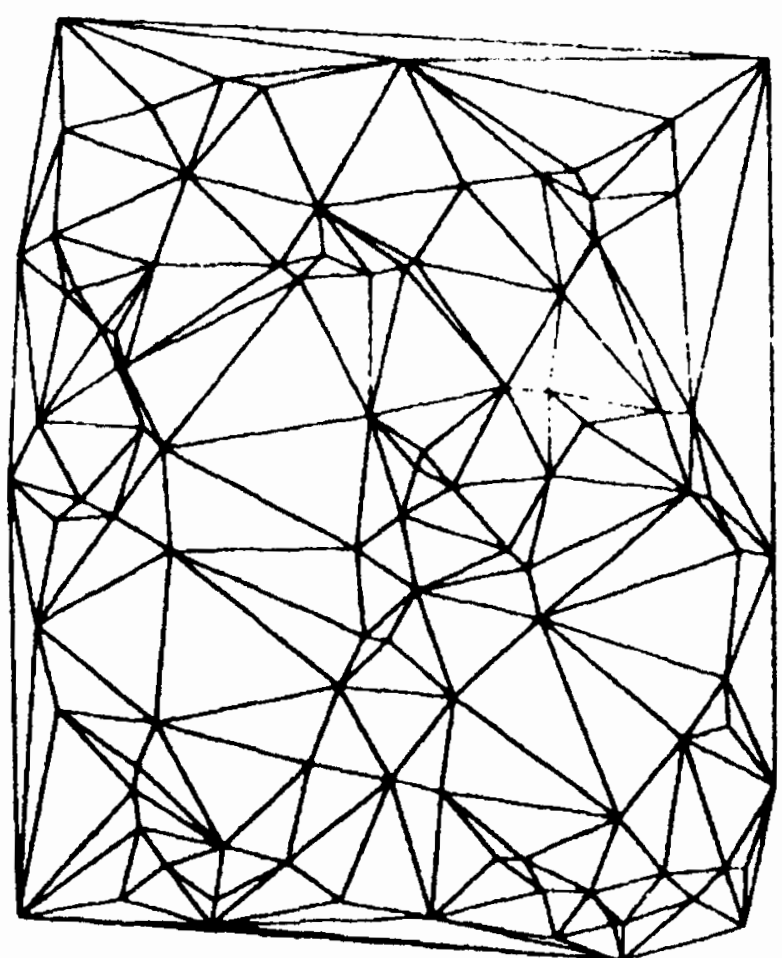

Triangulated Irregular Network (TIN)

Eigure 4. The two most commonly used data structures for Digital Terrain Models (DTMs): Digital Elevation Models (DEMs) and Triangulated Irregular Networks (TINs) (Weibel and Heller 1991:274). 
The implementation of the vector data structure is slightly different in Arcview 3.0 than it is in Arc/Info. Arcview 3.0 implements the vector data structure in a polygon list spatial encoding format which records each object separately as a series of the coordinates of its bounding arcs. The vector topologic structure implemented in Arc/Info explicitly records spatial relationships among objects to allow for neighborhood and overlay analyses not available in Arcview 3.0. Arc/Info also contains a TIN module that allows surface modeling in a vector environment. Both applications contain a separate raster module, Spatial Analyst in Arcview 3.0 and Grid in Arc/Info. Vector data layers in Arcview 3.0 are called shapefiles, in Arc/Info they are called coverages, and raster layers in both applications are called grids.

This thesis attempts to take advantage of the strengths found within both the vector and raster data structures and their implementations within the GIS software. The properties of each glacier targeted for representation in the Database are logically divided into separate data layers. Spatial properties of the glacier that behave as discrete objects are modeled in a vector environment while those properties that can be better conceptualized as a continuously varying field are modeled in a raster environment. For example, the areal extent of the glacier is better described by the discrete boundaries that divide the glacial ice from rock; therefore, it is modeled as a vector coverage. The surface elevation of the glacier behaves as a continuously varying value over the extent of the glacier; therefore, it is modeled as a raster grid. 
The decision to model surface elevation in a raster environment as a DEM was made because TIN modeling is not offered in Arcview 3.0, the intended primary interface for the Database. Further, one study that undertook a comprehensive comparison of TINs and DEMs derived from contour line data concluded that the, “...contour-based TINs developed here are not more efficient than gridded DEMs at modeling terrains found in the United States" (Kumler 1994:39).

\section{THE INTERPOLATION OF SURFACES FROM TOPOGRAPHIC MAPS}

The creation of glacier surface DEMs requires the interpolation of each surface from a set of known sample points derived from digitized contour lines. While no one interpolation technique is the best in all cases (Weibel and Heller 1991), the choice of technique greatly affects the nature, accuracy, and analysis of the DEM (Clarke 1990). Monmonier (1982:61) states, "Interpolation is a highly subjective process, and an estimation procedure is not right or wrong, but merely plausible or absurd."

Interpolation methods can be broadly divided between both global versus local and fitted surface versus distance weighted interpolators. Global interpolation refers to the estimation of a grid cell value from the entire data set while local refers to its estimation from "local" or "neighborhood" data points. Fitted surface interpolation refers to the application of a mathematical function that is statistically fitted to the surface defined by the known data points. The surface may or may not pass through the center of each grid cell; therefore, each grid cell's value is a function of its location 
relative to that surface (McCullagh 1988). Fitted surface functions can be global or local.

Distance weighted interpolation techniques derive the surface value for a specific cell, called the kernel, through an operation similar to the "moving window" operation often used in image processing. The concept of the "moving window" is that the value of the kernel is derived from the values of the set of cells within a window, a defined region of neighbor cells surrounding the kernel. The window moves from cell to cell across the entire grid to derive values for each cell (Lillesand and Kiefer 1994). The nature and number of nearest points within this "moving window" can be defined by a minimum number of points, radius around the kernel, or a combination of the two. There are various weighting schemes that can be applied to each sample point based on its location relative to the kernel (Clarke 1990). Distance weighted interpolation is, by definition, local in nature.

Arc/Info and Arcview 3.0 offer four interpolation techniques: Inverse Distance Weighted (IDW), trend, spline, and kriging. IDW derives a kernel's surface value from neighborhood sample point values that are reduced in weight relative to distance from the kernel (Clarke 1990). Trend creates a global fitted surface assuming that none of the known sample points are the maximum and minimum values in that surface (Clarke 1990). The trend surface usually does not pass through all the sample points. Spline interpolation creates a surface which passes through all the known sample points and seeks to minimize the curvature of the surface (McCullagh 1988). 
Interpolation by kriging involves a statistical analysis to derive the drift, the statistical pattern of change in data value over a distance (Clarke 1990). Because it requires an intensive statistical analysis of the data prior to surface generation, kriging is significantly more computationally intensive than the other three interpolation techniques (Clarke 1990). The parameters controlling local neighborhood definition and fitted surface functions are set by the user.

Interpolation of a gridded surface from points digitized along contour lines presents problems due to the irregular distribution of known sample points. Clarke (1990:257) comments that interpolation from contour line data works well only when, "...the point density along the lines is about the same as the map spacing between the contours and in terrain that is very rough." Usually, however, the density of points is much greater along the contour lines than between them. This applies especially to glaciers, where glacier slopes can increase abruptly or gradually along the long profile of a glacier. This creates varying degrees of sample point density along the glacier longitudinal axis, while the distance between points horizontally along the contour lines remains basically unchanged.

Often, the result of this problem is a "wedding cake" effect in which the DEM exhibits a series of step-like plateaus (Clarke 1990) (Figure 5). A number of studies have addressed more accurate sampling schemes to capture topographic data from maps (Balce 1987; Ayeni 1982; Gao 1995; Eklundh and Martensson 1995), however it is part of the strategy of the Database to preserve the originally digitized 


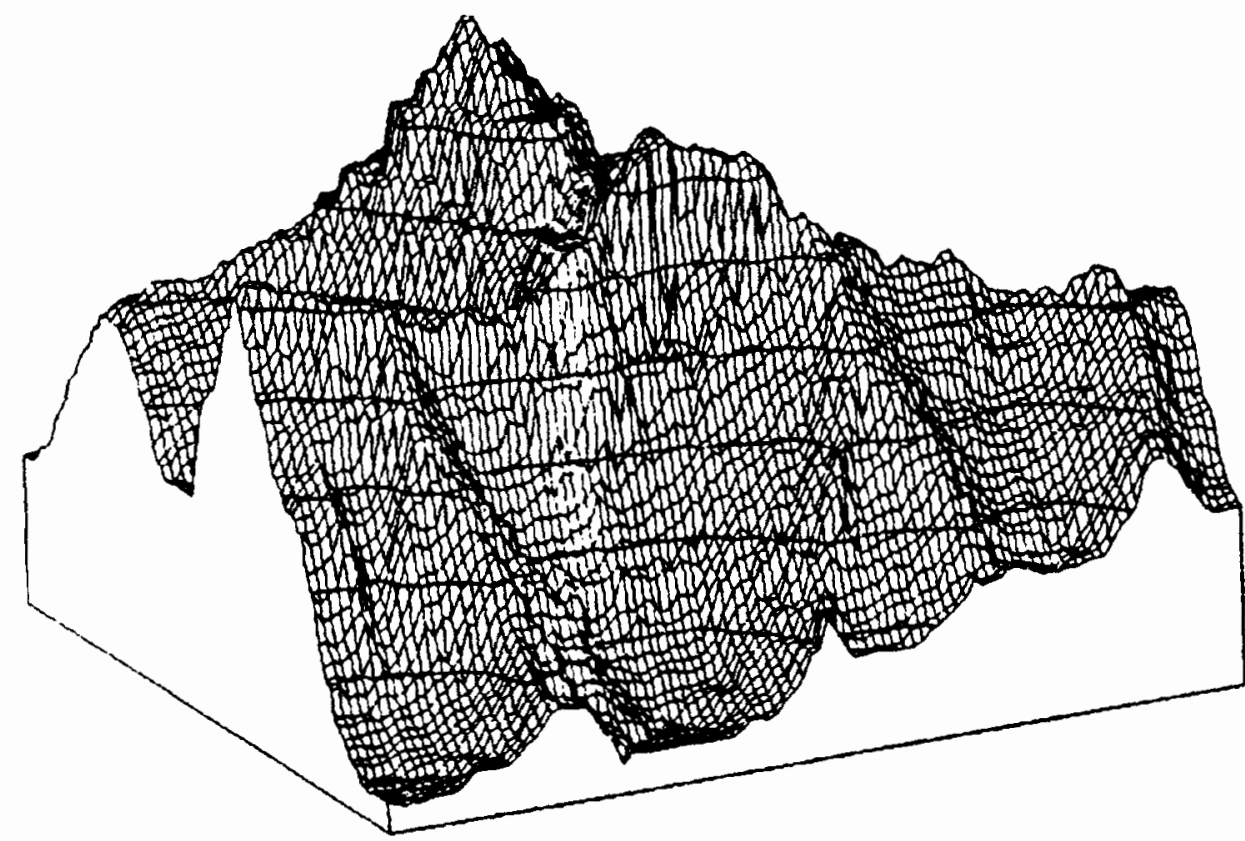

DTM created from a regular disribution of data points

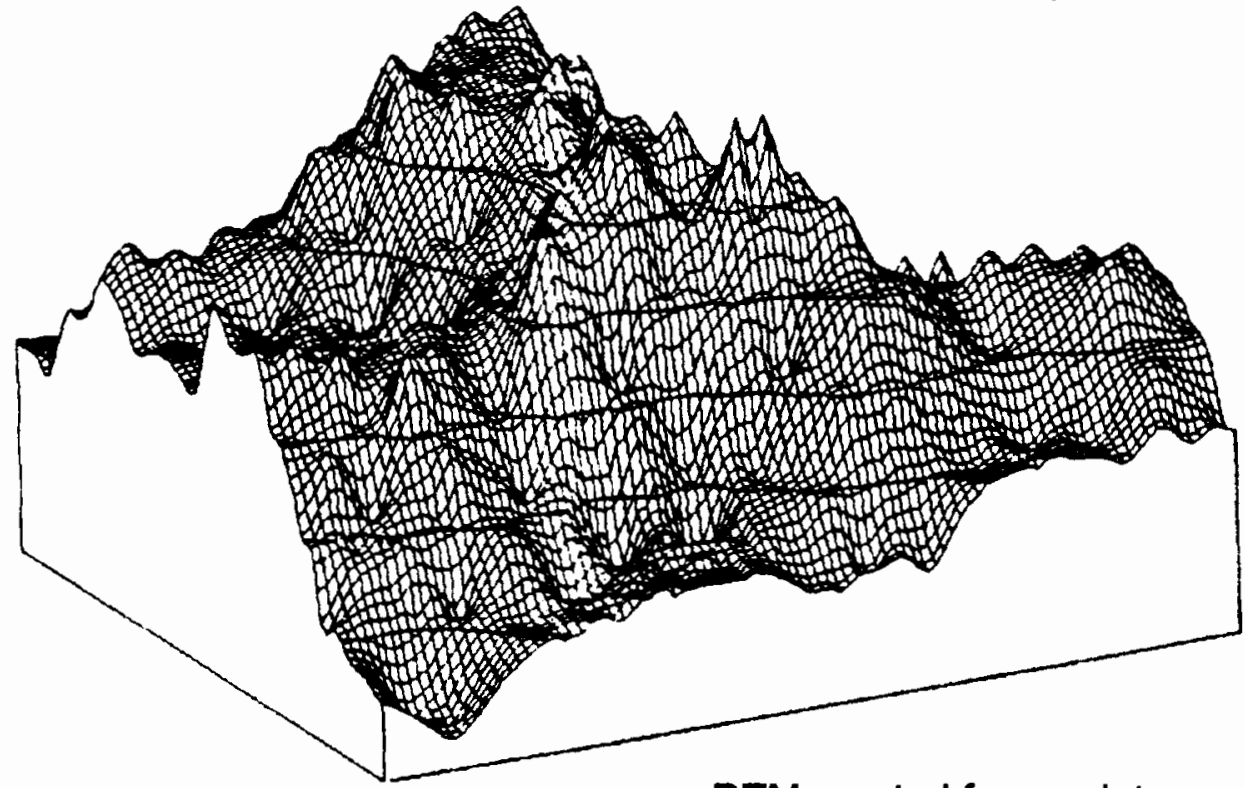

DTM created from points digitized along contour lines

Eiqure 5. The "wedding cake" effect. Note the plateaus evident in the DTM created from points digitized along contour lines (Clarke 1990:259). 
contour line data as an integral part of the Database. Since it would be impractical to digitize the same elevation data twice using two different strategies, elevation data derived from digitizing contour lines provides the basis for glacier surface model generation.

To choose the appropriate interpolation method and highlight their differences, the four available interpolation techniques were tested. The test is not meant to be an exhaustive and comprehensive survey of interpolation techniques, rather a brief trial to find the most accurate method for generation of glacier surfaces. A description of the interpolation trial is included in Chapter IV.

\section{REPRESENTING GLACIER ADVANCE AND RETREAT}

The primary goal of the Database is to facilitate the analysis of glacier geometric change through time. The Database needs to represent glacier change in the most accurate manner as possible. Unfortunately, the representation of temporal change within Arcview 3.0 and Arc/Info is limited by their data structures, which are not able to model temporal change in a robust manner. Because of the location-based and "static" nature of these data structures, temporal change has often been represented as a series of "snapshot" images representing a particular location at different points in time (Langran and Chrisman 1988). While this approach may allow temporal data storage and access on a superficial level, it does not allow for complex temporal data query or analysis. 
The subject of integrating the temporal component in GIS has been given some attention in recent GIS literature. Keller (1991) summarizes many of the issues and reasons for implementing temporality within GIS. Xiao, Raafat, and Gauthier (1989) discuss the implementation of a spatio-temporal remote sensing database to facilitate the detection of glacier boundary changes, and other spatial changes, through time. Langran (1992) takes a comprehensive look at the subject in terms of temporal data models, data access, and database design. Recently, Peuqeut and Duan (1995) have suggested the implementation of a temporal event-based, as opposed to location-based, data model. This would allow for temporal topologic operations between GIS data objects, such as the query and analysis of temporal proximity and overlap along a time-line (Langran and Chrisman 1988; Peuquet and Duan 1995).

A distinction can be made between "transactional" time, the time elapsed since the data was entered into the database, and "valid" time, the time elapsed since the time of the data representation (Worboys 1995). The purpose of this project is to analyze historic data, therefore, the Database contains only a record of "valid" time; "transaction" time is irrelevant. Langran (1992) suggests six major temporal GIS functions: inventory (including data access), analysis, updates, quality control, scheduling, and display. Because the nature of glaciologic modeling differs from other GIS applications, such as facilities management, these functions are not equally relevant to the Database. Given the goals of integrating all available historic glacier data, and the historic nature of the data itself, issues such as updates and scheduling 
are not applicable. The primary temporal issues of concern are, therefore, inventory, analysis, display, and quality control. Users must be able to access spatial data by temporal query, and temporal data by spatial query, at a variety of scales. Users must also be able to compare and analyze different temporal representations of a glacier to deduce changes in glacier character from one time to another. In addition, the cartographic visualization of glacier advance and retreat provides the opportunity for qualitative assessment and scientific communication. Quality control is relevant because of the change in data accuracy from older to more recent glacier maps and in maps of differing scales.

Langran (1992) also suggests a temporal data model that divides a spatial object into separate features based on its temporal character. An object in this case is defined as a feature whose location may change over time but whose "identity" remains the same. This strategy reduces the storage of redundant spatial information through the temporal deconstruction of an object. However, temporal glacier representations have different attributes concerning their data sources, accuracy, and morphology, therefore, each should be considered as a distinct object, possessing its own unique "identity".

The representation of temporal change within this project is limited by the software, and its data structures, upon which the Database is built. The strategy for implementation of the temporal component within the Database is to temporally "tag" each static spatial glacier representation and its attributes for a given time of record to 
mimic a more robust temporal GIS. For each glacier, each time of record is represented by one set of coverages and grids, spatially registered with the other temporal representations. Each of these layers is temporally attributed to facilitate data access by temporal query. Analysis of temporal change takes place through the overlay of two or more temporal "snapshots", while representation of temporal change can be accomplished through a time series.

\section{TABLE RELATIONS ACROSS TEMPORAL AND SPATIAL SCALES}

The Database utilizes a variety of hierarchical levels to accommodate different spatial and temporal scales. Spatial data can be divided along the lines of vector and raster; however vector data itself can also be subdivided into its basic elements of points, lines, and polygons. In addition, for each time of record each glacier has a separate set of these spatial representations. While the spatial representations can be easily categorized by time of record, organization becomes complex when considering the relation of attributes to spatial data across these spatial and temporal categories.

The relational database management system is the dominant database model used in current GIS software, including Arcview 3.0 and Arc/Info. The term relation refers to the automated "connection" between two related sets of data, whether spatial or attribute. In Arcview 3.0 and Arc/Info, spatial vector and raster data are related to two dimensional tables composed of columns, called fields, and rows, called records. Each record has one, and only one, value for each field. In coverages, each feature (point, line, or polygon) is represented by one record in the table. These tables are 
referred to as Feature Attribute Tables (FATs), a subset of which are Point (or Polygon) Attribute Tables (PAT) and Arc (Line) Attribute Tables (AAT). In grid attribute tables, each class of cell value is represented by one record.

Query operations are performed to retrieve information from a table, such as the retrieval of all records that have a certain value, or range of values, in a certain field. Because of the relation between spatial and attribute data, querying the FAT or grid attribute table results in a spatial selection, and vice-versa. Like records in different tables that share certain attributes can be identified through relation operations. Relation operations between attribute tables involve the identification of common values in a common field, allowing a query in one table to identify records in both tables (Figure 6).

Arcview 3.0 and Arc/Info allow two types of relation operations, joins and links. The table join operation takes one attribute table, the join table, and basically pastes it onto another table, called the destination table, based on the common values of each record within each table for a selected field, called the joinitem. In this table relation operation each record in the destination table must have only one associated record in the join table because only one field value may be joined onto one record. If a many to one join is attempted, either the software will prohibit the join or the first associated record that the software finds in the join table will be inserted into the destination table, ignoring the other associated records. This may lead to a misleading 


\begin{tabular}{|c|c|c|c|c|c|c|}
\hline \multicolumn{2}{|l|}{ Map } & \multicolumn{5}{|c|}{ Attribute Table I } \\
\hline \multirow[t]{2}{*}{19} & 12 & \multirow{5}{*}{ Aecord -} & $\begin{array}{l}\text { Map } \\
\text { ID }\end{array}$ & $\begin{array}{l}\text { Area } \\
\text { inat }\end{array}$ & $\begin{array}{c}\text { Perimeter } \\
\text { (mi }\end{array}$ & $\begin{array}{l}\text { Stand } \\
\text { Number }\end{array}$ \\
\hline & & & 11 & 435 & 680 & $\mathrm{~J} 227$ \\
\hline \multirow{3}{*}{13} & \multirow{3}{*}{14} & & $: 2$ & 210 & 580 & $\mathrm{~J} 420$ \\
\hline & & & 13 & 628 & 1140 & $J \cdot 760$ \\
\hline & & & 14 & 252 & 650 & J.127 \\
\hline
\end{tabular}

Attribute Table 2

\begin{tabular}{|c|c|c|}
\hline $\begin{array}{c}\text { Siand } \\
\text { Number }\end{array}$ & $\begin{array}{c}\text { Domiruant } \\
\text { Species }\end{array}$ & Age \\
\hline$J-127$ & W. Spruce & 45 \\
\hline$J 128$ & B. Spruce & 60 \\
\hline$J 129$ & W Spruce & 15 \\
\hline$J 130$ & Hemlock & 40 \\
\hline$J 131$ & Hemlock & 25 \\
$\cdot$ & $\cdot$ & $\cdot$ \\
\hline & $\cdot$ & $\cdot$ \\
\hline
\end{tabular}

Elgure 6. The relational database model as implemented in a GIS. A spatial selection selects a record in an attribute table which may then be related to other tables through the identification of common fields (Aranoff 1989:160). 
joined table, although this type of operation may be useful in some circumstances. Joins may be temporary or permanent.

The other type of table relation allowed in Arcview 3.0 and Arc/Info is the table link. The table link operation does not paste associated records from one table to another but simply establishes a relation between two tables based on the record values for the joinitem. In this way, the selection of records within one table automatically selects the associated records with an identical value for the joinitem in another table. Link operations have the advantage of not being hindered by many to one or one to many limitations since records are merely selected and not pasted onto another table. Links are generally temporary operations and table link relations are dissolved when each Arcview 3.0 or Arc/Info session is terminated, although through the scripting languages available with each software package, these applications can be customized so that the links can be "permanently" established.

The relational database scheme allows for the normalization of data, the, "appropriate structuring of relation schemes in a database" (Worboys 1995:81). Instead of repeating record values for certain fields repeatedly in only one table, records are grouped into separate tables so that the data redundancy contained within each table is minimized. While different tables may contain records that refer to the same object, fields within each table differ to maximize the number of unique record values. Although this procedure increases the number of tables and relative 
complexity of the database, it introduces database organization and minimizes data redundancy. Relational schemes may then be implemented to facilitate data access. Glacier attributes may include such diverse attribute information as glacier morphology or the source of data upon which a glacier feature's digital representation was derived. Some glacier attributes may apply to an entire glacier coverage (glacierbased attributes) and some may only apply to one polygon or line within a vectorbased glacier coverage (feature-based attributes). Some glacier attributes may apply to a glacier for one time of record (time-dependent attributes) and others may apply for all times of record (time-independent attributes).

It should be noted that feature-based attribute data generally cannot be applied to a glacier for all times of record because it is associated with a specific spatial element (point, line, or polygon) within a glacier representation at a time of record. Therefore, feature-based attribute data is nearly always associated with a glacier at a specific time. Glacier-based attribute data, however, is not limited to the temporal constraint of association with a particular glacier coverage and may therefore apply to a glacier not only for one time of record but for all times of record. The following combinations of spatial and temporal scalar attribute data can be defined:

- Feature-Based Attribute Data

Attribute data associated with a point, line, or polygon feature found within a vector glacier coverage representing one time of record (i.e. the area of a polygon). 
- Glacier-Based, Time-Dependent Attribute Data

Attribute data associated with an entire glacier at one time of record (i.e. the time of record or survey date).

- Glacier-Based, Time-Independent Attribute Data

Attribute data associated with an entire glacier for all times of record (i.e. the glacier name).

It should also be noted that the Database attribute data is developed only for use and relation with the vector spatial glacier representations. This is because of the nonexistent (in the case of floating point grids) or limited nature of grid attribute tables. Because all raster grids are derived directly from vector coverages (see Chapter IV) and reside within the same sub-directory (see Chapter III) it is not necessary, nor practical, to directly relate raster grids to glacier attribute information. This information can be easily accessed by referring to the associated vector coverages.

The challenge in organizing the Database lay in relating each spatio-temporal glacier representation element at each of its various scales to its associated attribute data without "cluttering" the Database with extraneous table relations and data redundancy. The strategy employed to solve this issue is to hierarchically organize the spatial data within the Database structure, first by glacier and second by time of record. Attribute data is organized into separate feature-based; glacier-based, time-dependent; and glacier-based, time-independent tables that can be related to their associated spatial representations. In addition, the attribute tables themselves can be inter-related through the identification of common values found in fields designed for this purpose. 


\section{THE ROLE OF METADATA IN MAINTAINING DATA QUALITY}

The issue of maintaining data quality is of major importance in construction of the Database because there are a variety of means by which the Database may contain significant data inaccuracy that is transparent to the user. This transparency may lead to inaccurate data analysis and representation, especially if the user is not a GIS specialist and is interacting with the Database through a customized application user interface that distances the user from the internal structure of the Database and software.

Data quality issues concern how much the spatial and temporal data mimic the "real world" phenomena. Aranoff (1989) suggests that the measure of data quality may be divided between micro and macro level components, generally conforming to the data quality components described in the SDTS. Micro level data quality issues can be summarized by positional accuracy, attribute accuracy, logical consistency, and resolution. Macro level data quality issues concern completeness and lineage.

Positional accuracy refers to the difference in GIS location of an object from its true location, while attribute accuracy refers to appropriate attribute classification of spatial data (Aranoff 1989). Logical consistency concerns, "how well logical relations among data elements are maintained" (Aranoff 1989:136) and resolution refers to the minimum representation size the GIS accommodates. Completeness refers to the degree of temporal and spatial coverage of the data and lineage refers to the data source history. 
The source of error in integrating diverse data sources mainly concerns the resolution and positional accuracy of the source maps. Positional accuracy can be divided among bias, a systematic error concerning map registration, and precision, or random dispersion of spatial error (Aranoff 1989). The data accuracy of topographic maps has improved significantly over the time span of data within the Database, not only positionally but in the shape and generalization of the contours (Mahoney, Carstensen, and Campbell 1991). Topography captured by survey in 1913 is significantly less accurate than that captured by photogrammetry in 1971 .

Managing data accuracy between temporal data is especially difficult. While there are obviously differences in bias and precision between the 1913 and 1971 representations of a glacier, the earlier representation cannot be corrected by reference to the more recent because one does not know whether the spatial difference between the two representations are due to inaccuracy on the part of one or both maps or simply represent a temporal change in glacier position. Similarly with resolution, the spatial differences between a glacier at two different times, one digitized from a small scale map and one from a larger scale, cannot be attributed to the difference in resolution because it may represent glacier change over time.

In addition, the manipulation of data during the interpolation process introduces further data inaccuracy. Lanter (1993) differentiates between "source" digital data, that digitized from a non-digital source, and "derived" digital data, whose source is the manipulation of existing digital data. This division is especially relevant 
to the Database considering the difference in the nature of data quality between spatial data digitized from maps and spatial data interpolated from those digitizations. By definition, interpolation implies an estimation between known data values. Error due to this estimation is further compounded by unquantifiable spatial inaccuracies within the original data upon which the interpolation is based.

Unfortunately, the vector and raster data structures do not implicitly record, or explicitly represent, spatial data quality. No matter the uncertainty of a particular glacier extent or elevation at a certain location, the vector structure will encode the extent as a discrete boundary represented by a line and the raster grid will encode the elevation as a real number at specific grid cell location. While there has been recent progress in the spatial representation of data uncertainty (Buttenfield 1993; McGranaghan 1993) there currently is no efficient way to represent uncertainty in Arcview 3.0 or Arc/Info.

In the face of these various pervasive and unquantifiable data inaccuracies, the Database must maintain a methodology for managing data quality and imparting the nature of the data quality for each spatial glacier representation to the user. Otherwise, the data will be of minimal value in its practical application to glacier monitoring, analysis, and representation. The approach taken towards this issue is the maintenance of a thorough metadata structure that explicitly documents the data quality of each individual spatial data representation. 
Goodchild (1995) notes that there are two different approaches to maintaining data quality through the use of metadata. The first concerns a description of how the data differs from the "real world", while the second describes the processes known to contribute to error. Since the gathering of "real world" data from the past is unobtainable, there is no "ground truth" with which to measure the difference between the GIS model and reality. Therefore, the Database emphasizes the second approach, a clear description of the source of all data and the process of data manipulation that may contribute to inaccuracy, so that the user may decide its "fitness for use."

The format of this metadata is presented in different ways dependent on the nature of the metadata itself and for the facilitation of access. Metadata that can be easily categorized by spatio-temporal glacier representation is implemented in a relational table that can be linked to the spatial representations. This allows the user to easily access data quality information concerning the data source, such as map scale and condition. In addition, the nature of the data manipulation and interpolation process is thoroughly documented and described to ensure that the data quality of these derivations may be assessed.

For many GIS users there is a tolerance, or limit, in terms of the data quality that is acceptable (Goodchild 1995). For the Database, however, this is not the case. The relative scarcity of historic glacier data makes every temporal glacier representation valuable, regardless of data quality. Therefore, the Database seeks to incorporate all spatio-temporal glacier data with the intent of providing thorough 
metadata and documentation to ensure the appropriate use and interpretation of that data.

\section{THE REPRESENTATION OF GLACIER PROPERTIES}

The Database transforms the spatial and attribute data presented on glacier topographic maps into sets of digital data that can be used for analysis and display. Spatially, this concerns the areal extent and three-dimensional surface geomorphometry of the glacier. Attribute data concerns the quantitative character of glacier geomorphometry, the location of the glacier, and information pertaining to the data source.

The strategy for spatial representation is to assign individual geomorphometric components, or groups of like components, to specific "layers" of spatial data. The layer may be either a raster grid or a vector coverage depending on the nature of the phenomena. Some of these layers are data digitized directly from the maps, while others are derivations from the manipulation of those original digitizations. The primary spatial components include: the glacier extent, the extent of glacier debris, and the surface elevation. On the original maps, these are each represented by shades of color and lines, in the case of elevation by contour lines.

Other geomorphometric components can be derived by visual analysis of the map, such as the interpretation of the distribution of mass balance flux over the glacier surface. Glacier mass balance involves the rates of glacier input, transfer of glacier ice downslope, and glacier output (Selby 1985). The surface of the glacier can be divided 
into zones of accumulation, in which mass is being added to the glacier in the form of snow, and ablation, in which the glacier loses mass due to melting, evaporation, or calving of icebergs (Figure 7). The division between these two zones is called the equilibrium line (ELA), the, "position on the glacier below which snow does not last through the melt season..." (Selby 1985:427).

Since the glacier extent is entirely composed of the zones of ablation and accumulation separated by the ELA, it is logical to group these together in one vector coverage. Glacier debris represents a specific geomorphometric feature while contour lines represent general geomorphometric character; they are therefore incompatible within the same spatial representation and each is assigned its own vector coverage.

Once the contour line coverage is in digital format, it is interpolated to produce a raster grid of the glacier surface. The raster data structure and automated analysis functions in Arcview 3.0 allow for the further derivation of glacier slope and aspect. A hillshade grid can also be created to mimic the reflection and shading across the glacier surface from a light source anywhere in the "sky." While hillshading can be used analytically, such as the modeling of albedo, it is most often used to enhance data display. Each of these representations is assigned its own raster grid.

The attribute representation goals of the Database encompass glacier geomorphometry, location, and metadata. Attributes tables are normalized by subject, such as glacier morphology or location, and by spatial and temporal scales. Two sets of tables describe glacier geomorphometry, the FATs associated with each vector 
Arrows indicate magnitude of ice gain, loss, and transfer.

\section{Equilibrium line} Annual snow line Lower firn limit

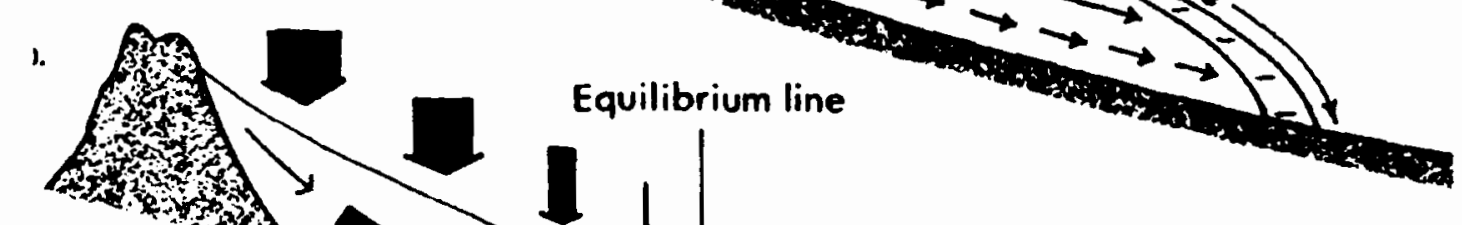

Arrows indicate ice flowlines.

Figure 7. Long profile of a glacier showing the zones of accumulation and ablation separatedby the equilibrium line (Selby 1985:427). 
coverage and a separate table describing geomorphometric attributes of entire glaciers. The table describing glacier location is constructed mainly as a tool for data access and query while the metadata table maintains data quality. 


\section{CHAPTER III}

\section{THE STRUCTURE AND ORGANIZATION OF THE DATABASE DATABASE ORGANIZATION: OVERVIEW}

For each time of record, each glacier is spatially represented by, at most, eight vector Arc/Info coverages and four raster Arc/Info grids. Feature-based attribute data are placed within the appropriate Polygon Attribute Table (PAT) and/or Arc Attribute Table (AAT) that define the attribute part of each Arc/Info vector coverage. Arc/Info and Arcview 3.0 automatically spatially relate this attribute data with the associated feature it describes. Therefore, feature-based attribute data are stored implicitly within a particular glacier coverage, parallel to its associated spatial representation.

Glacier-based, time-dependent attribute data are organized into three separate tables: Glacier Morphology, Map Source Metadata, and Article/Book Source Metadata. Glacier Morphology describes the basic morphologic glacier characteristics that are not associated with any one feature of a glacier but apply to the entire glacier at a specific time, such as total glacier area.

Map Source Metadata describes the origin and physical condition of the map from which the digital representation for a glacier at a time of record is derived. Article/Book Source Metadata contains the bibliographic reference information if the glacier data was derived from this source. Map Source Metadata and Article/Book Source Metadata are considered attributes linked to an entire glacier at one time of 
record. However, occasionally, features within one glacier coverage will be derived from different data sources. The Database structure allows for features within each individual glacier coverage to relate to individual maps or article/books and their characteristics.

Glacier-based, time-independent attribute data are also stored separately from any individual glacier coverage in a set of two tables, Glacier Location and Glacier Literature. The Glacier Location table contains location information about each glacier while the Glacier Literature table contains references to literature concerning a specific glacier.

Two fields have been created to facilitate the relation between different attribute tables. The first, metakey, contains a unique value for each glacier at a specific time of record. The second, the WGMS_num, based on the WGMS number assigned by UNESCO/IASH, contains a unique value for each individual glacier, regardless of time of record. All attribute tables contain one or both of these fields to facilitate relations across attributes of differing temporal and spatial scales.

Data retrieval can be initiated by spatial or attribute query to any of the coverages or glacier-based attribute tables, depending on the goals of the user. Queries may be based on a specific glacier at one time of record or within a range of years. Queries may also be based on varying scales of location and/or time. Table relations facilitate the access of linked spatial and attribute data once the queried records are selected. 


\section{SPATIAL DATA ORGANIZATION}

This section describes each of the up to eight vector Arc/Info coverages and four raster Arc/Info grids that compose the spatial representation for each glacier at a time of record. All spatial data is registered in Universal Transverse Mercator coordinates. Units are stored in meters.

\section{$\underline{\text { Vector Coverages }}$}

Eight vector coverages are used to represent each glacier for one time of record. Each is described by its name, type (point, line, and/or polygon), and a brief description of its nature.

- Glacier Extent (line and polygon) (Figure 8)

This coverage represents the areal extent of the glacier divided into polygons of zones of accumulation and ablation along the ELA. Outcrops of rocks appear as "islands".

- Debris Extent (line) (Figure 8)

This coverage represents the areal extent of the glacier covered by debris. This coverage is perfectly nested within the Glacier Extent coverage, such that if debris extends to the edge of the glacier, the Debris Extent boundary arc is identical to the Glacier Extent boundary arc.

- Original Contour (line) (Figure 8)

This coverage describes the elevation of the glacier surface by the originally digitized contour lines. The contour interval and units are identical to those of the source map. Contour lines extend across the entire area of Glacier Extent, having their beginning and ending nodes spatially concurrent with the Glacier Extent boundary arcs. In some cases, however, the contour lines may extend throughout the "island" rock outcrops present in the Glacier Extent coverage. 


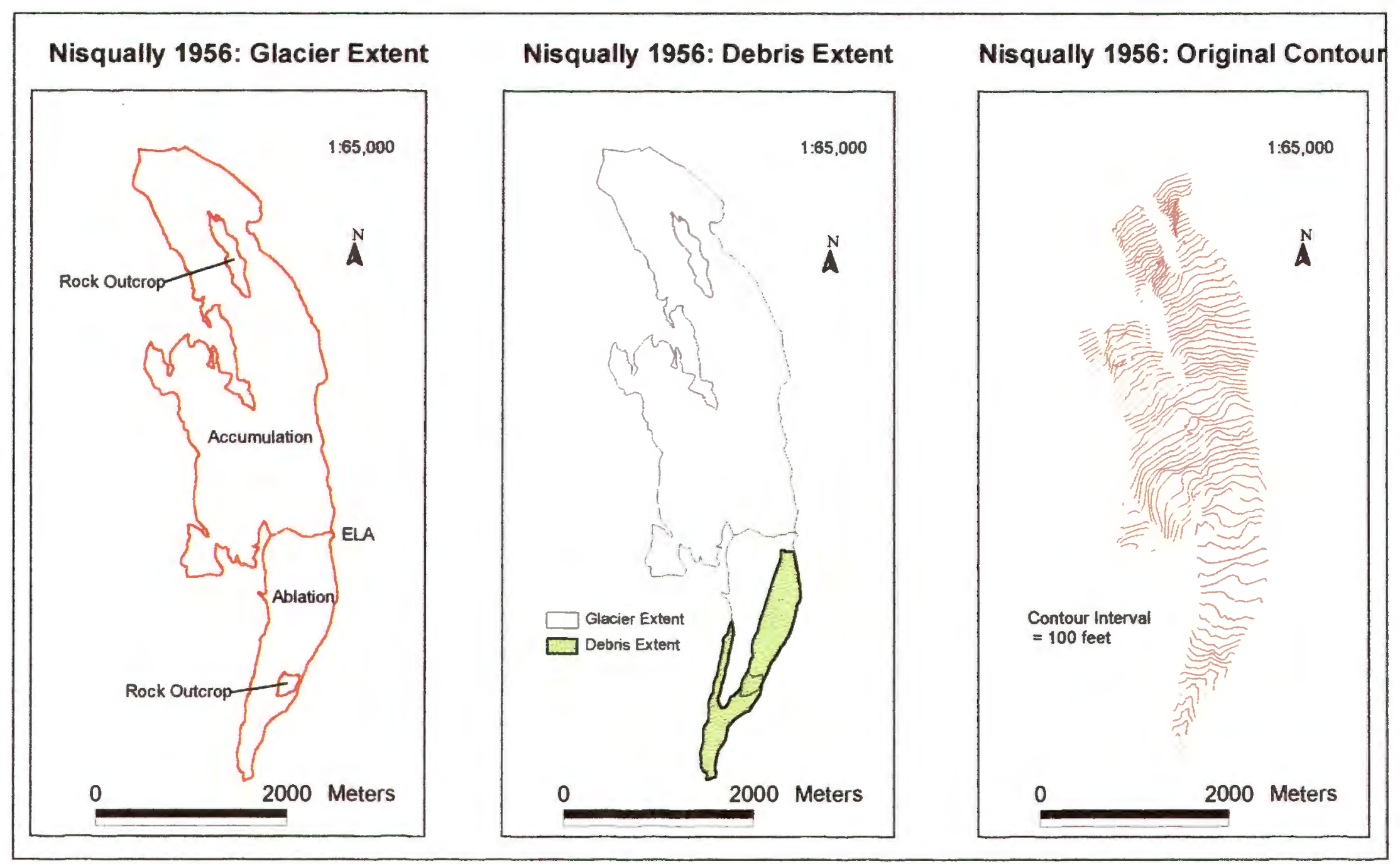

Eiqure 8. Example vector spatial data: Glacier Extent, Debris Extent, and Original Contour coverages. 
- Appended Contour (line) (Figure 9)

When contour data from one time of record is only available for part of the Glacier Extent, it is necessary to append contour line information from one time of record onto another to derive a complete glacier surface. This coverage is the destination contour line coverage after the append operation. Caution should be taken when viewing this coverage because often the source and destination Original Contour line coverages represent different contour intervals which can lead to incorrect visual interpretation of elevation and elevation change.

- Elevation Points (point) (Figure 9)

This coverage represents point elevation data derived directly from the vertices and nodes within the Original Contour or Appended Contour coverage. Nearly, but not all, contour line vertices are represented as elevation points (see Chapter IV). This coverage provides little visual information but plays an integral role in the generation of other derived spatial data.

- Interpolated Contour (line) (Figure 9)

This coverage represents the glacier surface through contour lines derived from an interpolation of the raster Glacier Surface grid (described below under Raster Grids). The contour interval is 50 meters and contour lines extend throughout the Glacier Extent but beginning and ending nodes are not perfectly nested along the Glacier Extent arcs. While the standardized nature of the data enhances visual comparison of surface elevation between different times, caution should be taken in interpreting the data at higher resolution because of the derivative nature of this coverage.

- Ice-Dammed Lake (polygon)

This coverage represents the extent of ice-dammed lakes caused by, and in proximity to, the glacier. Each lake is represented by one polygon, unless it contains islands, which are represented by additional polygons.

- Terminus Position (line) (Figure 10)

This coverage represents the terminus position of a particular glacier at many times of record. It contains a set of unconnected arcs representing active and non-active glacier termini that bound only the lower portion of the Glacier Extent. Terminus positions listed here 


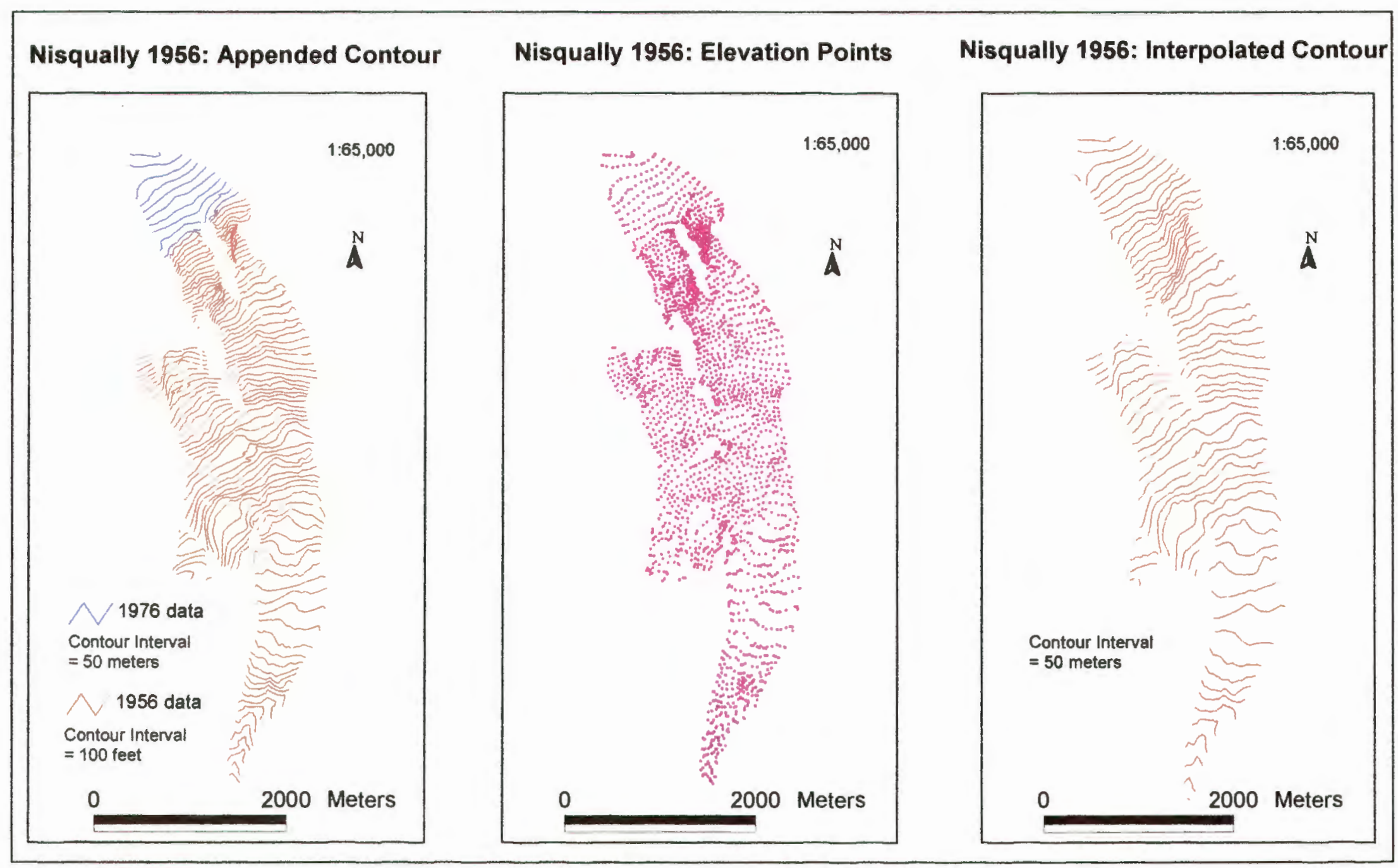

Eiqure 9 Example vector spatial data: Appended Contour, Elevation Points, and Interpolated Contour coverages. 


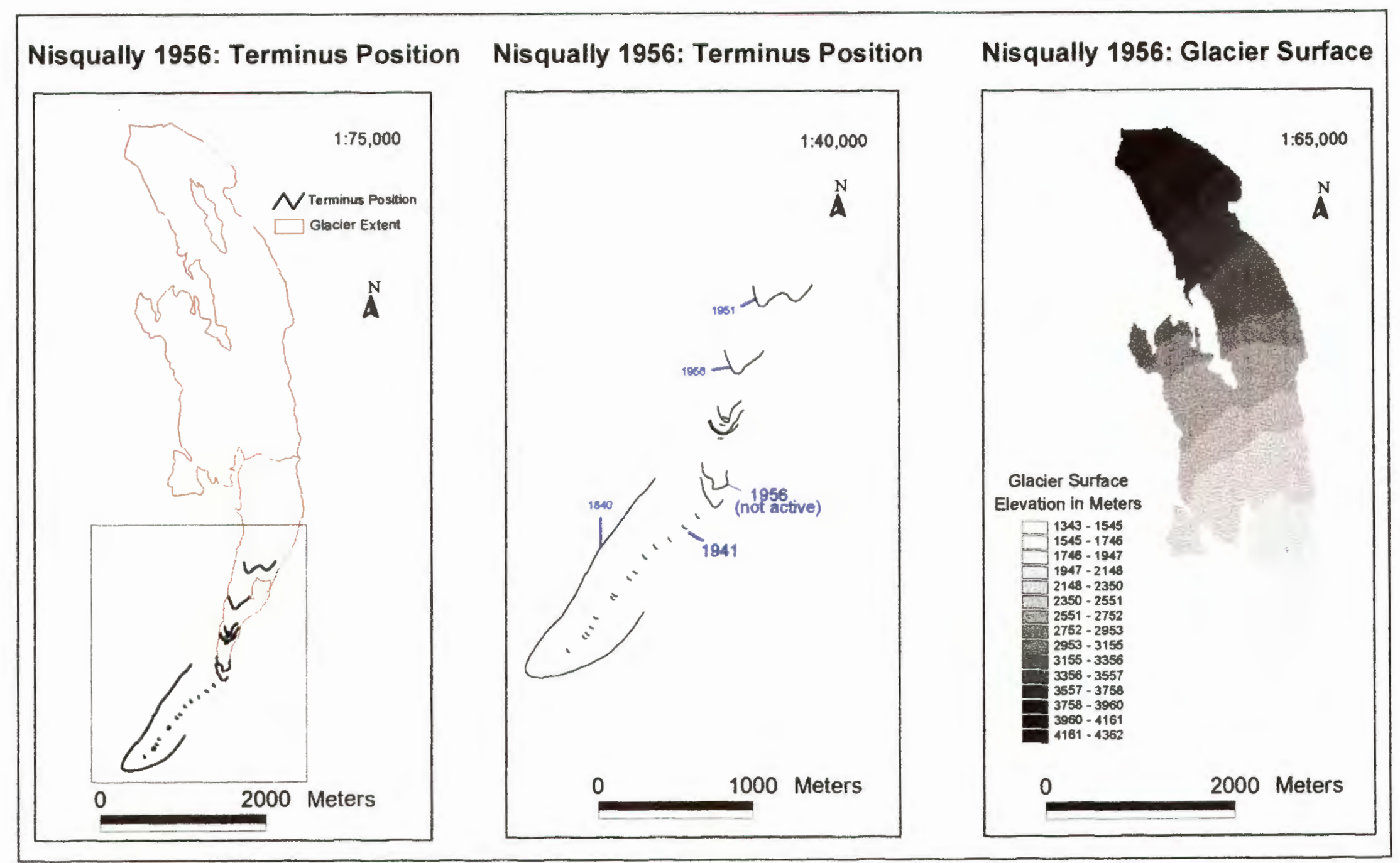

Eigure 10 Example vector and raster spatial data: Terminus Position coverage and Glacier Surface grid. 
may or may not be perfectly nested with related Glacier Extent coverages, even if they represent the same time of record, as there may be more than one source of terminus position data.

\section{$\underline{\text { Raster Grids }}$}

Four grids constitute the raster component of the Database, whose cell values extend over the entire area within the Glacier Extent, including "island" rock outcrops. Each grid is described by the grid category name, whether floating point (real number) or integer grid, and a brief description of its nature.

- Glacier Surface (Figure 10)

This floating point grid represents the glacier surface elevation as interpolated from the Point Elevation coverage (see Chapter IV).

- Glacier Slope (Figure 11)

This floating point grid represents the percent slope as it varies across the glacier surface. Each cell's value is derived from a calculation involving the surrounding Glacier Surface grid cell values. Minimum and maximum cell values reflect the flattest and steepest cells in the grid, between $0 \%-100 \%$.

- Glacier Aspect (Figure 11)

This floating point grid represents the aspect as it varies across the glacier surface. Each cell's value is derived from a calculation involving the surrounding Glacier Surface grid cell values. Minimum and maximum cell values vary between 1 - 360 degrees azimuth.

- Glacier Hillshade (Figure 11)

This integer grid represents the reflectivity of each grid cell from a light source at 315 degrees azimuth and 45 degrees above the horizon. Reflectivity values range between 0 (darkest) - 255 (brightest). It is derived from the Glacier Aspect grid and can be used for visualization and qualitative analysis. 


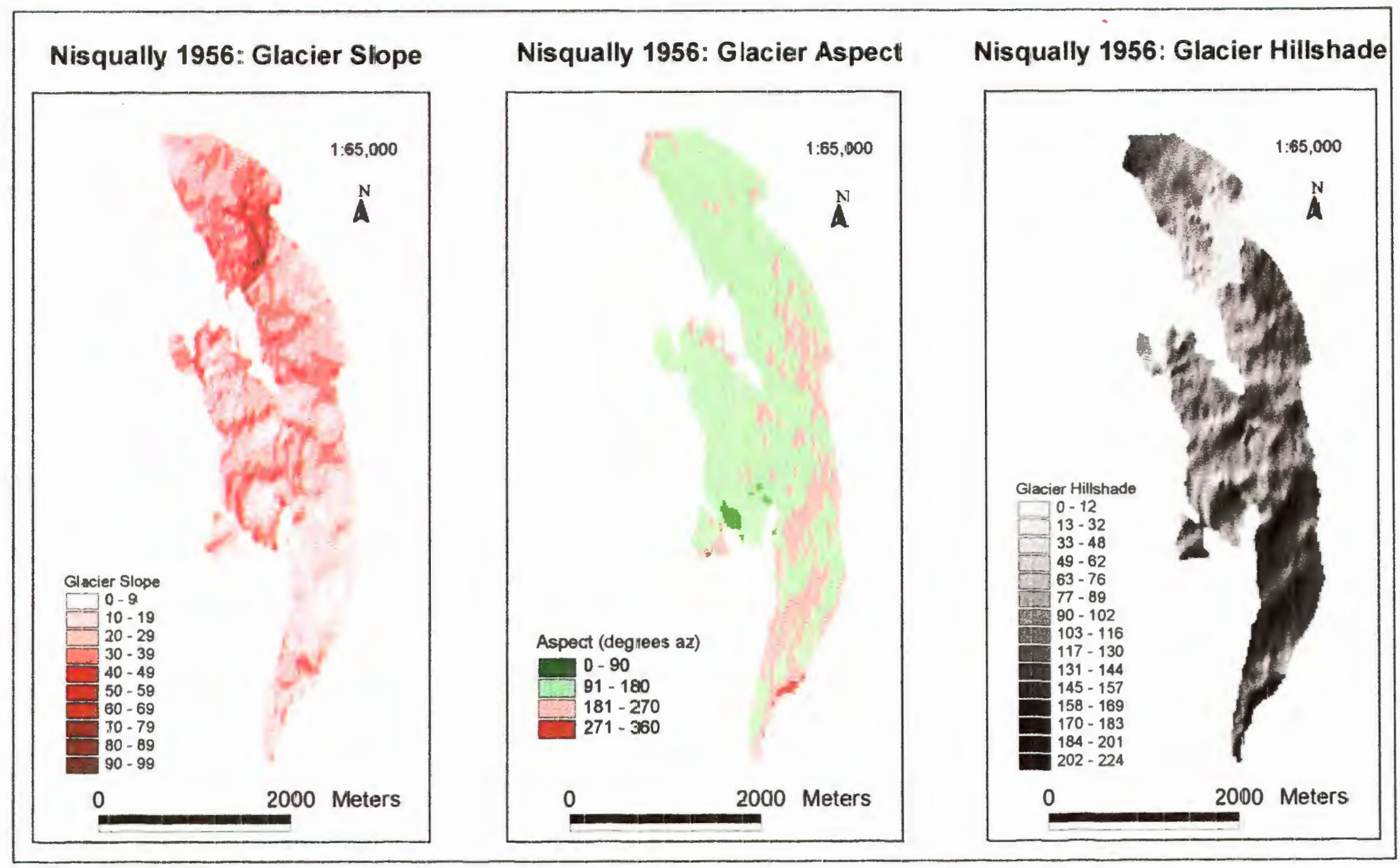

Eiqure 11 Example raster spatial data: Glacier Slope, Glacier Aspect, and Glacier Hillshade grids. 


\section{FEATURE-BASED ATTRIBUTE DATA ORGANIZATION}

For each time of record, each glacier coverage INFO file directory contains a number of tables and associated fields where each record in the table represents one feature (point, line, or polygon) of a glacier for that time of record. The field length, whether a number $(\mathrm{N})$ or a string $(\mathrm{S})$, and number of decimal places are given in parentheses. Fields automatically created by Arc/Info are omitted, unless deemed morphologically significant, and the range of field values is given in quotes, if applicable.

- Glacier Extent PAT

$\begin{array}{ll}\text { Area }(16, N, 0) & \text { - area of the polygon } \\ \text { Name }(16, S, 0) & \text { - name of the glacier } \\ \text { Zone }(12, S, 0) & \text { - area representation; "accumulation", } \\ & \text { "ablation", "rock", or "basal_topo" } \\ \text { High_elev }(5, N, 0) & \text { - highest elevation of the polygon } \\ \text { Low_elev }(5, N, 0) & \text { - lowest elevation of the polygon } \\ \text { Med_elev }(5, N, 0) & \text { - median elevation of the polygon } \\ \text { Length }(6, N, 0) & \text { - approximate length of the polygon } \\ \text { Metakey }(11, N, 0) & \text {-key field containing a unique value for each } \\ & \text { glacier for each time of record }\end{array}$

- Glacier Extent AAT

Length $(16, N, 0) \quad$ - length of each arc

Type $(6, S, 0) \quad$ - delineation the arc represents; "extent" or "ELA" 
Source $(11, S, 0)$

Metakey $(11, N, 0)$
- source of delineation; "interpreted" or "mapped"

- key field containing a unique value for each glacier for each time of record

- Debris Extent PAT
Area $(16, N, 0)$
- area of each debris polygon
Metakey $(11, N, 0)$
- key field containing a unique value for each glacier for each time of record

- Original Contour AAT
Length $(16, N, 0)$
- length of each contour arc
Elevft $(5, N, 0)$
- contour line elevation in feet
$\operatorname{Elevm}(5, N, 0)$
-contour line elevation in meters
Metakey $(11, N, 0)$
- key field containing a unique value for each glacier for each time of record

- Appended Contour AAT

Length $(16, N, 0)$

Elevft $(5, N, 0)$

Elevm $(5, N, 0)$

Metakey $(11, N, 0)$
- length of each contour arc

- contour line elevation in feet

-contour line elevation in meters

- key field containing a unique value for each glacier for each time of record

- Interpolated Contour AAT

Length $(16, N, 0)$

-length of each contour arc

Contour $(5, N, 0)$

-contour line elevation in meters

Metakey $(11, N, 0)$

- key field containing a unique value for each glacier for each time of record 
- Elevation Points PAT

Elevm $(4, \mathrm{~N}, 0) \quad$-elevation in meters

Metakey $(11, N, 0) \quad$ - key field containing a unique value for each glacier for each time of record

- Ice-Dammed Lake PAT

$\begin{array}{ll}\text { Area }(16, N, 0) & \text { - area of each lake polygon } \\ \text { Metakey }(11, N, 0) & \begin{array}{c}\text { key field containing a unique value for each } \\ \text { glacier for each time of record }\end{array}\end{array}$

- Terminus Position AAT

$\begin{array}{ll}\text { Year }(4, N, 0) & \text { - year of record } \\ \text { Active }(2, S, 0) & \begin{array}{c}\text {-does that terminus position represent the } \\ \text { extent of the active glacier; " } y \text { " or " } \mathrm{n} \text { " }\end{array} \\ \text { Metakey }(11, N, 0) & \begin{array}{c}\text { - key field containing a unique value for each } \\ \text { glacier for each time of record }\end{array}\end{array}$

\section{GLACIER-BASED, TIME-DEPENDENT ATTRIBUTE DATA ORGANIZATION}

Each record in the table represents an entire glacier at a specific time of record. The field length, whether a number $(\mathrm{N})$ or a string $(\mathrm{S})$, and number of decimal places are given in parentheses.

- Glacier Morphology
Name $(16, S, 0)$
- name of the glacier
Elev_ELA $(4, N, 0) \quad$ - elevation of the ELA
Area_accum $(10, N, 0)$ - area of accumulation zone
Area_total $(10, N, 0) \quad$ - total area of the glacier extent 
$\operatorname{Aar}(3, N, 2)$

Metakey $(11, N, 0)$

WGMS_num $(7, N, 0)$
- accumulation area ratio; the area of accumulation divided by total glacier extent

- key field containing a unique value for each glacier for each time of record

- World Glacier Monitoring System number

- Map Source Metadata

Name $(16, N, 0) \quad$ - name of the glacier

Publisher $(24, S, 0) \quad$ - publisher of the source map

Map_name $(24, S, 0) \quad$ - title of the map, if appropriate (e.g. Mount Rainier National Park)

Map_type (24, S, 0) - type of map, if standard (e.g. 15 minute quadrangle)

Date_survey $(4, N, 0) \quad$ - year the land was surveyed for the map, or initial map data was derived

Date pub $(4, N, 4) \quad$ - year the map was published

Map_scale $(9, S, 0) \quad$ - scale of the map in ratio (e.g. 1:24000)

Projection $(24, S, 0) \quad$ - projection and coordinate system of map

Map_acccura $(16, S, 0)$ - map accuracy if standardized (e.g. NMAS, National Map Accuracy Standards)

Material (10, S, 0)

- map material; "paper" or "mylar"

Condition $(9, S, 0)$

- condition of the map at the time of digitization (e.g. good, fair)

$\operatorname{Notes}(2, N, 0)$

Metakey $(11, N, 0)$

- key field containing a unique value for each glacier for each time of record

WGMS_num $(7, N, 0) \quad$-World Glacier Monitoring System number 
- Article/Book Source Metadata

$\begin{array}{ll}\text { Name }(16, S, 0) & \text { - name of the glacier } \\ \text { Auth_last }(16, S, 0) & \text { - last name of the author } \\ \text { Auth_first }(16, S, 0) & \text { - first name of the author } \\ \text { Year }(4, N, 0) & \text { - year of publication } \\ \text { Title }(24, S, 0) & \text { - title of book or article } \\ \text { Journal }(24, S, 0) & \text { - name of journal (if appropriate) } \\ \text { Publisher }(24, s, 0) & \text { - publisher (if appropriate) } \\ \text { Place_pub }(16, S, 0) & \text { - place of publication (if appropriate) } \\ \text { Metakey }(11, N, 0) & \text { - key field containing a unique value for each } \\ & \text { glacier for each time of record } \\ \text { WGMS_num }(7, N, 0) & \text { - World Glacier Monitoring System number }\end{array}$

\section{GLACIER-BASED, TIME-INDEPENDENT ATTRIBUTE DATA ORGANIZATION}

Each record represents an entire glacier for all times of record. The field length, whether number $(\mathrm{N})$ or string $(\mathrm{S})$, and number of decimal places are given in parentheses.

- Glacier Location

$\begin{array}{ll}\text { Name }(16, S, 0) & \text { - name of the glacier } \\ \text { Country }(16, S, 0) & \text { - country of glacier location } \\ \text { State_prov }(16, S, 0) & \text { - state or province of glacier location } \\ \text { Mt_range }(16, S, 0) & \text { - mountain range of glacier location } \\ \text { Mountain }(16, S, 0) & \begin{array}{c}\text {-specific mountain of glacier location (if } \\ \text { applicable) }\end{array} \\ \text { Latitude }(6, N, 0) & \begin{array}{c}\text { - approximate latitude of the glacier, } \\ \text { (e.g. 455000) }\end{array}\end{array}$


Longitude $(7, N, 0) \quad$ - approximate longitude of the glacier (e.g. 1214000)

WGMS_num $(7, N, 0)$ - World Glacial Monitoring System number

- Glacier Literature

Name $(16, S, 0) \quad$ - name of the glacier

Auth_last $(16, S, 0) \quad$ - last name of the author

Auth_first (16, S, 0) - first name of the author

$\operatorname{Year}(4, N, 0) \quad$ - year of publication

Title $(24, S, 0) \quad$ - title of book or article

Journal $(24, S, 0) \quad$ - name of journal (if appropriate)

Publisher $(24, s, 0) \quad$ - publisher (if appropriate)

Place_pub $(16, S, 0) \quad$ - place of publication (if appropriate)

WGMS_num $(7, N, 0) \quad$ - World Glacier Monitoring System number

\section{DIRECTORY STRUCTURE AND NAMING CONVENTIONS}

The most common and immediate use for the Database is the analysis of specific glacier change over time. The Database directory structure is therefore organized primarily by specific glacier and then by time of record. While this hierarchical structure facilitates data access by glacier, it complicates direct access by time of record. A customized data access and query system would perhaps make this complexity transparent to the casual user. The Database structure can be hierarchically divided into four "levels" below the root directory (Figure 12). 


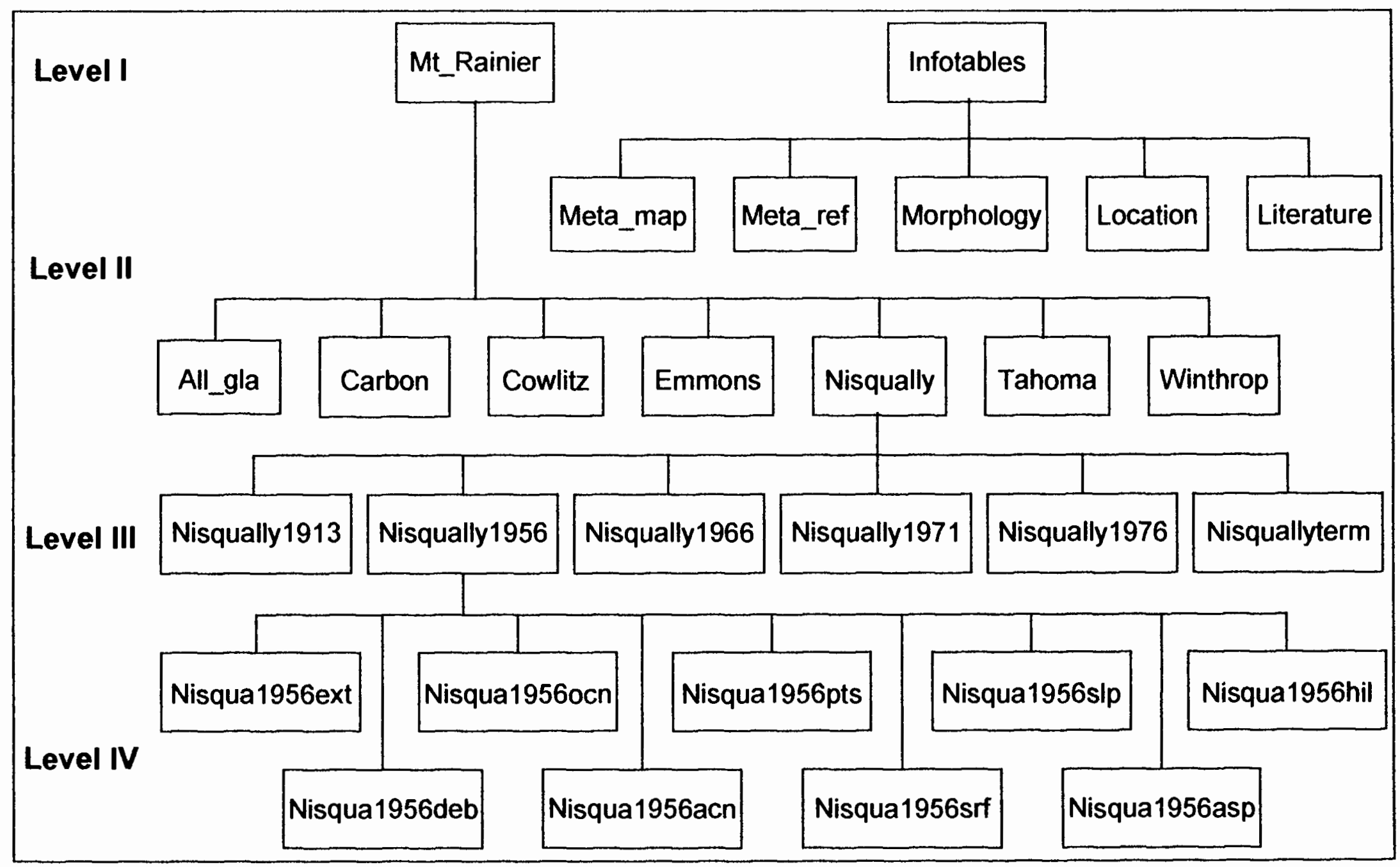

Eigure 12 Hierarchical directory structure for the Database by level. 


\section{$\underline{\text { Level I }}$}

At Level I all spatial and attribute glacier data concerning a specific glacier grouping, such as one particular mountain, is placed in a directory bearing the name of that mountain (e.g. Mt Rainier). This Level I hierarchy may be expanded upwards to nest mountain folders within a folder for one mountain range, or within a folder of a region, and so on. There is currently no need to build a more elaborate upper directory hierarchy for the current application of the Database to glaciers on Mount Rainier. In addition, this level contains a folder named Infotables that contains the INFO files describing the glacier-based attribute data.

Level II

Level II contains a series of folders named by the name of the glacier (e.g. Nisqually for Nisqually glacier). All spatial and temporal data concerning that glacier is found within that folder. Also at this level, a folder named All glaciers contains coverages or grids that describe more than one specific glacier within that glacier group. The glacier-based attribute tables also reside at Level II within the Infotables folder. They are named:

Glacier Morphology ..Morphology

Map Source Metadata Meta_map

Article/Book Source Metadata Meta_Ref

Glacier Location Location

Glacier Literature .Literature 


\section{$\underline{\text { Level III }}$}

Level III contains a series of folders, within the Level II glacier name folders, that contain all data for one time record of that glacier. This folder is identified by the glacier name followed by the year of record (e.g. Nisqually 1956). This Level III folder contains the four Arc/Info raster grids and up to seven of the eight Arc/Info vector coverages described in Chapter III. The exception is the Glacier Terminus coverage, which includes data for many different times of record and also resides at Level III. The Glacier Terminus coverage is identified by the glacier name followed by the letters "term" (e.g. Nisquallyterm). The INFO file containing the feature-based attributes for the Glacier Terminus coverage also resides at Level III.

At this level the coverages and/or grids within the All glacier folder are found. They are named according to the nature of their contents but should follow the general naming convention of "al_gla" for the first six characters followed by a code or abbreviation describing the content (e.g. al_glamrpdem for a DEM of the entire $\underline{\text { Mount }}$ Rainier National Park).

Level IV

At Level IV each individual glacier coverage and grid resides within its Level III glacier and time of record folder. Each coverage and grid is named by the first six letters of the name of the glacier followed by the year of record and a three letter code signifying the type of coverage or grid (e.g. Nisqually1956ext for Glacier Extent). 
The following suffix naming conventions will be used for each coverage or grid type:

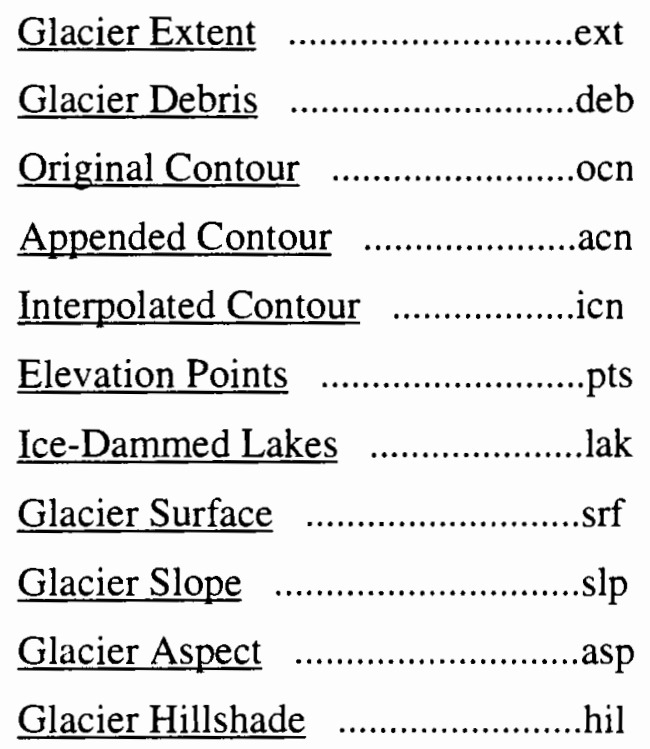

\section{DATA ACCESS: QUERY AND TABLE RELATIONS}

Information in the Database may be approached differently by different users depending on their analytical and data access goals. For instance, one user may be doing an analysis on one glacier's morphologic change through time while another may require the position of all glaciers in a region at a specific time, or may want information on one glacier at one time. The need for access to the Database at a variety of spatial and temporal scales necessitates a scheme by which the user can easily and efficiently query the Database to access the appropriate data. The Database is designed so that the user can access information through four separate avenues: 1) by glacier location, 2) by specific glacier , 3) by time of record, and 4) by specific glacier at a time of record. 
Data access by glacier location can be accomplished through a query of the Glacier Location attribute table. Because of the hierarchical nature of this attribute table, queries on glacier location can be performed at a variety of scales by political entity (country and state or province) or physiographic region (mountain range and specific mountain). Location queries can also address a specific, or a range of, latitude and longitude. This approach is useful for a user interested in glaciers within a physiographic region that crosses national borders.

Data access by glacier name can be accomplished through the query of one of a number of attribute tables depending on the user's interests. All glacier-based attribute tables contain the field Name and queries on this field for a glacier in any of these tables will yield a set of selected records regarding that glacier. Data access by time of record can be accomplished through a query of the Map Source Metadata attribute table. This table contains the field Date_survey whose value is the year the map data was derived. Temporal data for most glaciers is intermittent, so while queries for data on specific years is possible, more efficient access is gained by a query of a range of years.

Access by a specific glacier and time of record can be accomplished by querying any of the glacier-based, time-dependent attribute tables. Each of these tables contains the field Metakey whose value is unique for each glacier at a time of record. The field Metakey is a numeric field whose value is determined by the two digit country code, derived from the international phone system, followed by the five 
digit World Glacier Monitoring System (WGMS) number (with the numeric country code in place of the alphabetic code) and the four digit year of record. To access data for a specific glacier for a range of years, the user queries on a range of values in which the first seven digits (representing the glacier) remain the same and the last four numbers vary according to the year of interest.

Once an initial query results in a selection of records, relations between attribute tables facilitate access to data across spatial and temporal scales. For example, a query on the field Name in the Glacier Location table may result in the selection of one glacier record; however an additional link to the Glacier Morphology table, which contains a record for each glacier at a specific time, yields the temporal data available for that glacier. In addition, table relations allow the access of glacierbased attribute data from the spatial selection of a coverage feature, such as access to the data source record in the Map Source Metadata table from the selection of a line feature in the Terminus Position coverage.

The fields Metakey and WGMS_num were each expressly created to act as the joinitem in relation operations. Metakey provides relations between feature-based and glacier-based, time-dependent attribute tables while $W G M S \_$num provides relations between glacier-based, time-dependent and glacier-based, time-independent attribute tables. With the exception of the Terminus Position and Appended Contour coverages' FATs, all feature-based attribute tables contain the same Metakey value for each record throughout the entire table; however, each record within a glacier-based, 
time-dependent attribute table contains a unique Metakey value. Because all featurebased records represent objects that are nested within glacier-based objects, and those nested feature-based and associated glacier-based objects share the same Metakey value, those tables can be related. (Figure 13).

Similarly, all glacier-based attribute tables contain the field WGMS_num. Because WGMS_num has a unique value for each glacier (regardless of time), records within each glacier-based, time-dependent attribute table may have identical WGMS_num values, provided that data is available for a specific glacier for more than one time of record. However, all records within each glacier-based, time-independent attribute table have a unique value for the field WGMS_num. Therefore, these tables can be related (Figure 14). In this case, the time-dependent objects are temporally, as opposed to spatially, nested within the time-independent objects that share the same WGMS_num value.

Table relations between different glacier-based, time-dependent attribute tables include joins and links using the Metakey field as the joinitem without any destination table restrictions. The same is true for inter-relational operations with glacier-based, time-independent attribute tables using the WGMS_num field as the joinitem. The relation of feature-based attribute tables and glacier-based, time-independent attribute tables requires a "double" link using a glacier-based, time-dependent attribute table as the "bridge" (Figure 15). Because all spatial data is automatically related to its 


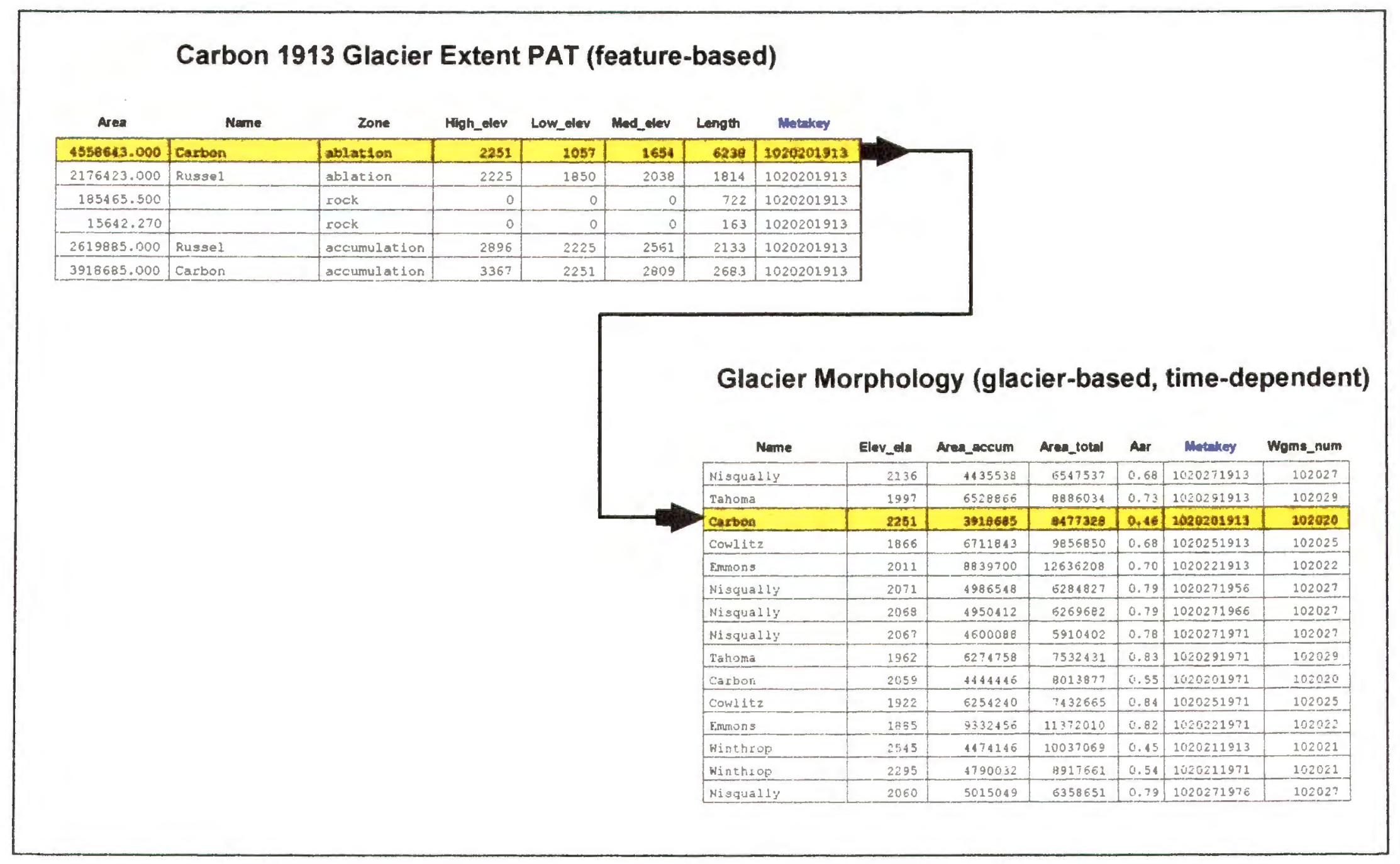

Figure 13. Table relations between feature-based and glacier-based, time-dependent attribute tables. 


\begin{tabular}{|c|c|c|c|c|c|c|c|c|c|c|}
\hline \multicolumn{11}{|c|}{ Glacier Location (glacier-based, time-independent) } \\
\hline Name & Country & \multirow{3}{*}{ Washington } & \multicolumn{2}{|c|}{ Mt_range } & Mountain & Latitude & \multicolumn{2}{|c|}{ Longitude } & Wgms_num & \\
\hline Nisqually & United States & & Cascades & Mt. Ra & inier & 464700 & 1214 & 500 & 102027 & \\
\hline Tahoma & United States & & Cascades & Mt. Ra & inter & 465000 & 1214 & 900 & 102029 & \\
\hline carbon & United statos & Hashington & Cascades & Me. Ra & $\ln \lfloor-\theta$ & 465100 & 1214 & 1700 & 102020 & \\
\hline Cowlitz & Inited States & Washington & Cascades & ME. Ra: & inier & 464700 & 1214 & 100 & 102025 & \\
\hline Emmons & United Statos & Washingtori & Cascades & Mt. Ra & infer & 465200 & 1214 & 400 & 102022 & \\
\hline \multirow[t]{18}{*}{ Winthrop } & United States & Washington & Cascades & Mt. Ra: & Iniar & 465300 & 1214 & 1400 & 102021 & \\
\hline & & \multicolumn{9}{|c|}{ Glacier Morphology (glacier-based, time-dependent) } \\
\hline & & & Name & Elev_ola & Area_accum & $n$ Area_t & total & Aar & Motakey & Wgma_num \\
\hline & & & N1squally & 2136 & 4435538 & 65475 & 7537 & 0.68 & 1020271913 & 102027 \\
\hline & & & Tahoma & 1997 & 6528866 & $8886 \mathrm{C}$ & 6034 & 0.73 & 1020291913 & 102029 \\
\hline & & & Carban & 2251 & 3918665 & 94773 & 7328 & 0.46 & 2020201913 & 102020 \\
\hline & & & Cowlitz & 1866 & 6711843 & 98568 & 6850 & 0.68 & 1020251913 & 102025 \\
\hline & & & Enmons & 2011 & 8839700 & 126362 & 6208 & 0.70 & 1020221913 & 102022 \\
\hline & & & Nisqually & 2071 & 4985548 & 62848 & 4827 & 0.79 & 1020271956 & 102027 \\
\hline & & & Nisqually & 2068 & 4950412 & 62696 & 9682 & 0.79 & 1020271966 & 102027 \\
\hline & & & Nisqually & 2067 & 4600088 & 59104 & 0402 & 0.78 & 1020271971 & 102027 \\
\hline & & & Tahoma & 1962 & 6274758 & 7532 & 2431 & 0.83 & 1020291971 & 102029 \\
\hline & & & Carbon & 2059 & 4444446 & 8013 & 3878 & 0.55 & 2020201971 & 102020 \\
\hline & & & Cowlitz & 1922 & 6254240 & 7432 & 2665 & 0.84 & 1020251971 & 102025 \\
\hline & & & Emmons & 1885 & 9332456 & 11372 & 2010 & 0.82 & 1020221971 & 102022 \\
\hline & & & Winthrop & 2545 & 4474146 & 100370 & 7069 & 0.45 & 1020211913 & 102021 \\
\hline & & & Winthrop & 2295 & 4790032 & 8917 & 7561 & 0.54 & 1020211971 & 102021 \\
\hline & & & Nisqually & 2060 & 5015049 & & 8651 & 0.79 & 1020271976 & 102027 \\
\hline
\end{tabular}

Eigure 14. Table relations between glacier-based, time-independent and glacier-based, time-dependent attribute tables. 


\begin{tabular}{|c|c|c|c|c|c|c|c|c|c|c|c|c|}
\hline Area & Name & Zone & High_elev & Low_elev & Mod_elev & Length & Metakey & \multirow{7}{*}{\multicolumn{4}{|c|}{$\begin{array}{l}1913 \text { Carbon Glacier } \\
\text { Glacier Extent PAT }\end{array}$}} & \\
\hline 4558643.000 & Carbon & abration & 2251 & 1057 & 1654 & 6236 & 1020201913 & & & & & \\
\hline 2176423.000 & Russe1 & ablation & 2225 & 1850 & 2038 & 1614 & 1020201913 & & & & & \\
\hline 125465.500 & & rock & 0 & 0 & 0 & .722 & 1020201913 & & & & & \\
\hline 15642.270 & & rock & 0 & 0 & 0 & 163 & 1020201913 & & & & & \\
\hline 2619895.000 & Russel & accuaulation & 2896 & 2225 & 2561 & 2133 & 1020201913 & & & & & \\
\hline \multirow{24}{*}{3728685.000} & Cambor & |acousulation | & 3367 | & 2261 & 2009 & 2603 & 1020202913 & & & & & \\
\hline & & & & & \multicolumn{2}{|c|}{ Name } & Elev_ela & Area_accum & Area_total & Aar & Metakey & Wgms_num \\
\hline & & & & & \multicolumn{2}{|l|}{ Hi squa 11 . } & 2136 & 4435538 & $654753 ?$ & 0.68 & 1020271913 & 102027 \\
\hline & & & & & \multicolumn{2}{|l|}{ Tahoma } & 1997 & 6528066 & 8886034 & 0.73 & 1020291913 & 102029 \\
\hline & & \multirow{13}{*}{\multicolumn{3}{|c|}{ Glacier Morphology }} & \multirow{2}{*}{\multicolumn{2}{|c|}{ Coubon }} & 2251 & 3012065 & $\operatorname{1674326}$ & 0.46 & 2020201923 & 202020 \\
\hline & & & & & & & 1866 & 6711843 & 9856850 & 0.68 & 1020251913 & 102025 \\
\hline & & & & & \multicolumn{2}{|l|}{ Emmons } & 2011 & 8839700 & 12636208 & 0.70 & 1020221913 & 102022 \\
\hline & & & & & \multicolumn{2}{|l|}{ Nisqually } & 2071 & 4986548 & 6254827 & 0.79 & 1020271956 & 102027 \\
\hline & & & & & \multirow{2}{*}{\multicolumn{2}{|c|}{\begin{tabular}{|l} 
Nizqually \\
Nisqually \\
\end{tabular}}} & 2068 & 4950412 & 6269682 & 0.79 & 1020271966 & 102027 \\
\hline & & & & & & & 2067 & 4600088 & 5910402 & 0.78 & 1020271971 & 102027 \\
\hline & & & & & \multirow{2}{*}{\multicolumn{2}{|c|}{\begin{tabular}{|l} 
Tahoma \\
Carboa
\end{tabular}}} & 2962 & 6274758 & 7532431 & 0.83 & 1020291971 & 102029 \\
\hline & & & & & & & 2059 & 4444446 & 8013877 & 0.35 & 2020201971 & 102020 \\
\hline & & & & & \multicolumn{2}{|l|}{ Cow11tz } & 1922 & 6254240 & 9432665 & 0.84 & 1020251971 & 102025 \\
\hline & & & & & \multicolumn{2}{|l|}{ Emmons } & 1885 & 9332456 & 11372010 & 0.82 & 1020221971 & 102022 \\
\hline & & & & & \multicolumn{2}{|l|}{ Winthrof } & 2545 & 4474145 & 10037069 & 0.45 & 1020211913 & 102021 \\
\hline & & & & & \multirow{2}{*}{\multicolumn{2}{|c|}{\begin{tabular}{|l|} 
Winthrop \\
Hisqually
\end{tabular}}} & 2295 & 4790032 & $\begin{array}{l}8917661 \\
02059\end{array}$ & 0.54 & 1020211971 & 102021 \\
\hline & & & & & & & 2060 & 5015049 & 6359651 & 0.79 & 1020271976 & 102027 \\
\hline & Name & Country & \multicolumn{2}{|c|}{ State_prov } & \multicolumn{2}{|c|}{ Mt_range } & Mountain & \multicolumn{4}{|c|}{ Latitude Longitude Wgms_num } & \multirow{7}{*}{ Glacier Location } \\
\hline & Higquasly & United Stateg & Kashingt & & \multicolumn{2}{|l|}{ Cascades } & Mt. Rainier & 464700 & \begin{tabular}{l|l|}
0 & 1214500 \\
\end{tabular} & \multicolumn{2}{|r|}{102027} & \\
\hline & Tahoma & United States & Hashingt & & \multirow{2}{*}{\multicolumn{2}{|c|}{ Cascades }} & \begin{tabular}{|l} 
Me, Rainier \\
Het. Rinier
\end{tabular} & 465000 & $\begin{array}{ll}1214900 \\
\end{array}$ & \multirow{2}{*}{\multicolumn{2}{|c|}{102029}} & \\
\hline & Carbon & United Stateo & Washlagt & & & & Het. Salnites & 465400 & 10. 1224780 & & & \\
\hline & Cowlitz & United States & Washirget & & \multicolumn{2}{|l|}{ Cascades } & Mr. Rainier & 464700 & \begin{tabular}{l|l}
10 & 1214100 \\
\end{tabular} & \multicolumn{2}{|r|}{102025} & \\
\hline & Emmons & United States & Kashingt & & Coscades & & Mt. Rainier & 465200 & 201214400 & & 102022 & \\
\hline & Hinthrop & United States & Washingt & & Cascades & & Mt. Rainier & $4 \leqslant 5300$ & $\begin{array}{l}1214400 \\
\end{array}$ & & 102021 & \\
\hline
\end{tabular}

Eiqure 15. Table relations between feature-based and glacier-based, time-independent attribute tables. 
associated FAT, all attribute data can be linked to an associated spatial representation (Figure 16).

One unresolved issue is the automated access and retrieval of spatial data from the query of glacier-based attribute data. Tables can only be linked or joined when both tables are open and common fields selected. Since there are few glacier-based tables it is not a problem to have them constantly open and available for linking to feature-based tables. However, the relatively large number of feature-based attribute tables makes it impractical to keep all of them open in order to relate a selection in a glacier-based table to spatial data. To access spatial data from glacier-based queries, whether spatial or temporal, a folder name search must be conducted. This search may be automated within a customized GIS application. 


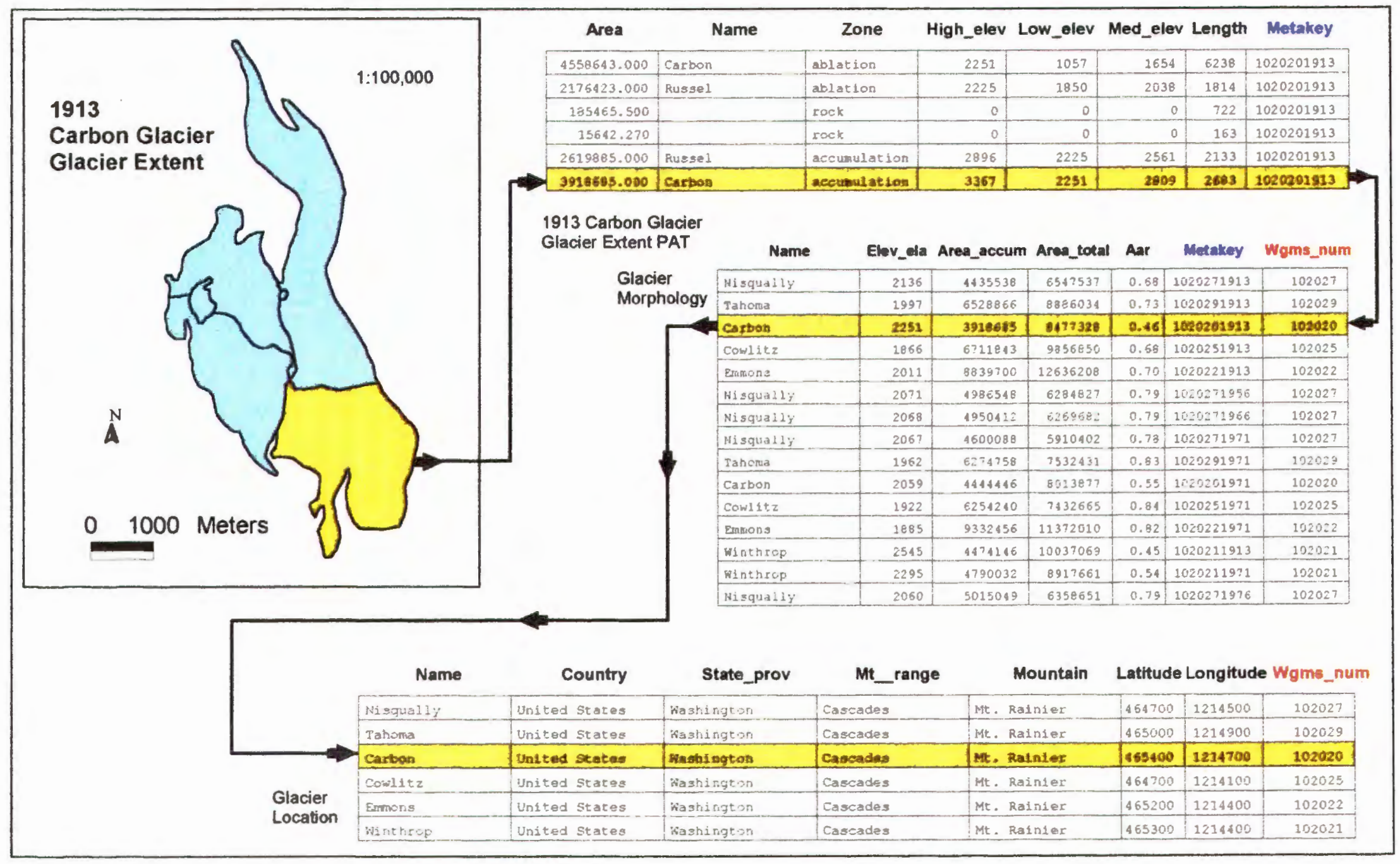

Eiqure 16 Relations between spatial data and glacier-based, time-independent attribute tables. 


\section{CHAPTER IV}

\section{METHODOLOGY FOR CONSTRUCTION OF THE DATABASE DATA ACQUISITION}

Spatial glacier data for the Database was acquired from the United States

Geological Survey (USGS), Water Resources Division, Cascade Volcano Observatory located in Vancouver, Washington. This data consisted of a series of paper and mylar topographic maps of various glaciers on Mount Rainier mainly spanning the years 1913 to 1971 . There was high variability in the data quality, scale, and temporal and spatial coverage of the data.

Many of the maps were of individual glaciers although some included the entire Mount Rainier National Park. Many of the maps of individual glaciers included only the lower half or three quarters of the glacier in an attempt to merely show the change in glacier terminus position from one year to another. Most of the maps were in good condition without significant tears or folds but a few had seen considerable wear. Data was generally available for only two or three times of record for each glacier and often this data was not spaced consistently throughout historic time but existed bunched together during certain time periods so that there were many longer time periods with scarce data available.

The maps came in various scales and units of measure. Scales ranged from maps of the entire Mount Rainier National Park at 1:62,500 to larger scale maps of 
individual glaciers at 1:12,000. While most often the maps contained benchmarks in latitude and longitude and contour intervals in feet, some maps contained benchmarks in Universal Transverse Mercator and units in meters. Also, the accuracy of the maps varied greatly due to the range of years of data and improvement in survey techniques throughout the period of historic time.

In addition to this diverse collection of glacier data, a map describing the subglacial topography for the largest glaciers on Mount Rainier was also acquired from the USGS. This $1: 12,000$ scale 200 foot contour interval map was created by Driedger and Kennard (1986) through the use of ice radar to measure the thickness of the glacier at certain points. The sub-glacial, or basal, contours were drawn on top of an enlarged USGS 1971 topographic quad map. While this type of information is not available for most glaciers in the world, it can be applied to the spatial modeling of glaciers on Mount Rainier for a variety of analytical and cartographic purposes.

It was decided that for the purpose of this study each of the five glaciers for which the basal topography was known, Nisqually, Carbon, Emmons, Winthrop, and Tahoma, would be incorporated into the Database. In addition, the one major glacier for which basal contour data did not exist, Cowlitz, would also be incorporated into the Database. Since good quality maps existed for the years 1913 and 1971 for all of these glaciers, these would be the times of record digitized for each glacier.

By far the most data was available for Nisqually glacier, which at one point was surveyed and mapped every five years from the 1930's through the 1970's. 
Because of this comparative plethora of data, it was decided that the Database would incorporate five different temporal representations for Nisqually glacier. The years of data entered into the Database for Nisqually glacier are 1913, 1956, 1966, 1971, and 1976.

\section{DATA INPUT}

Data was digitized into a common projection using common units of measurement to facilitate analysis and data sharing. Because the USGS and Mount Rainier National Park both store their GIS spatial data in Universal Transverse Mercator projection, all Database spatial data is stored in Universal Transverse Mercator coordinate system. Units are therefore in meters.

\section{Coverage Creation and Map Registration}

Each map contained a set of benchmarks, or registration tics, generally in latitude and longitude. A Database File (DBF) was created in Dbase (by Borland, Inc.) with one record describing the latitude and longitude of each of these tics, or as many tics as were deemed necessary for accurate registration. Using the Project and Generate commands in pcArc/Info, this file was converted into UTM coordinates and made into a new point coverage. The $A d d x y$ command added the coordinate data associated with each point to the PAT of the coverage. This PAT was then manipulated in the Tables module to identically resemble a tic file as it appears in a normal pcArc/Info coverage. The original tic file was then deleted and replaced by the one containing the registration locations. 
This coverage was then brought into pcArcedit where it was used to register the map from which the tic file was created. The registration process was repeated until the Root Mean Square (RMS) error was less than 0.002, although in some cases when the map was not in pristine condition the lowest RMS error possible was up to 0.005 .

In rare cases there were less than adequate registration marks on the part of the map targeted for digitization. To solve this problem other registration points were found on a related map that was previously digitized and the points' coordinate locations added to the tic file of the poorly registered map. These hand-picked registration marks were easily identifiable locations that would not change over the historic record, such as road intersections, trail intersections, named isolated rock outcrops, buildings, and bridges. These registration tics were later overlaid on a one meter resolution digital orthophoto of Mount Rainier National Park derived from 1994 aerial photos and found to be accurate within ten meters. While this technique was rarely employed for this project it may be useful when digitizing glaciers where such well documented and registered maps do not exist.

\section{Glacier Digitization}

The Glacier Extent coverage was the first to be digitized. On most maps the glacier boundary was well delineated, although on some maps there were areas in which the glacier and snow cover formed an ambiguous boundary that was digitally interpreted by the author. Criteria for delineation between glacier cover and snow 
cover was kept consistent through out the digitizing process, especially when comparing a glacier from one year to another in which the snow and glacier patterns had not significantly changed.

Another ambiguous glacier boundary appeared at the upper reaches of the glaciers near the summit cone. At approximately 12,000 feet most of the glaciers converge into one glacier mass and it is difficult to distinguish one glacier from another. When a map contained glacier delineations that extended to this altitude they were digitized as the Glacier Extent, but most maps did not. When they did not, the Glacier Extent boundary was based on the flow of the glacier and the inferred drainage basin morphology. If it appeared from the glacier contours, and/or the basal contours, that snow and glacial ice in an area in the upper reaches of the mountain would flow into a particular glacier valley, it fell within that glacier's Glacier Extent. While no two Glacier Extent coverages contain overlapping areas, most are adjacent to one another at higher elevations.

This technique was also used to delineate glaciers that were next to each other, and sometimes joined, but constituted distinctly different glacier flows. To avoid "slivers" from double digitization of adjacent glacier boundaries, especially at the highest reaches of the mountain, arcs that were shared by more than one glacier were incorporated into the adjacent glacier's Glacier Extent coverage during the initial digitization. In this way all Glacier Extents are perfectly nested. 
The ELA was digitized from the reference map based on the change in glacier contour line shape in relation to elevation (UNESCO/IASH 1970). The ELA was digitized so that it extended beyond the Glacier Extent boundary. The coverage was then Cleaned and brought back into pcArcedit so that the overshoots could be deleted. While pcArc/Info tolerances such as dangle length and snap could accomplish the same process, intentional overshoots, cleans, and deletes ensured perfect nesting given the uncertain accuracy of the digitization. To facilitate the reference of metadata to the origin of a particular Glacier Extent feature, nodes were inserted at the points at which an extent boundary changed from being derived from the map to being interpreted by the author. Each arc was therefore derived wholly from the source map or from author interpretation.

The Debris Extent coverage was created from a copy of the Glacier Extent coverage to facilitate registration. The extent of debris was not present on all maps, but if it was it was generally well marked. The Debris Extent was digitized directly onto a copy of the Glacier Extent with the Debris Extent boundaries overshooting the boundaries of the Glacier Extent if the debris extended to the edge of the glacier. This new coverage was then Cleaned and brought back into pcArcedit so that the overshoots and unneeded Glacier Extent arcs could be deleted, leaving a spatial representation of only the glacier debris.

The Original Contour coverage was created next by copying the Glacier Extent coverage and deleting all the arcs so that the Original Contour coverage could be 
registered from the same tic file. The contours were digitized at an interval at which the author could confidently distinguish individual contour intervals at the steepest terrain. This interval was often every four or five minor contour lines present on the map, or constituted only the mapped contour lines in bold. The elevation of the contour line was recorded in the user_id field for each digitized arc.

Contour lines were manually generalized as they were digitized to represent the trend of elevation across the glacier. Elevation variations due to small scale features such as crevasses were usually not digitized unless they described major elevation trends or breaks in slope. The digital contour line was always made to extend beyond the Glacier Extent boundary. The Original Contour coverage was then intersected with the Glacier Extent coverage so that the former is perfectly nested within the latter.

No ice dammed lakes were present on any of the maps digitized for this project; however if there were they would be digitized at this time in a manner similar to the previously mentioned coverages. They would be digitized directly onto a copy of the Glacier Extent coverage, Cleaned, and had the overshoots and extraneous Glacier Extent arcs deleted in pcArcedit.

All three coverages were finally Cleaned and/or Built to construct the appropriate topology and visually inspected separately and together in pcArcplot and pcArcedit. All coverages were edited to remove any dangling arcs and unnecessary nodes so that the minimum number of features described each coverage. Finally, files 
within line coverages that are found only in polygon coverages were deleted from the line coverage folders.

\section{DATA MANIPULATION}

At this point in the Database development each glacier was represented by three pcArc/Info vector coverages: Glacier Extent, Debris Extent and Original Contour. These coverages did not contain any attribute fields aside from the default fields created by pcArc/Info during generation of the coverage. All other spatial glacier representations, both vector and raster, are derived from data manipulation involving the Glacier Extent and Original Contour coverages.

These three coverages were then exported as Arc/Info export files, transferred onto a UNIX Sun sparcstation 5, formatted for use within a UNIX platform, and imported into workstation Arc/Info. Minor attribute table operations and creation of the Glacier Surface grid was performed in this computing environment. While many of these operations could also be performed using Arcview 3.0, the complex processing required to generate surfaces was faster on the UNIX platform than the available DOS Arcview 3.0 platform.

In addition, performing the data manipulation in Arc/Info provided the opportunity to standardize all vector data into Arc/Info coverage format. While Arcview 3.0 can read both pcArc/Info and Arc/Info vector coverages, it only has the ability to create shapefiles. If the coverages were imported directly into Arcview 3.0, the Database would be composed of up to three types of vector data: pcArc/Info 
coverages, Arc/Info coverages, and Arcview 3.0 shapefiles. While this may be transparent to the casual user, it creates unnecessary complexity and may lead to problems when converting the Database for use on platforms other than Windows 95 or Windows NT.

Further, because shapefiles are based on the vector polygon list data structure, as opposed to the vector topologic data structure implemented in Arc/Info, complex overlay operations would be restricted. Because of these considerations, it was decided that all vector data would be standardized in Arc/Info coverage format. Since Arc/Info and Arcview 3.0 treat raster grid data in exactly the same way, further generation and manipulation of this type of data was not restricted to either application.

\section{The Special Case of Appended Contour Coverages}

In certain cases where the source map only described the lower half or three quarters of a glacier, the Glacier Extent coverage and the Original Contour coverage do not contain enough data to produce a surface of the entire glacier. This issue of incomplete data presents problems when analyzing glacier area and volume change over time. There must be uniform spatial and temporal coverage to produce accurate results.

Because of the dynamics of glacier mass balance flux, most glacier volume and area change takes place at the lower elevations. To integrate the temporal occurrences of incomplete spatial data into the analysis of glacier change, it was assumed that 
throughout historic time the upper reaches of the glaciers on Mount Rainier had undergone no significant change. Therefore, the Glacier Extent and Original Contour coverages for a glacier with missing data at the upper reaches could be improved by adding that missing spatial information from another temporal representation of that same glacier.

Only two temporal glacier representations were missing data in their upper elevations, Nisqually 1956 and Nisqually 1966. The appropriate Glacier Extent and Original Contour coverage data from the upper reaches of Nisqually 1976 were reselected and appended to these two coverages to ensure standardized and complete spatial coverage. Since the contour interval and units of measurement differed between the 1976 data and the 1956 and 1966 data, the Appended Contour coverage is misleading when visually interpreted. However, all elevation data is converted and standardized in meters for the purpose of data manipulation.

\section{Creation of the Elevation Points Coverage}

Once the Glacier Extent, Original Contour, and Glacier Debris coverages were imported into Arc/Info, the Original Contour and Glacier Extent coverages were used to create the Glacier Surface coverage. This process involved three steps: 1) the creation of the Elevation Point coverage from the Original Contour coverage, 2) the interpolation of a gridded surface from the Elevation Point coverage, and 3) the masking of the gridded surface coverage with the gridded Glacier Extent coverage. 
To derive the Elevation Points coverage it was first necessary to standardize units of measurement for all glaciers. Because of the diverse nature of the data, however, coverages varied in units of elevation; most maps stored elevation data in feet while some used meters. To address this issue, two fields were added to each Original Contour coverage, elevft and elevm. If the elevation was in feet, each record's elevft value was set equal to its $u s e r \_i d$ which was then converted to meters in the field elevm. If the elevation data was originally in meters then the operation was performed vice-versa. The result was that all Original Contour coverages contained explicit elevation data in meters, even if the meter-based contour interval was at an odd number and awkward to visually interpret.

The Elevation Points coverage was derived using the Arcpoint command in Arc/Info to generate a point coverage from the vertices and nodes of the Original Contour coverage. By choosing elevm as the selected field for this operation, the new coverage's attribute table contained only the field elevm in addition to the default Arc/Info point coverage fields. In this way a point coverage representing sample elevation points in meters was created.

Because of the extreme irregularity in the distribution of sample elevation points across the glacier, it was decided that not every vertex in the Original Contour coverage should became a point in the Elevation Point coverage. To solve the distribution problem, the weed tolerance parameter allowed in the Arcpoint command was used to acquire the most regularly spaced distribution of points. This parameter 
sets the minimum distance between vertices that become points in the newly created point coverage. If two vertices fall within the distance set in the weed tolerance, the second vertex found during the algorithm vertex search will not be included in the new point coverage.

Because of the diverse nature of the maps and Original Contour coverages, there is not one weed tolerance setting that is appropriate for all gridded surface generations, but a methodology for choosing a weed tolerance based on the character of each individual Original Contour coverage. This methodology consists of setting the weed tolerance to half the minimum planimetric distance between contour intervals in the Original Contour coverage. This distance was derived through visual interpretation and the distance measuring tool found in Arcview 3.0.

During the local interpolation process, a cell's surface value is determined by that of its nearest neighbors. Ideally, a cell halfway between two contour intervals should draw its value equally from points along the two nearest contours and less so from farther contours. If the weed tolerance is set to more than the distance between that cell and the two contour lines, the weeding search algorithm may eliminate certain vertices so that the surface value for that cell is derived from distant contour lines as much as from contour lines immediately proximal.

In short, if the weed tolerance is set to more than half the planimetric distance between contour lines, vertices that are necessary to calculate the accurate surface value of certain grid cells will be eliminated. This still does not result in a regular 
distribution of points because of the slope change throughout the glacier and the irregular distribution of the contour lines themselves. While the ultimate solution to this problem is beyond the scope of this paper, suffice to say that the weed tolerance setting produced an Elevation Points coverage with less total sample elevation points but a slightly higher degree of accuracy in the resultant surface interpolation.

\section{Creation of the Glacier Surface Grid: A Trial of Interpolation Techniques}

Once the Point Elevation coverage was created, the Spline command in the Arc/Info GRID module was used to create a gridded surface. The parameters entered for this operation were the following: a grid cell size of 20; a spline based on either the 10 or 30 nearest sample points (depending on resolution of the Elevation Points coverage); a regularized spline (as opposed to tension); and a weight of 0.0 . The extent of the grid was set to coordinates approximately 500 meters beyond that of the Glacier Extent coverage so that the surface would extend beyond the boundary of the Point Elevation coverage.

The decision to use the spline interpolation method and the specific parameters used was made through a brief review and trial of the four surface generation functions offered in Arc/Info: trend, spline, kriging, and IDW. While this trial is not intended to be an intensive survey of the general accuracy of these interpolation algorithms, it serves to clarify the differences in interpolated surfaces and shed some light on the best methods for interpolation of glacier surfaces. While parameters for each method 
differ somewhat, the parameters set for each interpolation method reflect the greatest degree of standardization possible so a fair comparison between them can be made.

The 1913 Carbon glacier Point Elevation coverage, converted to units in feet, served as the trial data. Each interpolation method produced a gridded surface and then a contour line coverage based on this data. The contour interval of the newly generated contour line coverage was identical to that of the 1913 Carbon glacier Original Contour coverage, 500 feet, so that a comparison could be made between the two. These two contour coverages were overlaid in Arcview 3.0 and visually inspected for general accuracy and patterns of distortion. Reference to the original source map provided further validation of the accuracy of the entire process of digital surface generation.

The inspections revealed that while none of the interpolators produced a contour line coverage identical to the Original Contour coverage, there were marked differences in quality between the four methods. The major differences between the methods were most apparent in the lower elevations of the glacier where the terrain becomes flatter and the sample elevation points are scarce. Breaks in slope between the upper and lower portions of the glacier also caused inaccuracies in all four methods, which tended to overshoot or undershoot the true surface to derive nonexistent hills and depressions.

The only user controlled parameter allowed for the trend interpolator is order. Order was set to 3,6, and 9 and all three interpolations resulted in an RMS error of 
between 133 and 136. These relatively high RMS values indicate that the global nature of trend interpolation greatly compromises the complexity of the glacier surface. The interpolation with an order of 6 was used for the visual inspection. The nature of this interpolation method captures the pattern and aspect of the glacier surface (Figure 17) but to such a degree of generality and smoothing that the generated surface is practically useless for analysis. This interpolation method is not recommended for elevation surface generation.

Parameter settings for the IDW interpolator were as follows: a sample (as opposed to radius) point search, 10 sample points per search, and a power of 0.1 . This interpolation produced a more detailed, but only slightly more accurate, contour line map than the trend interpolation technique (Figure 17). Contour lines were bunched together in a step like pattern, becoming especially severe in the lower glacier elevations. The IDW contour lines and the Original Contour coverage contour lines did not overlay each other except at the highest elevations.

The parameter settings for kriging are more complex and varied than those of the other interpolation methods. The following settings were used for this interpolation: ordinary kriging using a spherical mathematical function, a sample (as opposed to radius) point search, 10 sample points per search, and a maximum search radius of 1000 meters. Kriging produced a contour line coverage of significantly higher accuracy than either the IDW or trend interpolators but one whose accuracy varies over the surface of the glacier (Figure 18). Kriging contours overlaid those of 


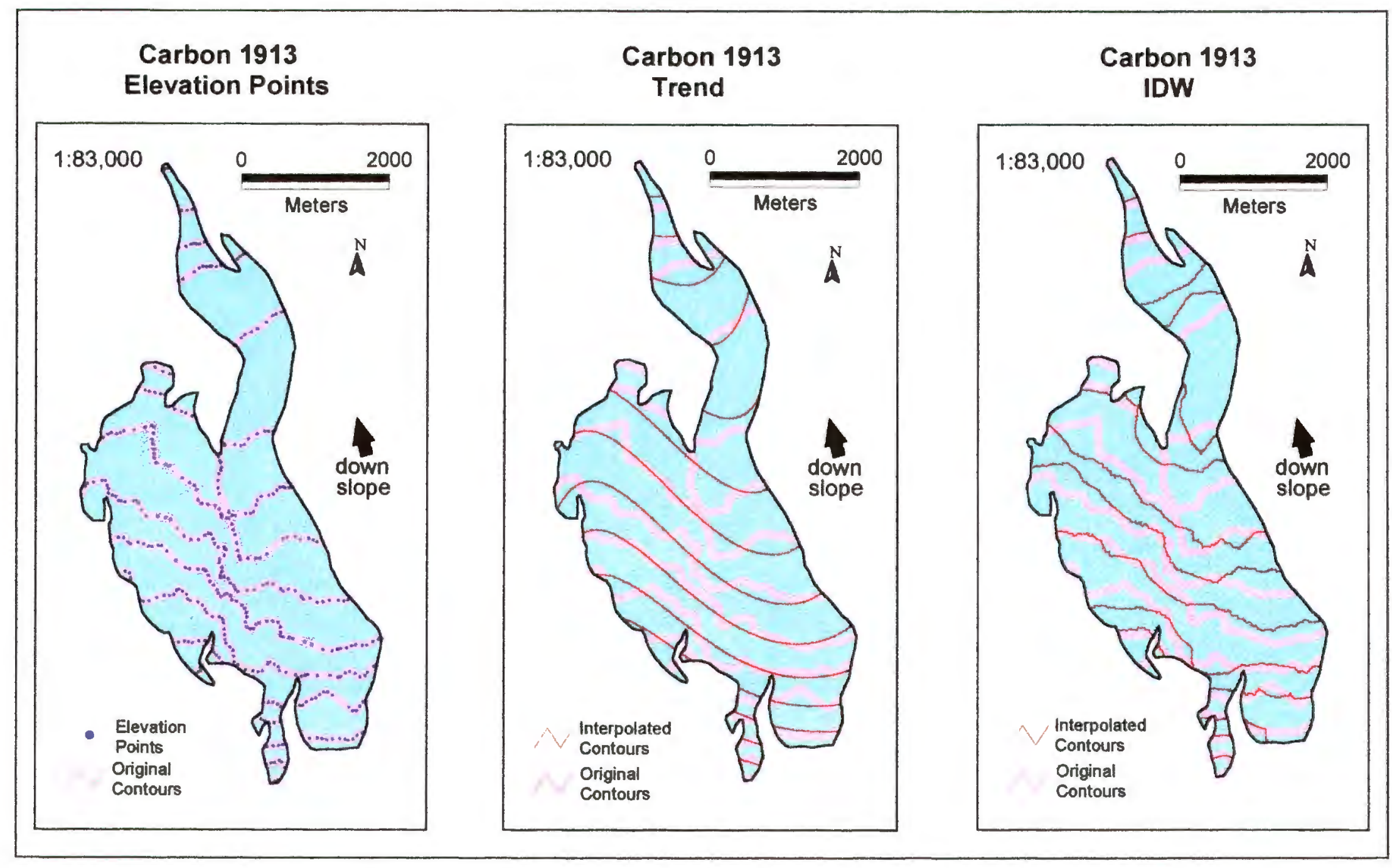

Eiqure 17. Interpolation method trial: trend and IDW. 


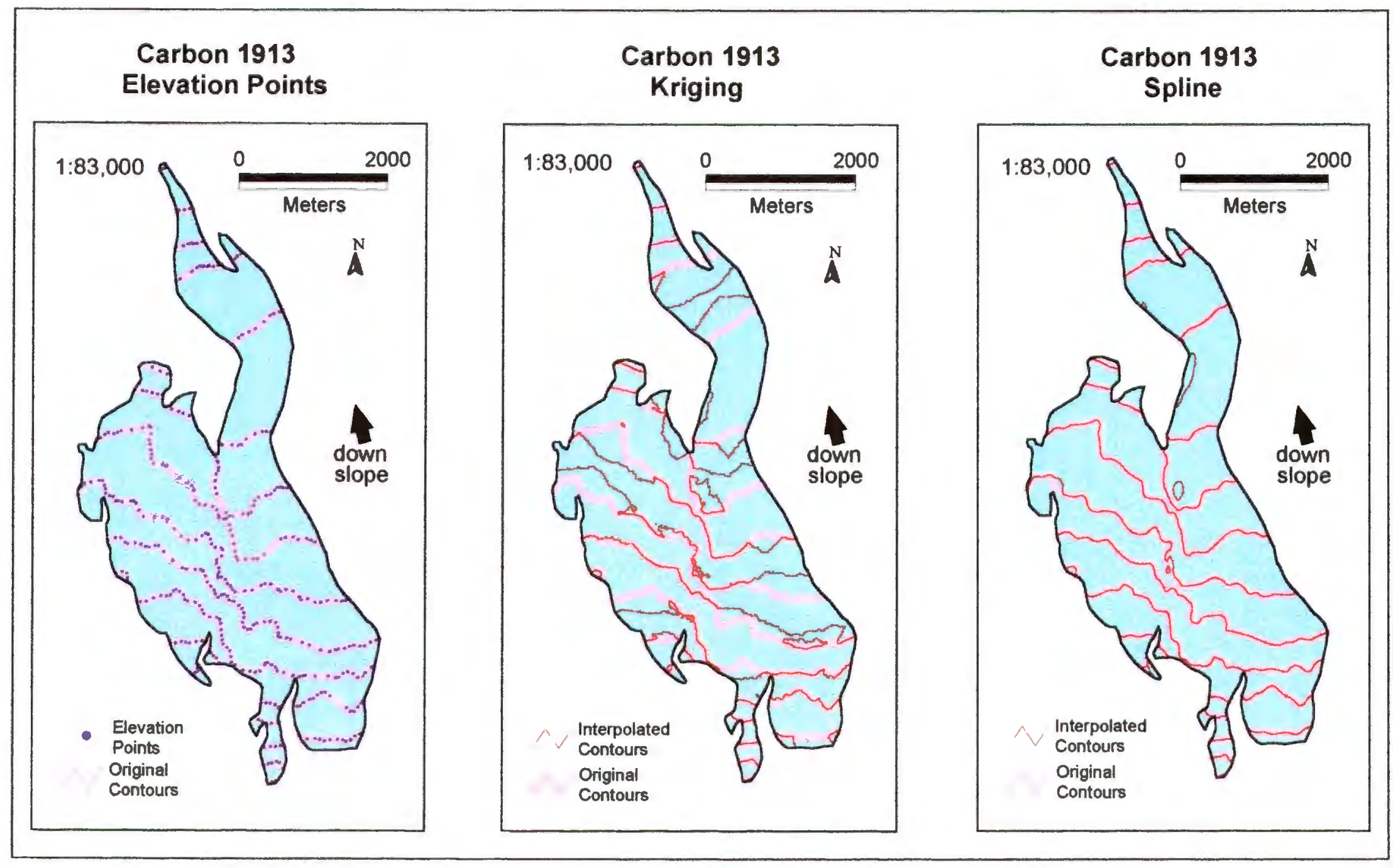

Eigure 18 Interpolation method trial: kriging and spline. 
the Original Contour coverage at the upper and lower elevations, but contours at the middle elevations contained significant error.

Spline parameters were set as follows: regularized (as opposed to tension), a weight of 0.01 , a grid cell size of 20 , and 10 points per search.. The spline interpolator clearly produced the most accurate contour line derivation (Figure 18). Because the spline creates a surface that passes through all the data points, the spline contours overlaid the Original Contour lines nearly perfectly. Since the spline also seeks to minimize the curvature of the surface, breaks in slope caused some inaccuracy. The spline tended to overshoot the breaks in slope, creating hills in the flatter areas at lower elevations. However, the gridded surface at lower elevations was still just as accurate as with kriging and significantly more so than with IDW or trend.

Once splining was chosen as the interpolation method, a trial of the various parameter values for splining was undertaken to derive the most accurate Glacier Surface grid. The user sets the following parameters for each spline interpolation: weight, number of points, and type. The weight setting controls the rate of change of slope, functionally the degree of minimization of curvature of the surface. The number of points is the number of nearest sample points used in the spline for each grid cell, and the type is either regularized or tension. Tension produces a "taut" surface with more severe breaks in slope while regularized produces a smoother surface. 
This trial was not meant to be a comprehensive survey of spline interpolation parameters but a brief test to determine the best method for deriving glacier surfaces. An attempt was made to toggle each parameter while holding the other parameters constant so that a comparison could be made between the surface derivations produced only by the differences in each parameter. However, because the derivations are affected not only by each individual parameter but also by the combination of parameter settings, there is no "control" group with which to make a standardized comparison. Allowing for the multivariate nature of this experiment, noticeable differences in surface derivation still prove useful in determining the most accurate parameter settings.

Spline weights were set at $0.0,0.01$, and 0.1 . Changes in weights produced insignificant changes at the middle and higher elevations but noticeable alterations took place at the lower reaches of the glacier (Figure 19). While there is severe distortion noticeable in the lower glacier elevations for all weights at this stage of the trial, weights of 0.01 and 0.1 produce a steeper hill just south of the difluence of the two glacial lobes.

The tension spline setting produced a surface more inaccurate than any of the other parameter settings (Figure 20). The tension derived surface contained various nonexistent hills and valleys throughout the entire glacier surface. While a grid cell size of 10 , as opposed to 20 , may be of higher resolution, it produced a less accurate contour line coverage (Figure 20). The grid cell size 10 contours exaggerated the 


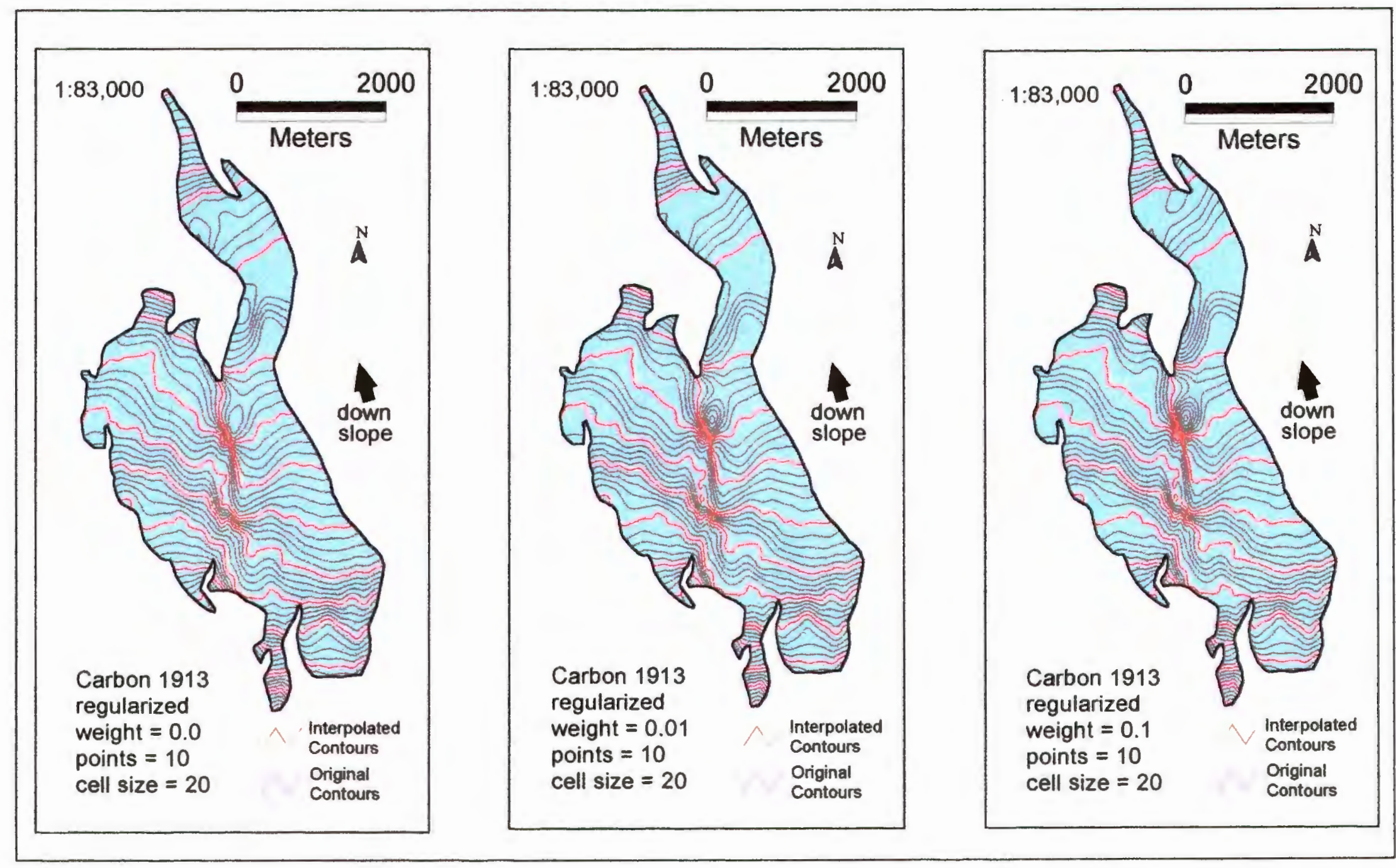

Eiqure 19 . Spline interpolation parameter trial: weighting. 


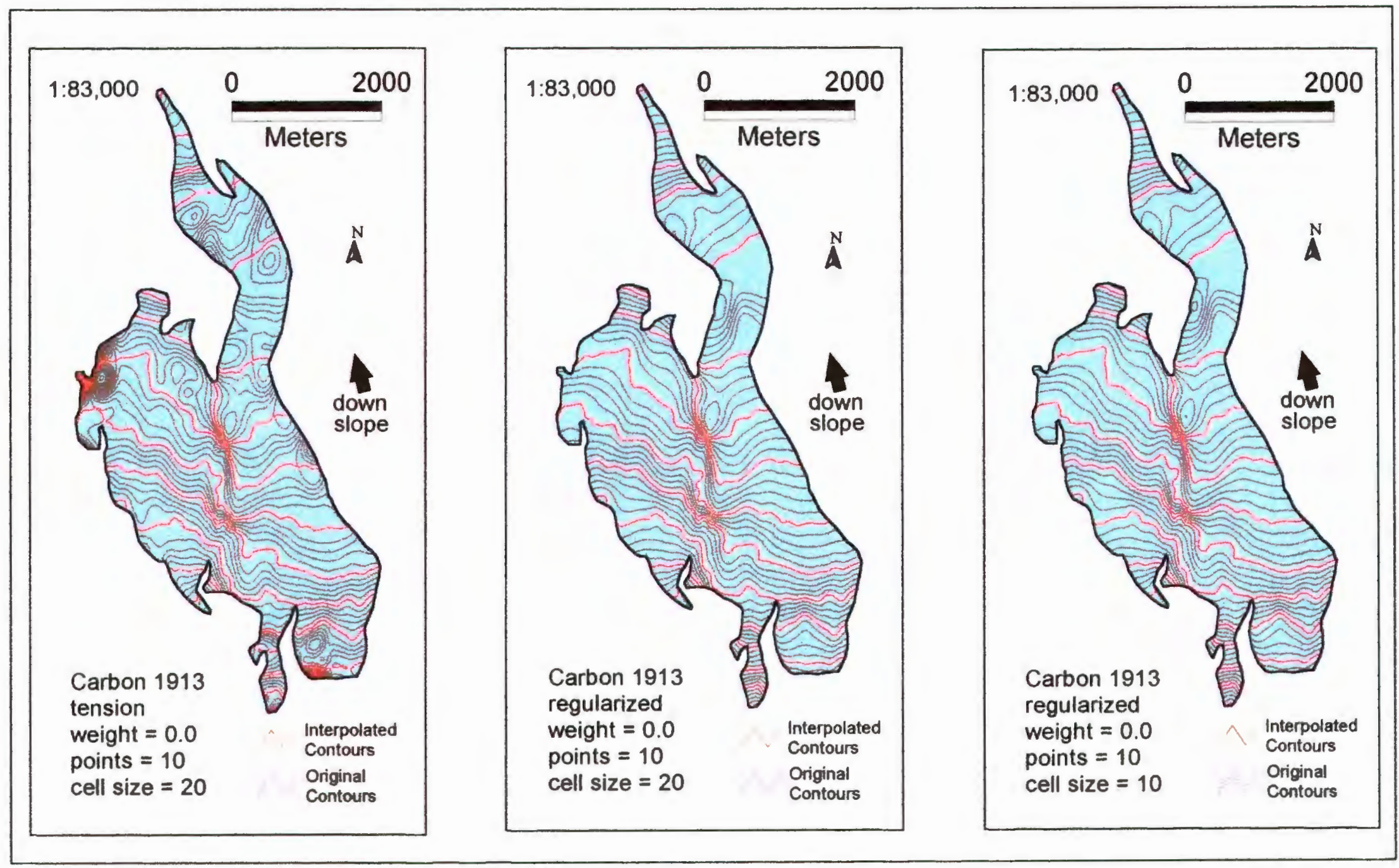

Eigure 20. Spline interpolation parameter trial: regularized versus tension and grid cell size. 
nonexistent hills at the flatter glacier sections more than the grid cell size 20 interpolation did.

The number of sample points proved to be a significant parameter in controlling the derivation of nonexistent hills and valleys in the flatter sections of the glacier (Figure 21). While all surface derivations produced some distortion in the flatter sections, the 30 and 50 sample point derivations produced significantly less distortion than the 10 sample point interpolation. When this test was applied to the 1971 Carbon glacier Point Elevation coverage, however, a different picture emerged. This time, the 30 point and 10 point interpolations both produced accurate contours at the lower elevations, but at the upper elevations the higher sample point interpolations proved less accurate than the 10 point search. In a coverage such as the 1913 Carbon glacier Elevation Points, in which there is scarce data at lower elevations, a high number of search points provides the smoothing necessary for more accurate surface modeling. If a smaller number of points is used for the interpolation, such as 10 , the spline is distorted by local trends in the data which produce exaggerated hills and valleys, when in reality the terrain is gently sloping. At higher elevations where the terrain is much steeper and the sample elevation points much denser, the smoothing associated with a high number of sample points results in greater inaccuracy. In this case, 10 sample points are sufficient to derive an accurate surface elevation value; a higher number of points in the search distorts the local surface trend with the global surface trend. 


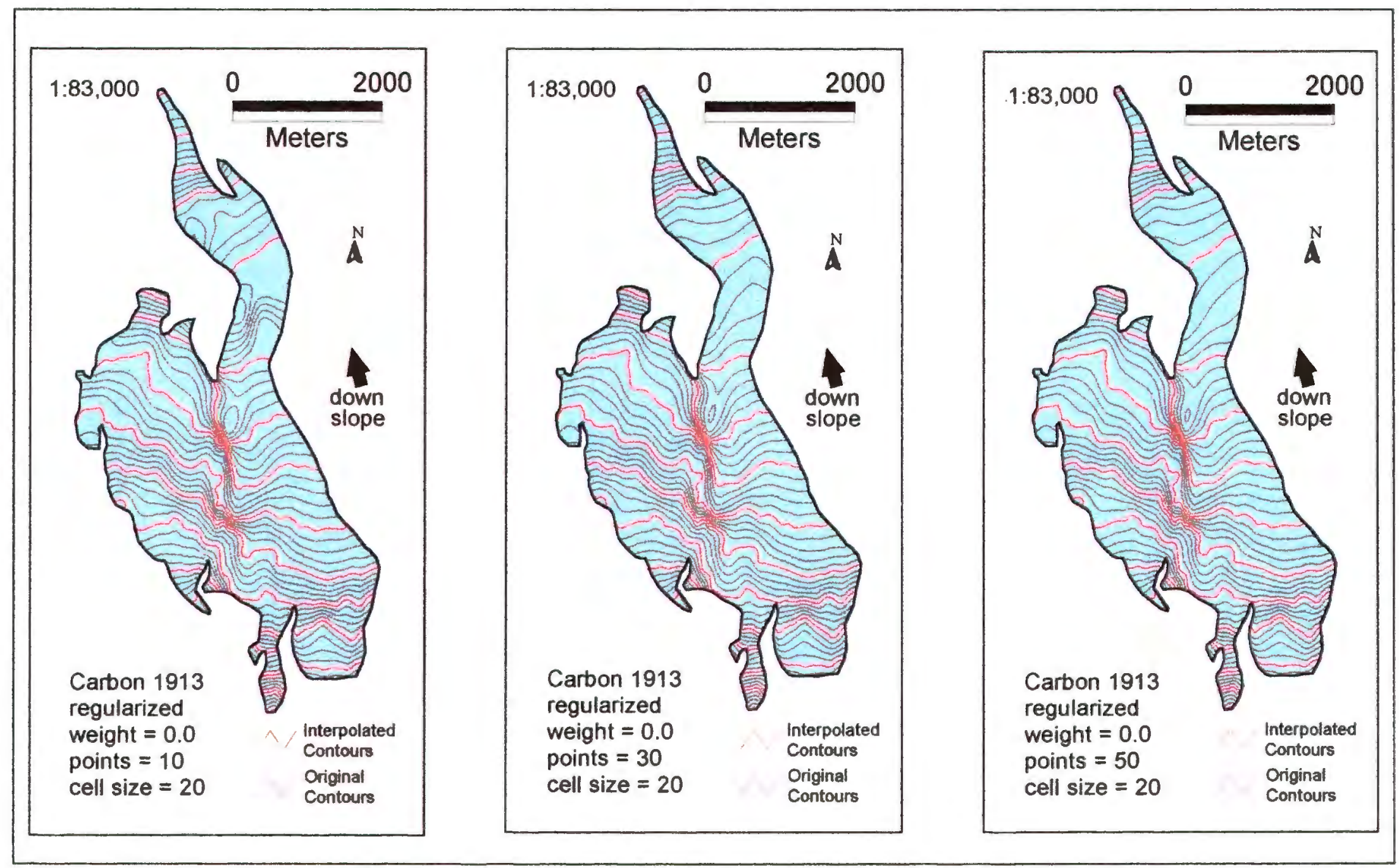

Eiqure 21. Spline interpolation parameter trial: number of search points. 
Ideally, different spline parameters should be applied to the spline interpolation algorithm at different parts of the glacier depending on the density of Elevation Point data. The complexity of this type of operation makes it impractical, however. Instead, the Database implements either a 10 or 30 point search based on the density of the Elevation Point coverage. The improvement in accuracy with a 50 point search, as compared to the 30 point search, was deemed insignificant in relation to the additional processing time required for the interpolation. Generally, the 1913 glaciers' Glacier Surface grids were generated with a 30 point search and the rest with a 10 point search.

Another comparison was made with different weights implemented and the number of sample points held constant at 30 . In this test, a weight of 0.0 conclusively proved to be more accurate than the others (Figure 22). Therefore, all Glacier Surfaces were derived with a regularized spline with a weight of 0.0 and a point search of either 10 or 30 .

Once the interpolation method was decided upon, gridded glacier surfaces were derived. However, this gridded glacier surface extended throughout the entire raster grid and did not describe the glacier extent. The final step to create the Glacier Surface grid was to mask the area outside the Glacier Extent boundary so that the grid surface only described the surface of the glacier. This was done by converting the Glacier Extent coverage into a grid and using the Selectmask command in Arc/Info 


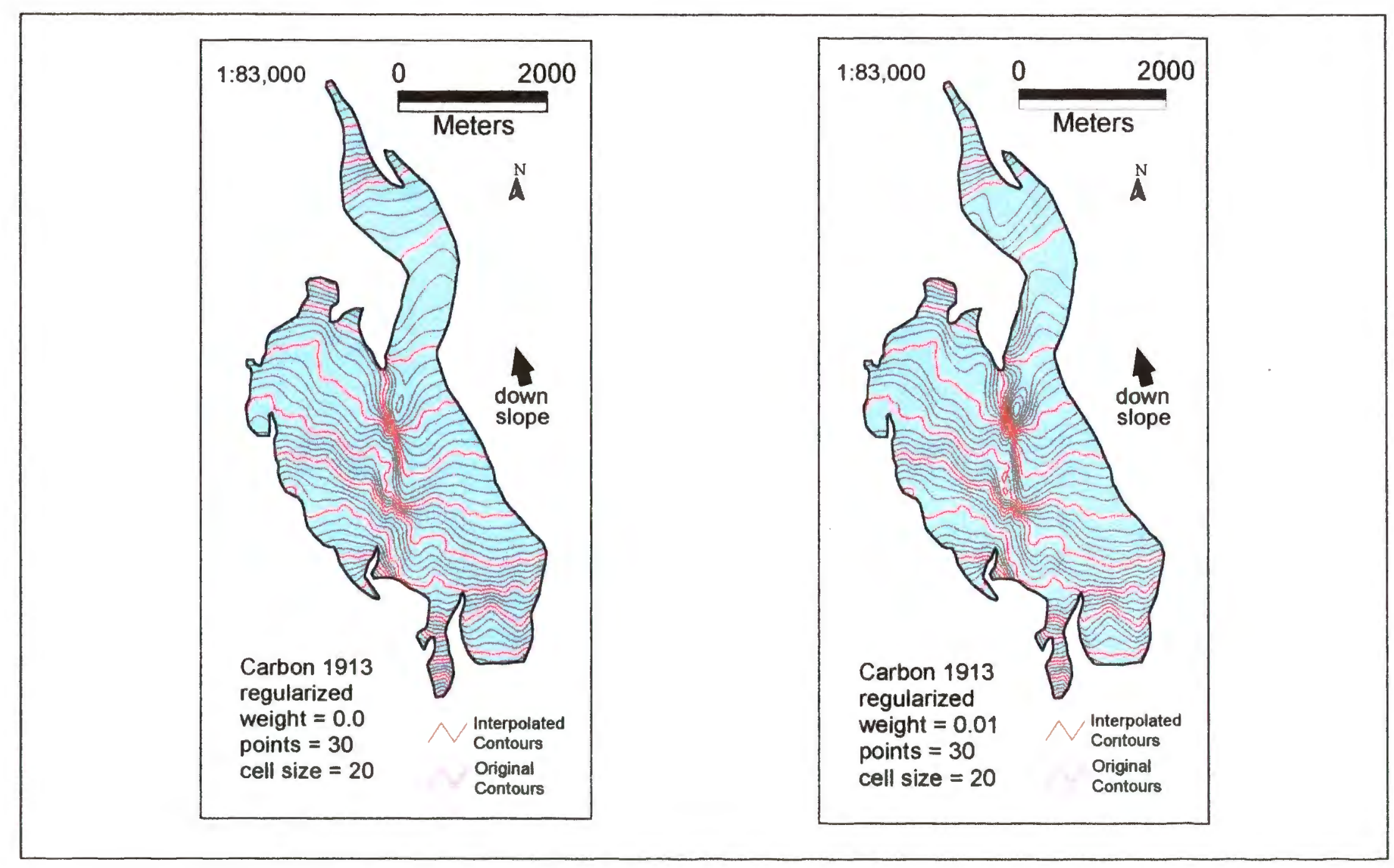

Eigure 22 Spline interpolation parameter trial: weighting with 30 search points. 
GRID module to set the gridded universal polygon to "No Data" in the resulting Glacier Surface grid.

Spatial Representations Derived from the Glacier Surface Grid

Once the Glacier Surface grid was created it was imported into Arcview 3.0 for further data manipulation. Through Arcview 3.0's automated Surface Functions the following grids were created: Glacier Aspect, Glacier Slope, and Glacier Hillshade. Each of these was created with a 20 meter grid cell size to be compatible with the Glacier Surface grid. The Interpolated Contour coverage was also automatically derived from the Glacier Surface grid and later converted into coverage format in Arc/Info. All coverages were visually inspected separately and together to ensure logical consistency among temporal and spatially grouped data sets.

\section{ATTRIBUTE TABLE CONSTRUCTION}

The appropriate fields and their values were entered into the feature-based attribute tables for each coverage in the Tables module of Arcview 3.0. Fields that described glacier morphology that were not contained explicitly in the coverage, such as Low_elev in the Glacier Extent coverage, demanded minor analysis involving the overlay of the Glacier Surface grid with the Glacier Extent coverage. The glacierbased attribute tables were created in Dbase and attributed appropriately. These tables were then converted into INFO format in Arcview 3.0 to be standardized with the rest of the Database. 


\section{CHAPTER V}

\section{ANALYSIS OF GLACIER AREA AND VOLUME CHANGE OBJECTIVE AND METHODOLOGY}

The purpose of this exercise is to demonstrate a set of GIS techniques that can be used in tandem with the Database to facilitate glaciologic analysis. The measurement of glacier volume and area, and the temporal changes to each, represents one such analytical application. Glacier area and volume were found for all glaciers in the Database for the years 1913 and 1971. In addition, area and volume were found for Nisqually Glacier for the years 1956,1966 , and 1976. Changes in area and volume between times of record were calculated.

The area of each glacier was found by summing the areas of the zones of ablation and accumulation polygons within each Glacier Extent coverage. To find the volume of each glacier, the basal topography surface grid was subtracted from each Glacier Surface grid for each time of record. This results in a grid that represents the thickness of the glacier, a glacier isopach map, in which each cell represents a three dimensional "voxel." The volume of each voxel is defined by the multiplication of its length, depth, and height. Because each record in the grid attribute table represents one class of grid cell values, the volume of each cell value class can be found by multiplying a record's glacier depth value by the grid cell area (400 square meters) and then by the number of cell occurrences of that depth value. If a cell contained a 
negative depth value due to map source or analytical error, it was given a volume of zero. The results were then summed to find the total glacier volume. Temporal changes to glacier area and volume were found by subtracting the earlier glacier area and volume figures from the later.

The area and volume results are compared to those found by Driedger and Kennard (1986) in their study of 1971 area and volume estimation for Cascade Range glaciers. Their methodology consisted of modeling the glacier as a series of contour interval "steps" in which each step volume was calculated and summed to find the total glacier volume. The basal topography data produced in their report was used for this project, so with the exception of the 1913 data and 1956, 1966, and 1976 Nisqually data, the source of glacier data is consistent between the 1986 report and this one.

\section{RESULTS AND DISCUSSION}

Glacier area and volume, and changes to each, are presented in Table 1 alongside the results of Driedger and Kennard (1986). The project's 1971 area and volume results are consistent with those reported by Driedger and Kennard (1986). Significant differences between the two studies, such as with Tahoma glacier, are proportional to each other in glacier volume and area, indicating that the differences in results stem mainly from interpretation of glacier boundary rather than analytical technique. 
TABLE I

AREA AND VOLUME OF MOUNT RAINIER GLACIERS, 1913 -1971

Area and volume is measured in square and cubic meters, respectively.

D \& K stands for Driedger and Kennard (1986).

\begin{tabular}{|c|c|c|c|c|c|c|c|}
\hline Glacier & Year & Area & Area Change & Volume & Volume Change & D \& K's Area & D\& K's Volume \\
\hline \multirow[t]{2}{*}{ Carbon } & 1913 & $13,273,636$ & & $959,220,800$ & & & \\
\hline & 1971 & $11,015,441$ & $-2,258,195$ & $811,320,800$ & $-147,900,000$ & $11,213,396$ & $798,535,073$ \\
\hline & & & & & & & \\
\hline \multirow[t]{2}{*}{ Emmons } & 1913 & $12,636,208$ & & $856,527,200$ & & & \\
\hline & 1971 & $11,372,010$ & $-1,264,198$ & $625,973,200$ & $-230,554,000$ & $11,166,945$ & $673,940,948$ \\
\hline & & & & & & & \\
\hline \multirow[t]{5}{*}{ Nisqually } & 1913 & $6,547,537$ & & $156,137,600$ & & & \\
\hline & 1956 & $6,284,827$ & $-262,710$ & $247,494,800$ & $91,357,200$ & & \\
\hline & 1966 & $6,269,682$ & $-15,145$ & $254,779,600$ & $7,284,800$ & & \\
\hline & 1971 & $5,910,402$ & $-359,280$ & $249,818,000$ & $-4,961,600$ & $6,057,278$ & $274,673,411$ \\
\hline & 1976 & $6,358,651$ & 448,249 & $274,408,000$ & $24,590,000$ & & \\
\hline \multirow[t]{2}{*}{ Total } & & & $-188,886$ & & $118,270,400$ & & \\
\hline & & & & & & & \\
\hline \multirow[t]{2}{*}{ Tahoma } & 1913 & $8,886,034$ & & $518,169,600$ & & & \\
\hline & 1971 & $7,532,431$ & $-1,353,603$ & $407,024,400$ & $-111,145,200$ & $5,648,504$ & $334,138,789$ \\
\hline & & & & & & & \\
\hline \multirow[t]{2}{*}{ Winthrop } & 1913 & $10,037,069$ & & $645,063,600$ & & & \\
\hline & 1971 & $8,917,661$ & $-1,119,408$ & $517,321,600$ & $-127,742,000$ & $9,113,788$ & $523,861,661$ \\
\hline & & & & & & & \\
\hline \multirow[t]{2}{*}{ Total } & 1913 & $51,380,484$ & & $3,135,118,800$ & & & \\
\hline & 1971 & $44,747,945$ & $-6,632,539$ & $2,611,458,000$ & $-523,660,800$ & $43,199,913$ & $2,605,149,886$ \\
\hline
\end{tabular}


Glacier area, and area change, for the years 1913 and 1971 are graphically presented in Figure 23. In 1913 Carbon Glacier (including Russell Glacier) contained the greatest areal extent $(13,273,636$ square meters); however, after mountain-wide glacier area loss, by 1971 Emmons Glacier surpassed it with an area of $11,372,010$ square meters. Cowlitz Glacier lost the most area of all glaciers during this period, $2,424,185$ square meters. It appears that those glaciers trending towards the south and southwest showed greater retreat, and lost a greater percentage of their total area, than those facing north. Area loss to the north facing Winthrop and Carbon glaciers is due more to shrinkage on the glacier sides rather than at the terminus. Given the degree of positional error in the Glacier Extent coverages and the subjective nature of differentiating the glacier from surficial snow, it is probable that area loss on the glacier sides to the north facing glaciers is significantly over-represented.

Nisqually Glacier lost 188,886 square meters in area between 1913 and 1976 (Figure 24). Most area loss occurred between 1913 and 1956 and can be attributed to retreat of the glacier terminus. Calculated area loss between 1956 and 1976 appears to be mainly due to interpretation of the glacier boundary, although some terminus retreat did take place. This is especially evident in the magnitude of area change between 1966, 1971, and 1976. Area change within these years is exaggerated because of the exclusion of the southwest corner of Wilson Glacier and the thinner glacier extent in the upper elevations in the 1971 representation. The 1976 Nisqually Glacier Extent 


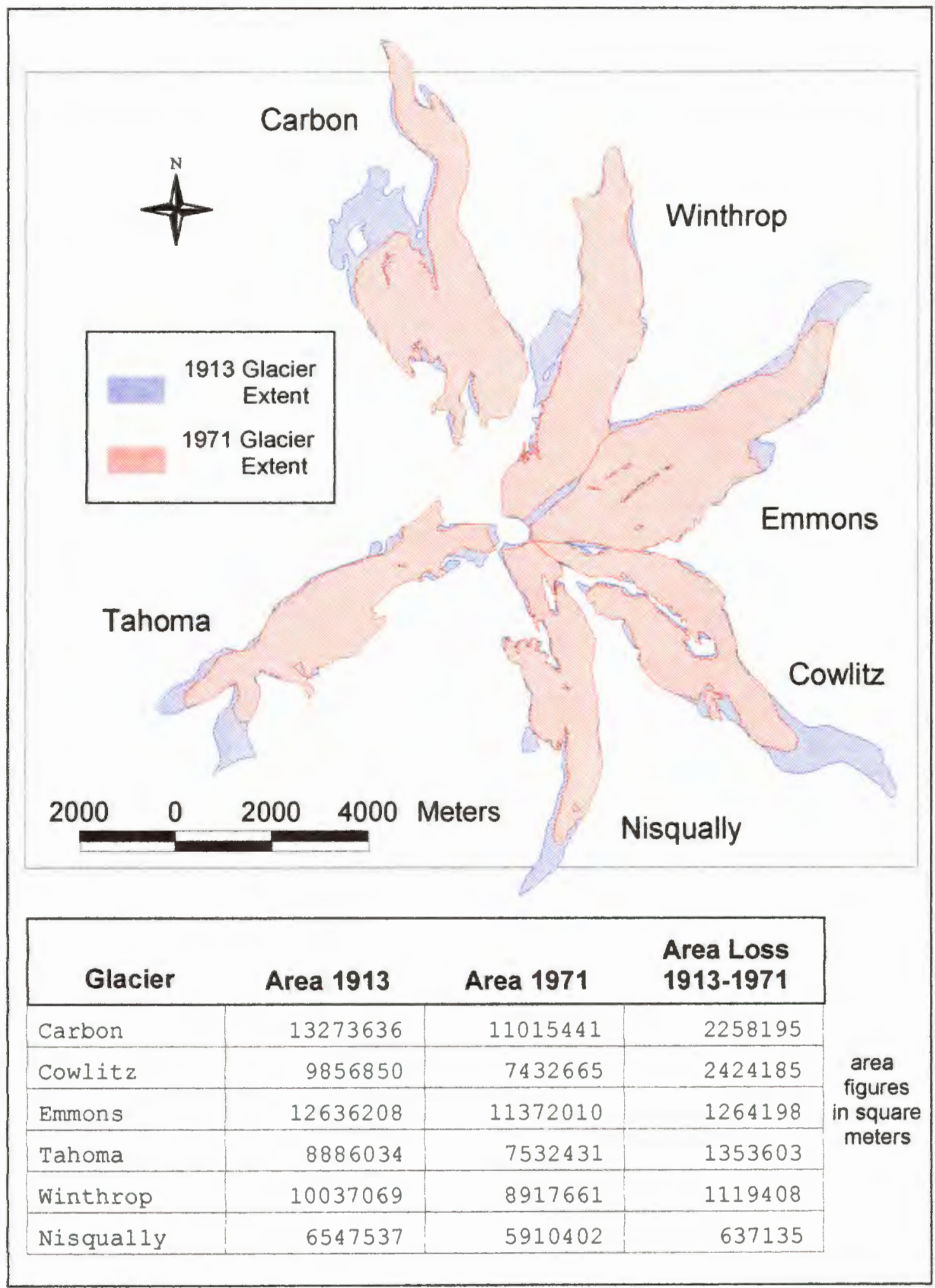

Eiqure 23. Change in planimetric area of five glaciers on Mount Rainier, 1913 - 1971. 


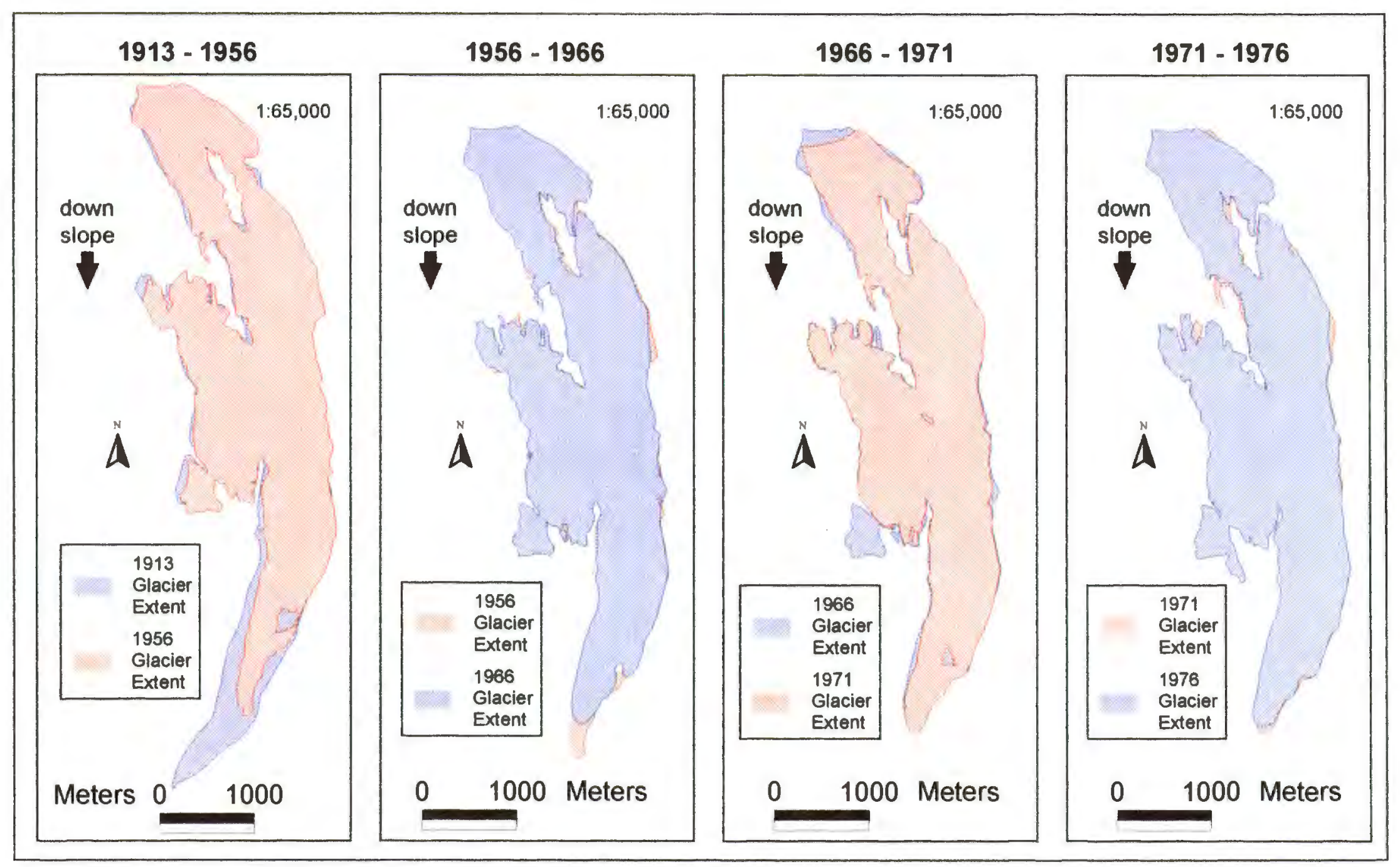

Eigure 24. Change in planimetric area of Nisqually Glacier, 1913 - 1976. 
coverage returns to the 1966 interpretation of these areas and corrects the discrepancy in area.

Glacier volume and volume change for the years 1913 and 1971 are presented in Figures 25 - 30. Carbon Glacier (including Russell Glacier) remained the most voluminous throughout the years of record with a 1971 volume of $811,320,800$ cubic meters (Figure 25). It appears that Russell Glacier contributes a small amount of glacier volume proportional to its area contribution, the main channel of Carbon Glacier being much deeper than the thin, sheet-like morphology of Russell Glacier. All glaciers lost volume during the period $1913-1971$ with the exception of Nisqually Glacier (Figure 27); however, the 1913 Nisqually Glacier results are particularly prone to the error introduced by cells of negative glacier depth and are therefore judged to be unreliable.

The problem of negative cell depth value contributes significant error to the total volume calculations, most likely in the underestimation of total volume. By definition of the mapped glacier, there must be at least some glacier volume associated with each cell in the Glacier Surface grid. The cells that have a negative depth value are generally "thin" areas of the glacier; however, if a large percentage of the total glacier isopach map cells are assigned a zero volume because they contain negative values (such as in the 1913 Nisqually Glacier), it can alter the total volume calculation to the point where it is grossly inaccurate and misleading. 


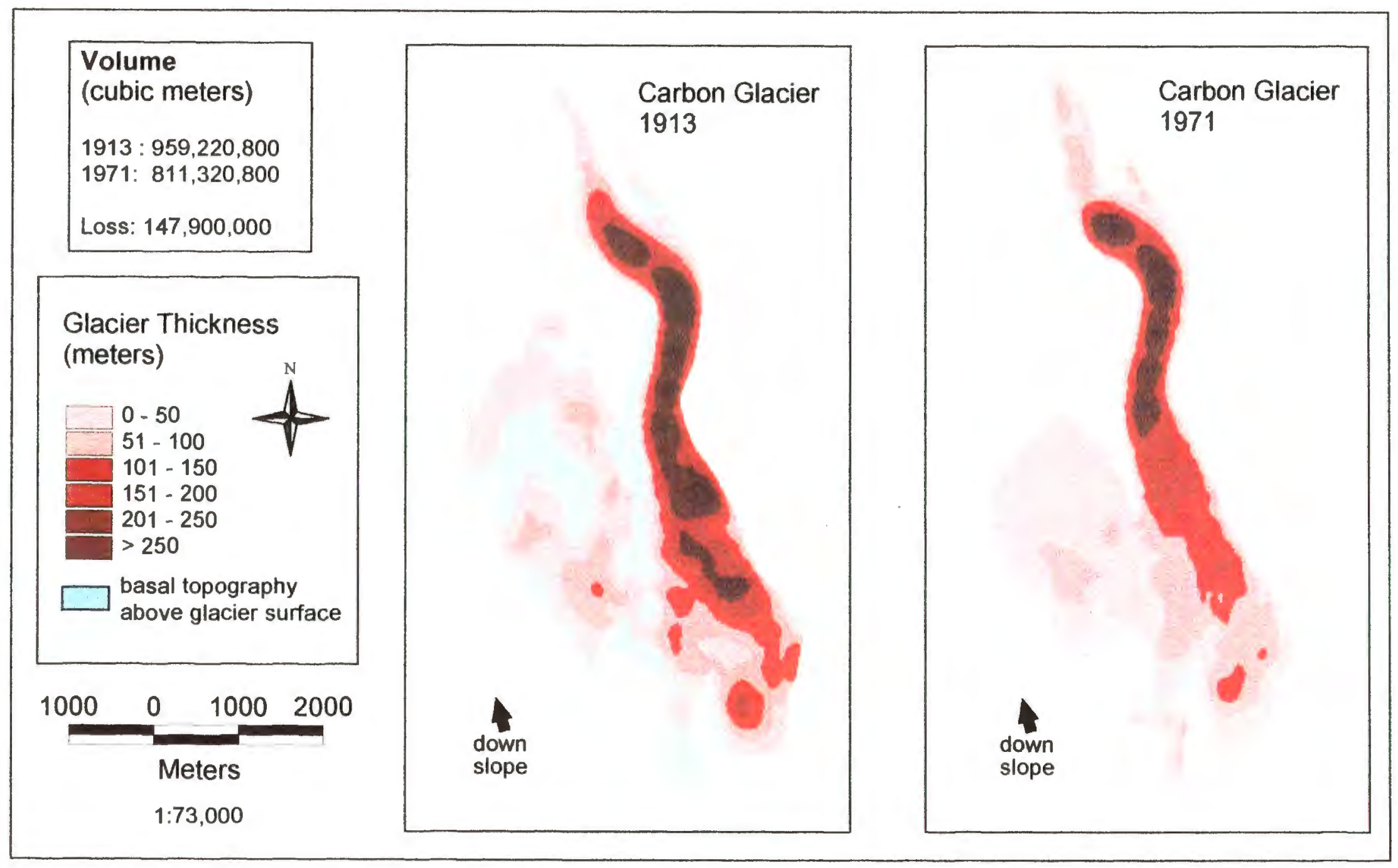

Eiqure 25. Isopach maps of Carbon Glacier, 1913 and 1971. 


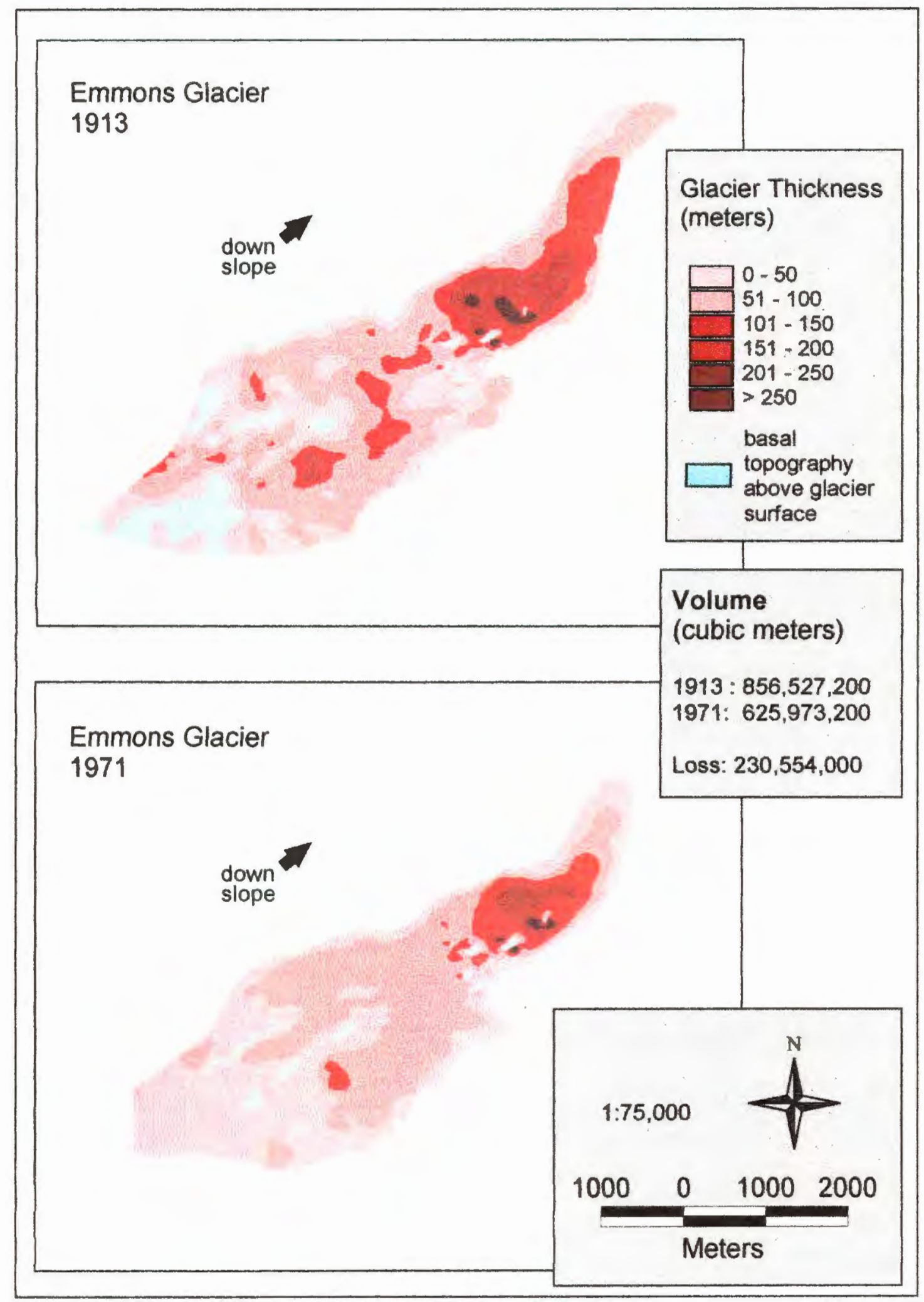

Eigure 26. Isopach maps of Emmons Glacier, 1913 and 1971. 


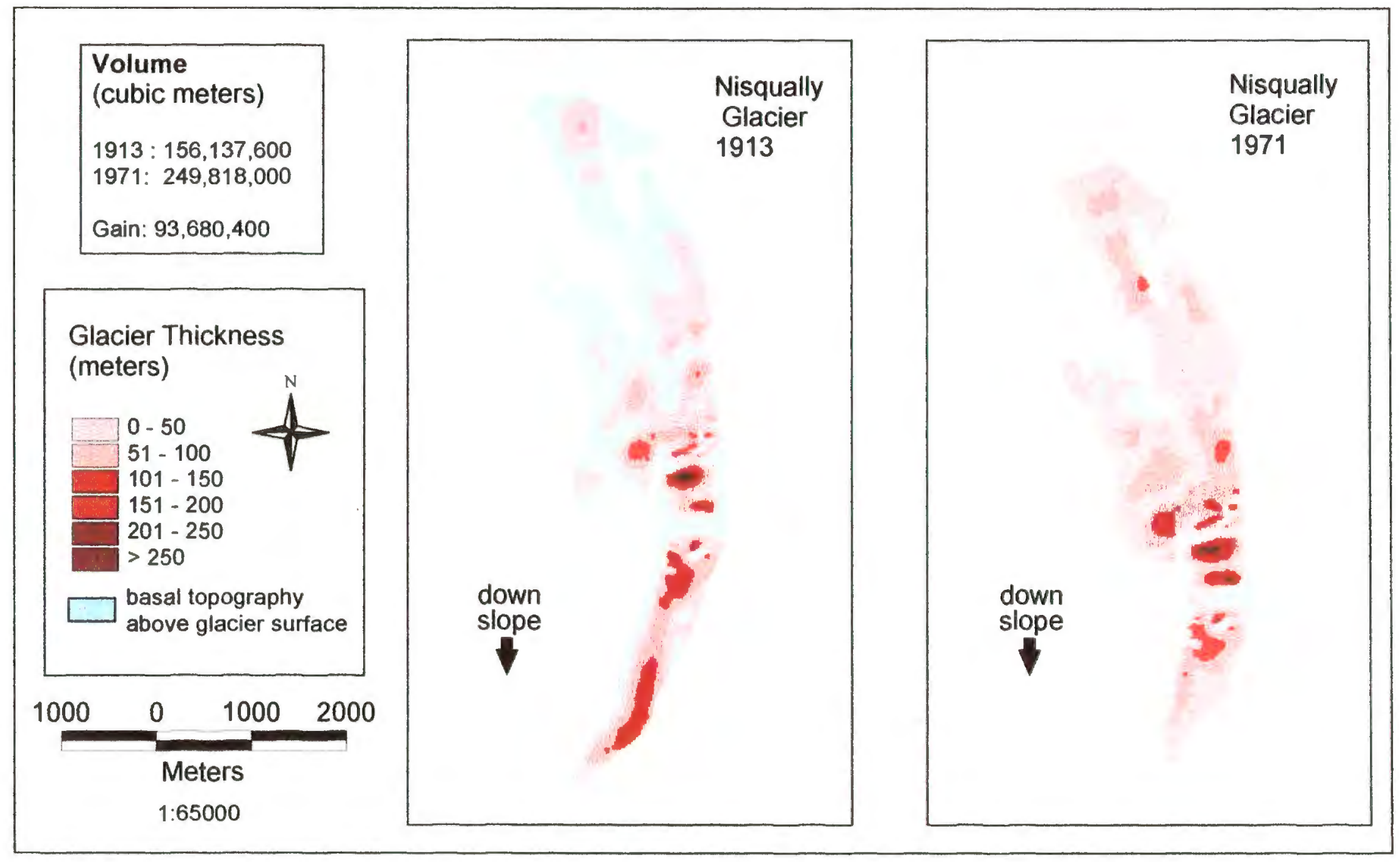

Eigure 27. Isopach maps of Nisqually Glacier, 1913 and 1971. 


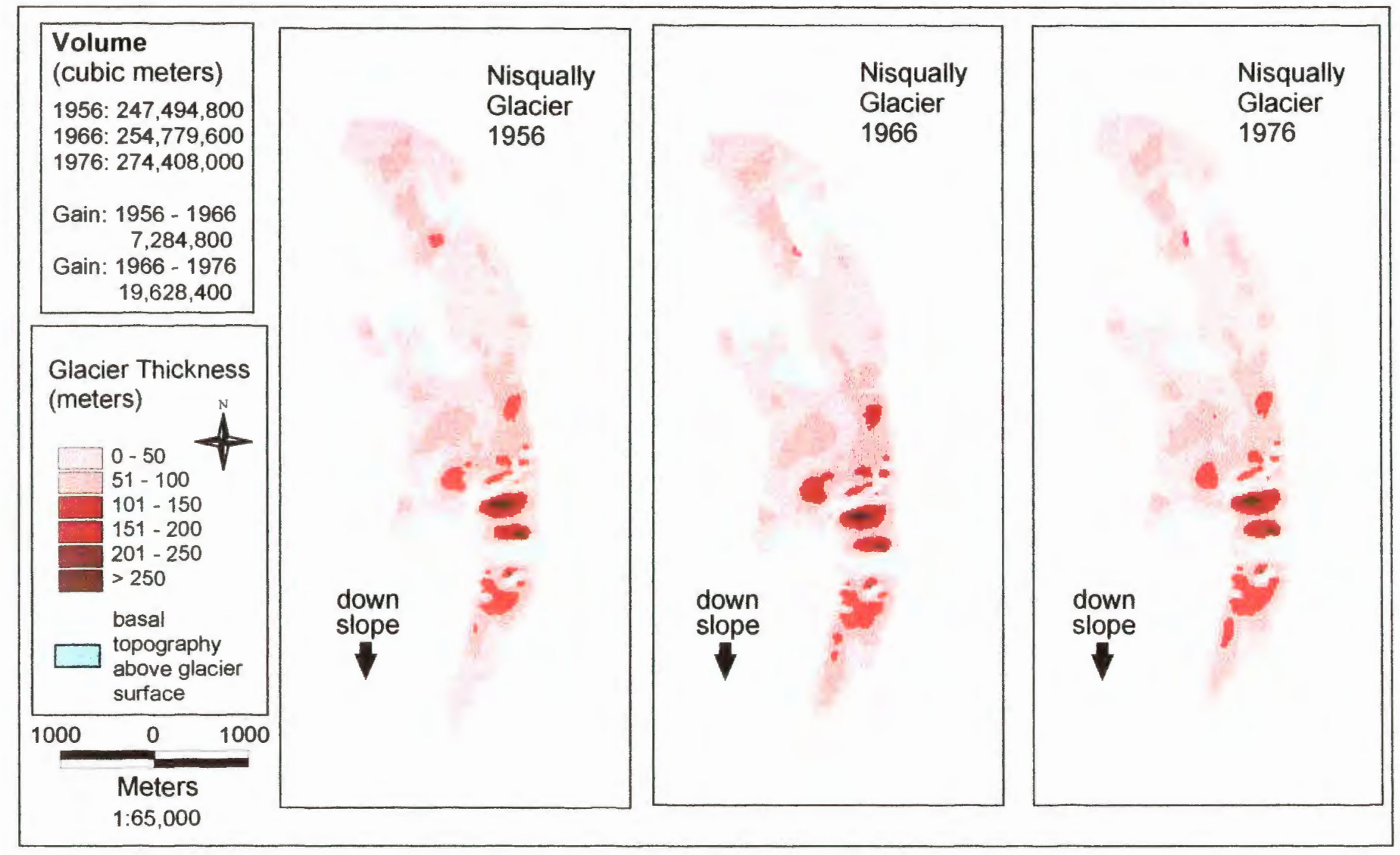

Fiqure 28.Jsopach maps of Nisqually Glacier, 1956, 1966, and 1976. 


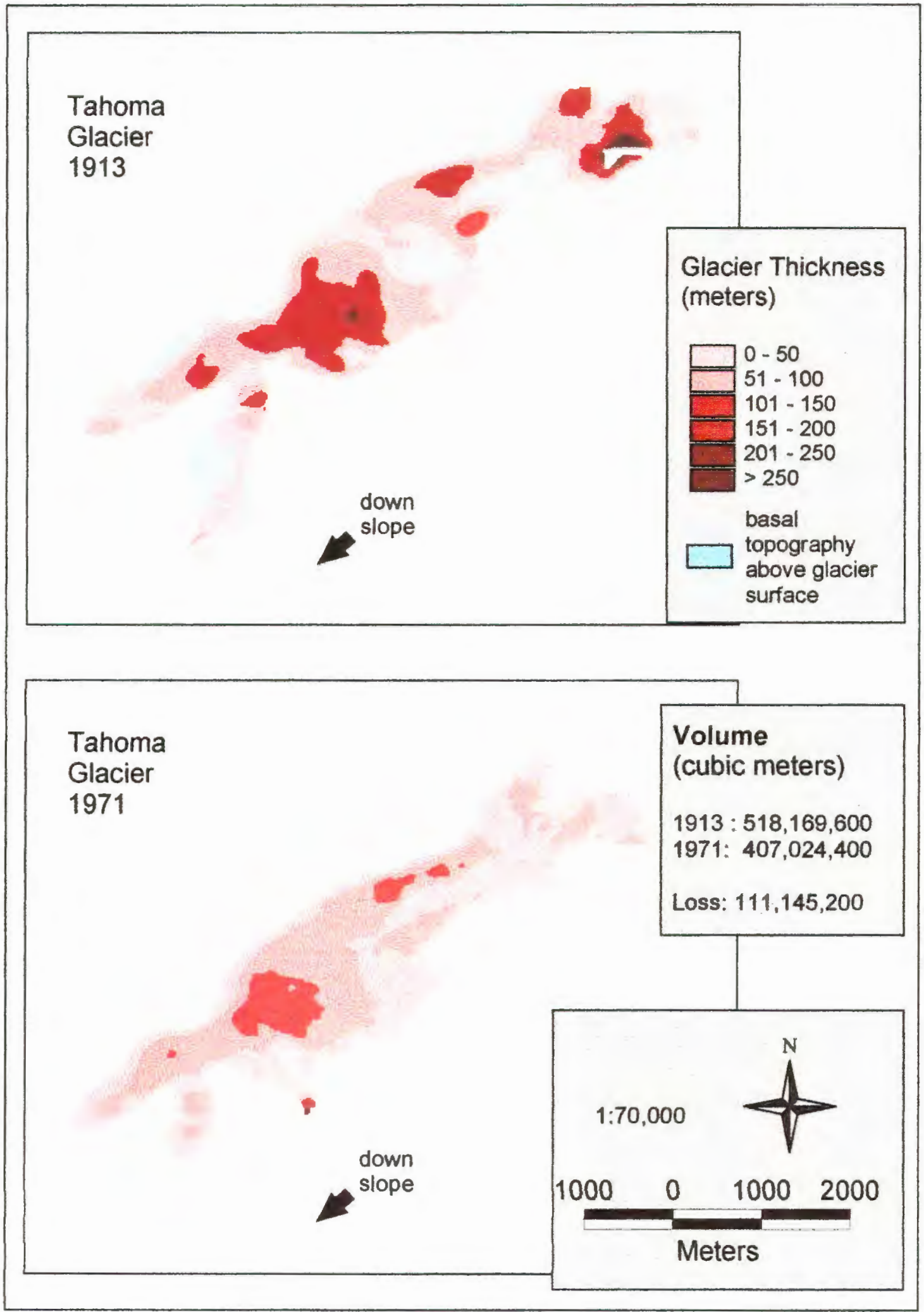

Eigure 29. Isopach maps of Tahoma Glacier, 1913 and 1971. 


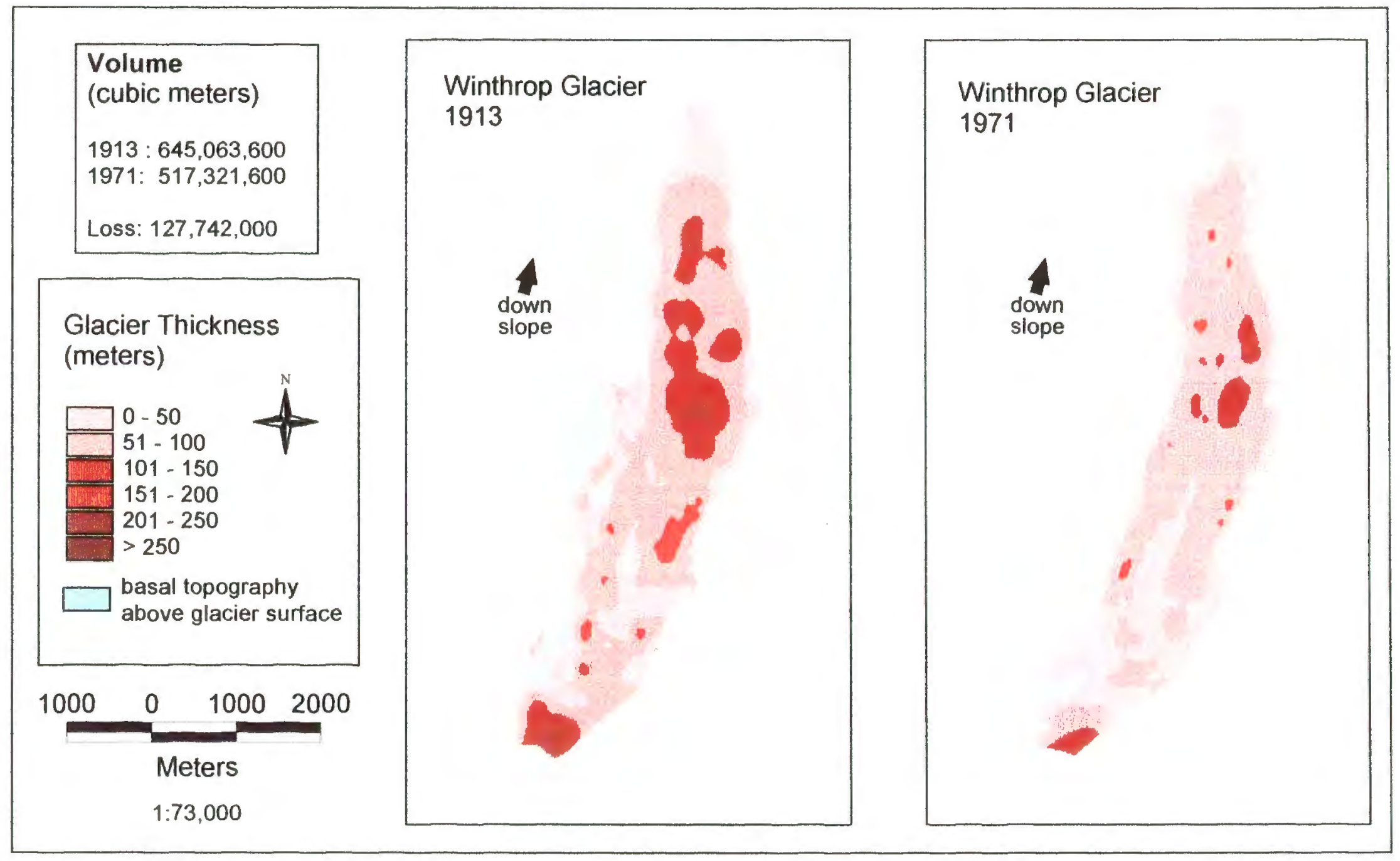

Eiqure 30. Isopach maps of Winthrop Glacier, 1913 and 1971. 
This logical inconsistency is especially evident at higher elevations in the 1913 glacier isopach maps (Figures 26 and 27). The source of this error can be attributed to precision and bias positional error within the original map, registration error within the Database, and error associated with the interpolation of the glacier surface and basal topography. From a visual review of the 1913 glacier isopach maps, it appears as though the 1913 surveyor often generalized the glacier surface slope globally across the entire glacier, so that the lower part of the glacier is mapped as steeper than in reality while the upper portion is not steep enough.

In addition to the 1913 glacier representations, the basal topography surface is also particularly prone to error. The basal topography surfaces are based on a contour map that was hand drawn from a relatively sparse series of data points derived from ground-based ice radar (Driedger and Kennard 1986). Data points in this survey were conspicuously absent in the higher elevations because of the inaccessible nature of the terrain. The 1913 glacier surfaces are based on a 1913 1:62,500 scale contour map constructed with, by today's standards, primitive survey techniques. Unfortunately, we cannot go back in time to 1913 , nor underneath the glacier, to test the model against any ground truth. In addition, there is no consistency to the type of error indicated by these data quality issues; there is no way to distinguish between errors in registration or errors in interpolation, although each may have different effects on the calculation of glacier volume and area. Therefore, there is no apparent method to 
quantify the amount of error within each spatial representation, or area or volume calculation, against a standard of known value.

In the absence of standardized accuracy measurement, there exists a set of techniques for relative error assessment that allows for the minimization of error throughout the analysis. Table II shows the relative impact of negative cell depth values in each temporal glacier isopach map construction. While the average percentage of negative depth value cells out of the total number of cells for the 1971 glacier isopach maps is a reasonable six percent, this figure rises to 22 percent for the 1913 glacier isopach maps. In both years, the Nisqually Glacier map contains the highest percentage of negative depth value cells, reaching 51 percent in 1913, enough to render meaningless any derived volume calculation. Note also that in general, the higher the total percentage of negative depth value cells, the higher the average value of negative cell depth.

Another methodology for assessment of this type of error concerns the relationship between glacier area and volume. A regression analysis of the areas and volumes of glaciers within a specific physiographic region may reveal a correlation between these variables, described graphically by a line of best fit on a scatter diagram of the area and volume values for each glacier. Once an analysis such as this is completed with a reasonable degree of confidence, the results of the GIS analysis of glacier area and volume can be plotted and compared to the line of best fit. Because the GIS calculation of glacier area is derived from the direct explicit observation of 
TABLE \|

VOLUME ERROR DUE TO NEGATIVE

CELL DEPTH VALUES IN GLACIER ISOPACH MAPS

\begin{tabular}{|c|c|c|c|c|c|}
\hline Glacier & Year & \# Cells, Depth < 0 & Total \# Cells in Grid & $\%$ of Total Cells, Depth $<0$ & mean depth (meters) of cells, depth $<0$ \\
\hline \multirow{2}{*}{ Carbon } & 1913 & 8.039 & 33,679 & 24 & -114 \\
\hline & 1971 & 1,047 & 27,621 & 4 & -29 \\
\hline & & & & & \\
\hline \multirow[t]{3}{*}{ Emmons } & 1913 & 3,382 & 31,689 & 11 & -56 \\
\hline & 1971 & 912 & 28,654 & 3 & -57 \\
\hline & & & & & \\
\hline \multirow[t]{6}{*}{ Nisqually } & 1913 & 8,437 & 16,385 & 51 & -105 \\
\hline & 1956 & 2,445 & 16,128 & 15 & -90 \\
\hline & 1966 & 2,169 & 15,686 & 14 & -89 \\
\hline & 1971 & 1,378 & 14,831 & 9 & -89 \\
\hline & 1976 & 1,804 & 15,898 & 11 & -86 \\
\hline & & & & & \\
\hline \multirow[t]{2}{*}{ Tahoma } & 1913 & 3,932 & 22,207 & $\overline{18}$ & -59 \\
\hline & 1971 & 531 & 18,850 & 3 & -24 \\
\hline & & & & & \\
\hline \multirow[t]{2}{*}{ Winthrop } & 1913 & 2,082 & 25,252 & $\overline{8}$ & -117 \\
\hline & 1971 & 614 & 22,293 & 3 & -28 \\
\hline & & & & & \\
\hline & & & average $\% 1913$ & 22 & \\
\hline & & & average $\% 1971$ & 6 & \\
\hline
\end{tabular}


the glacier boundary, as opposed to the interpolation necessary for glacier volume calculation, GIS calculation of glacier area is generally more accurate than it is for volume. Therefore, if a particular glacier's GIS derived area and volume scatter plot value shows significant divergence from the line of best fit, it most likely indicates significant error in volume calculation. Another method for assessment of this type of error includes the display and comparison of longitudinal glacier profiles at different times of record. Visualization of this nature may reveal logical inconsistencies and graphic trends common to glacier representations that share a common map source and/or certain time frames.

One potential strategy to minimize this type of error is simply to improve the accuracy of the data as it is input from the original map and manipulated within the application. This concerns the method of digitization and data point sampling and the choice of interpolation algorithm and parameters. While different methodologies in this area have been discussed and briefly tested, it is beyond the scope of this project to thoroughly test each method against the others. Potential improvements in data input and interpolation are discussed in the final chapter. This approach will not work, however, if the error is contained in the original map source itself.

If one makes the assumption that change in glacier volume and area take place primarily within the zone of ablation, it is possible to calculate the volume and area of only the lower section of each temporal glacier representation. The volume and area of the upper section would be calculated based on one temporal glacier representation 
that is determined to be the most accurate and appended onto the others to calculate a total volume for each glacier representation. The disadvantage here is that if significant change does take place at the upper elevations, it is obviously not accounted for.

Another error assessment methodology calls for the measurement of elevation differences between known registration points found on both the Glacier Surface grid and basal topography surface. While a difference in elevation at these points does not necessarily imply the same elevation difference between the gridded areas at the glacier bed, it may provide an "offset" figure that can be used for grid-wide elevation correction. This technique may even be applied to the original source maps for each of the grids with the similar results.

Perhaps the best strategy for managing error due to registration between glacier surface and basal topography is the minimization of negative glacier depth values through an iterative process of registration between temporal glacier representations. This process would consist of "moving" the Glacier Surface grid across the basal topography grid one cell at a time and recalculating the cell depths at each iteration. The registration with the minimum number of negative depth values, or the greatest glacier volume, is the "best" fit.

Sub-glacial topography for most glaciers throughout the world is unknown. However, GIS analysis may still aid in the calculation of glacier volume and area change over time provided that temporal glacier data is available. Instead of 
subtracting the sub-glacial topography grid from the Glacier Surface grid to calculate total volume for each glacier, two Glacier Extent coverages and Glacier Surface grids from different times of record can be subtracted from one another to calculate area and volume change, respectively. The only issue here is that the resultant grid of glacier volume change only contains grid cells that are common to both Glacier Extents, similar in result to a Boolean and overlay operation between the two temporal glacier representations. To solve this problem, each Glacier Surface grid must be "pasted" onto a DEM of the non-glaciated surface so that volumes can be calculated for parts of each glacier not common to both temporal representations.

There are further analytical applications that are natural extensions to this exercise. These include the construction of cross-section and longitudinal glacier profiles; summary of area and volume, and area and volume change, by elevation; and comparison of rates of area and volume change with other characteristics, such as glacier aspect. Data can be presented graphically in a variety of map, chart, and tabular formats automated in Arcview 3.0. Data can also be exported to spreadsheet or statistical software for more advanced manipulation or presentation. 


\section{CHAPTER VI}

\section{RECOMMENDATIONS FOR FUTURE DEVELOPMENT AND RESEARCH DATABASE DEVELOPMENT}

Research conducted in the area of data input, sampling, and interpolation methods should improve the efficiency and accuracy of the Database. This specifically concerns the digitization of contour line data and the interpolation of glacier surfaces from that contour line data. This project took the approach of preserving the original contour line data as it appeared on the map for the purpose of comparison to later derived data representations, but it is possible that this approach is less accurate than other data input strategies. Additionally, while the project found the spline interpolator to be most accurate in a brief survey, by no means did it exclude the possibility that ultimately another interpolation technique may prove be more accurate.

As stated in Chapter II, the sampling scheme of simply digitizing contour lines from topographic maps creates an irregular distribution of sample points that tends to distort the interpolation of surfaces in predictable and unpredictable ways. There are various systematic and purposive sampling strategies that have been proposed to generate surfaces from topographic map data. Systematic sampling is based on a regular grid pattern of data points while purposive sampling, varies the data input pattern with density of sampling as compared to complexity of terrain (Gao 1995). 
Gao (1995) reports that purposive sampling is consistently more accurate than systematic sampling of elevation points from topographic maps. Ayeni (1982) recommends the use of statistical analyses to determine the most accurate sampling strategy while Balce (1987) proposes an automated method for the derivation of optimal sampling based on empirically derived testing of photogrammetric elevation data. Of particular relevance to the Database, Eklundh and Martensson (1995) report on a point sampling strategy combining systematic and selective sampling to generate surfaces from topographic maps. They recommend the sampling of contour line data throughout a general grid pattern, growing progressively more detailed in rough terrain. They note that this method is more accurate and less time consuming than digitizing contour lines directly.

Another option for data input is the direct scanning of topographic maps into digital format, however, this demands a significant amount of map preparation time and relatively expensive hardware and software. It is most useful when digitizing large amounts of data from maps with a minimal amount of "noise" that may complicate the automated recognition of the target data input feature (Aranoff, 1989). Armstrong (1991) reviews the steps taken to input topographic data by scanning. Technologic developments since 1989, however, have made raster scanning and raster to vector conversion algorithms more efficient and accurate; given the large volume of glacier data, an available automated method such as scanning would have the advantage over manual digitization. 
While the choice of spline for the interpolation of glacier surface in this project was shown to be the most accurate within the bounds of the brief survey undertaken, there are various methodologies available that may be more appropriate. One such possibility is kriging. Oliver and Webster (1990) advocate the use of kriging for surface interpolation because it incorporates regionalized variable theory to model the distribution of surface elevation based on the statistical "drift" of the sample data. It seems that this would be an ideal method given the consistent unidirectional increase of elevation throughout a glacier from toe to head. While this did not prove correct in the survey conducted here, given the correct parameter settings, kriging may produce a more accurate surface than splining.

The Database would be further improved through the reduction of data storage to the minimum data sufficient for analysis. The Database was constructed with the intent of facilitating analysis of glaciers on Mount Rainier; however if the Database is applied on a wider region, the amount of data stored per spatio-temporal glacier representation should be significantly reduced. Since all spatial data is directly derived from the Glacier Extent, Original Contour, and Debris Extent coverages, this would not hinder the analytical options the Database offers.

To eliminate all the spatial data aside from the coverages listed above would necessitate complex surface generation for every new analytical operation requiring a Glacier Surface grid. A compromise between the competing goals of data storage reduction and thorough data representation would be for each spatio-temporal 
representation to include the three primary coverages listed above in addition to the Elevation Points coverage, Glacier Surface grid, and Interpolated Contour coverage. This strategy provides a stored topographic glacier surface and standardized contour line map within the Database and allows the user to derive the other raster grids from the stored Glacier Surface. Further, the user has the option of using another interpolation technique to create a different Glacier Surface grid using the Elevation Points coverage. The creation of these derivative coverages that are now explicitly stored within the Database would be made available to the user through the analytical options developed within the customized GIS application.

Considering the vast amount of glaciologic data gathered from remote sensing sources, it is essential that future development of the Database integrate remote sensing imagery with other digital spatial data. The amount of available remote sensing data will only increase in the future as more commercial and government sponsored observation satellites are launched. Research concerning the integration of the display and analysis of raster images and vector data is ongoing (Simonett 1988; Ehlers 1992), the results of which are being implemented in a number of prominent GIS packages.

Two options exist for the incorporation of remote sensing imagery into the Database structure. First, remote sensing data can be temporally referenced and placed within the structure of the Database. This would allow users to interact with the data in the same manner as they would with the vector and raster data currently in place. 
However, the Database is structured to facilitate the organization of vector coverages and their derivative raster products; problems may arise in terms of attributing and organizing the remote sensing imagery given its raster format. A second approach is to construct a parallel database of remote sensing data which could be linked and accessed through a query system similar to the one used by the Database. Access and analysis of vector, raster, and remote sensing imagery would be facilitated by the application environment.

\section{APPLICATION DEVELOPMENT}

Customizing Arcview 3.0 involves both improving the user interface to facilitate data query and access and building a set of analytical and display tools that can be implemented easily by the user. While the generic Arcview 3.0 interface can be used to perform the data access and display functions necessary for application of the Database, the purpose of customization is to shift the burden of knowledge of GIS and the Database structure from the user to the application. In this way, a glaciologist with limited knowledge of GIS can benefit from the Database and GIS analytical techniques.

Examples of the types of functions envisioned for the interface include developing a query dialog box that prompts the user for the type of data needed, whether accessed by temporal or spatial component. Relations between tables should be established so that spatial data can be displayed directly from the query of its attributes and, vice-versa, all glacier attributes should be accessible by spatial query. 
The nature of this interface should be a series of dialog boxes that gives the user a set of hierarchical options in narrowing down the nature of their query. This set of options may mirror the hierarchical nature of the Database structure if it is a spatial query or involve a more complex folder search if the query is of a temporal nature. Either way, the manual operation of searching through folders for data will be transparent to the user.

Finally, the customized GIS application should facilitate visualization and display of the data for qualitative analysis and scientific communication. While there is no one correct way to display glacier data, choices in the display parameters can greatly influence the interpretation, and therefore the value, of the data. The application should give the user choices of visualization techniques based on the user goals. Construction of this type of sub-application requires a thorough study on the perception of glacier data as it is presented in a variety of formats.

\section{SPATIAL ANALYSIS DEVELOPMENT}

The development of spatial analysis and analytical cartography techniques in the analysis of glacial phenomena presents a great opportunity for methods of investigation only recently made possible by technologic progress. While the implementation of these techniques in generic GIS packages has been slow due to the demands of the market, the growing application of GIS to fields outside the traditional concentration of facilities management and natural resource management is spurring research in this area (Goodchild, Haining, and Wise 1992). While some spatial 
analysis techniques are generic in nature, such as the measurement of distance, other more complex techniques can be developed based on the demands of their application. Such is the case with glaciology.

Giordano et al. (1994:49) notes six GIS spatial analysis functions, "that are used to derive relationships implicit in source data." These include logical, arithmetic, overlay, geometric property, geometric transformation, and geometric derivation operations. Moellering (1991) includes a wider, and deeper, range of topics in his discussion of analytical cartography including defining spatial data structures, database systems, and query languages. Goodchild, Haining, and Wise (1991) focus on the application of statistical techniques to data analysis. Glaciology benefits most from the spatial data analysis techniques that concern the nature of glaciologic inquiry: form, material properties, process, and temporal change. The setting for the development of spatial analysis techniques should incorporate vector and raster glacier representations, remote sensing imagery, and the combination of the two.

Spatial data analysis techniques concerning form focus on the identification of the geomorphometric character of the glacier and changes to the geomorphometric character of the glacier through time. This includes data that is already made explicit in the attribute tables, such as glacier area, and more complex operations such as the deduction of volume from differences between two or more temporal glacier surface representations. Other transformative analytical functions include the construction of 
glacier cross sections, longitudinal profiles, and the graphing of changes to glacier surface characteristics through time.

As noted in Chapter I, there is currently a wealth of glaciologic research using remote sensing imagery in topographic analysis. Ehlers (1992:55) notes that GIS, in combination with remote sensing data, "can assist in the automation of interpretation, change detection, map compilation, and map revisions functions." He specifically mentions the application of GIS in the construction of DEMs, database production and topographic mapping, and change detection. Other potential remote sensing applications to GIS spatial analysis include analysis of the distribution, and patterns of distribution, of general and specific glacial geomorphometric features. Algorithms may be developed to automate recognition of certain features through statistical analysis of patterns of feature distribution, in addition to the shape of the features themselves. Finally, analysis of the spatial coincidence of certain features may reveal relationships between those features and other glacier characteristics.

In a similar vein, GIS may also be used to map the distribution of material properties as they vary throughout a glacier and the change in this distribution through time, as noted in Chapter I. The application of GIS techniques to this data, as opposed to traditional mapping methods, allows for the statistical analysis of the distribution of a property for pattern recognition. Additionally, spatial overlay of a series of distribution patterns of material properties may reveal spatial correlations between these properties or between certain properties and geomorphometric character. 
Research in integrating numerical process models in GIS concerns developing data structures that are better able to represent dynamic process. Other issues deserving attention concern the application of a model over an area of "real" data, such as the previously mentioned study that models avalanching over snow covered terrain with known geomorphometric and physical property characteristics. Issues here include overcoming differences in model and data resolution and the incorporation of uncertainty within the data, the model, and results.

\section{CONCLUSION}

The Database developed by this project demonstrates one instance of how GIS can successfully be applied to glaciology. GIS provides the means for data integration by which diverse sources of data with varying accuracies, resolutions, and projections can be compared and analyzed. This procedure facilitates the analysis of historic glacier change which may otherwise be inaccurate, cumbersome, and time consuming. In addition, a comprehensive world wide glacier database similar in structure to the one presented in this paper would facilitate data sharing throughout the glaciologic research community. The centralization of glacier data and the spatial and temporal access tools that allow efficient searches stimulate the sharing of information.

GIS also provides a set of analytical tools that allow the automated analysis of glacier form, material properties, and process in addition to how these characteristics may change over time. In combination with remote sensing imagery, these tools provide the means to model ever more complex relationships between different glacier 
characteristics and these characteristics and glacial process. This allows for the coupling of glacial and climate models which may contribute to theory concerning the nature of earth environment evolution.

Advances in GIS and remote sensing technology are moving towards integration of vector and raster data structures and remote sensing imagery so that GIS techniques may be applied to the vast data resources provided by airborne and satellite platforms. While some integration and analysis functions are available in generic GIS and image analysis packages, the customization of GIS specifically for applications in glaciology will ultimately improve data access, sharing, and analysis. 


\section{EPILOGUE}

In closing, I would like to mention a conversation I had recently with a glaciologist. I mentioned to him that I was interested in the integration of GIS and glaciology to which he remarked that he had always thought of GIS as simply a "box of crayons." Obviously, to him the words GIS conjured up impressions of map making but not analysis. I would like to draw an analogy to shed some light on this grave misunderstanding of the nature of GIS and its potential role in the scientific community.

This analogy refers to a prominent analytical technique that has only recently been accepted into much of the scientific community. Kuhn (1996) states that scientific research takes place within a temporal framework of assumptions, methods, and goals called a paradigm. The theory of paradigms has become well accepted within theories concerning the evolution of science, and the term "paradigm shift" has come to refer to changes within the approach of the scientific community at a variety of scales.

During the 1950's and 1960's one such paradigm shift took place that has come to be known as the "quantitative revolution", in which the focus of research throughout the scientific community shifted from a descriptive nature to one in which quantitative models of natural and human phenomena are used to build theory about the nature of those phenomena. In Geography, this paradigm shift is exemplified by 
the debate between Richard Hartshorne and Fred Schaefer (Livingstone, 1992) and in Chorley and Haggett's (1967) Models in Geography. In glaciology it is revealed by Paterson's (1994:6) remark in his landmark book, The Physics of Glaciers, "Too often in the past, glaciologic measurements have been made on the premise that the mere acquisition of data is a useful contribution in itself. This is seldom the case."

Statistical analysis and numerical process modeling are the main methods by which quantitative analysis is carried out. While quantitative measurement had for a long time been part of the scientific process, the construction of predictive quantitative models, probabilistic statistical models, and statistical correlations between variables were not. While there are, of course, other valid methods for understanding the world we live in, these quantitative techniques have come to dominate many branches of science, including glaciology (Bjornsson 1986; Richards 1990). One of the main reasons for this dominance is the ability to make predictions about the behavior of the phenomena being modeled.

I can only imagine that some of the scientists initially presented with the tools to carry out quantitative analysis saw it as merely a means to do the same calculations and measurements they had been doing before, albeit faster and more efficiently. But those who recognized the vast potential for the application of complex statistical analysis to the recognition of relationships between sets of numbers have changed the nature of science itself. Mere description has been derided in glaciology, as in many 
other sciences, as pale in comparison to the ability to quantify the character of earth phenomena so that models can be constructed and theories tested (Richards 1990). I propose that analytical cartography and spatial analysis in the 1990's are akin to statistical analysis in the 1960's and that GIS software applications are the calculators, or statistical packages, used to apply these powerful techniques. In GIS exists a powerful set of mathematical tools to extend measurement, statistical analysis, and process modeling across the spatial and temporal dimensions in which all earth phenomena take place. So in reference to the glaciologist who likened GIS to a box of crayons, I say: do not think of GIS as the calculator that can simply add two plus two faster than before (or make a better map), but as a mathematical toolbox that can help you investigate glaciologic phenomena in ways that were not before possible.

I recommend the eventual dissolution of GIS as a distinct sub-field of Geography and a firmer linguistic distinction between GIS, the calculator, and GIS, the set of analytical techniques. The stigmatization associated with such designations is stunting the application of quantitative spatial modeling to scientific inquiry that could benefit from such techniques. Eventually, it is hoped that GIS will assume a position akin to statistics, a set of tools which a scientist can use to make sense of the complex set of interrelated phenomena that is the world in which we live. 


\section{REFERENCES}

Anderson, M.G. and Burt, T.P. 1990. Introduction. In Geomorphological Techniques, Second Edition, ed. A. Goudie, pp.33-35. London: Unwin Hyman.

Aniya, M. and Naruse, R. 1986. Mapping Structure and Morphology of Soler Glacier, Chile, Using Vertical Aerial Photographs. Annals of Glaciology 8:8-10.

Aranoff, S. 1989. Geographic Information Systems: A Management Perspective. Ottowa, Ontario: WDL Publications.

Armstrong, D.H. 1991. Scanning - An Alternative Means of Spatial Database Construction. In GIS Applications in Natural Resources, ed. M. Heit and A. Shortreid, pp.183-188. Fort Collins, Colorado: GIS World, Inc.

Ayeni, O.O. 1982. Optimum Sampling for Digital Terrain Models: A Trend Towards Automation. Photogrammetric Engineering and Remote Sensing 48(11):16871694.

Balce, A.E. 1987. Determination of Optimum Sampling Interval in Grid Digital Elevation Models (DEM) Data Acquisition. Photogrammetric Engineering and Remote Sensing 53(3):323-330.

Bjornsson, J. 1986. Welcoming Address on Behalf of Co-Sponsors. Annals of Glaciology 8:3.

Brun E. et al. 1992. A Numerical Model to Simulate Snow-Cover Stratigraphy for Operational Avalanche Forecasting. Journal of Glaciology 38(128): 13-22.

Budd, W.F. and Jensenn, D. 1989. The Dynamics of the Antarctic Ice Sheet. Annals of Glaciology 12:16-22.

Burrough, P.A. 1986. Principles of Geographical Information Systems for Land Resources Assessment. Oxford: Clarendon Press.

Buttenfield, B.P. 1993. Representing Data Quality. Cartographica 30(2,3):1-7.

Casassa, G. and Brecher, H.H. 1993. Relief and Decay of Flow Stripes on Byrd Glacier, Antarctica. Annals of Glaciology 17:255-261. 
Champoux, A.C. and Ommanney, C.S.L. 1986. Evolution of the Illecillewaet Glacier, Glacier National Park, B.C., Using Historical Data, Aerial Photography and Satellite Image Analysis. Annals of Glaciology 8:31-33.

Chorley, R.J. and Haggett, P. 1967. Models in Geography. London: Methuen and Co. Ltd.

Chrisman, N.R. 1991. The Error Component in Spatial Data. In Geographical Information Systems: Principles and Applications, ed. D.J. Maguire, M.F. Goodchild, and D.W. Rhind, pp.165-174. Essex, England: Longman Scientific and Technical.

Clarke, K.C. 1990. Analytical and Computer Cartography. Englewood Cliffs, New Jersey: Prentice Hall.

Delmas, R.J. 1994. Ice Records of the Past Environment. The Science of the Total Environment 143:17-30.

Dikau, R., Cavallin, A., and Jager, S. 1996. Databases and GIS for Landslide Research in Europe. Geomorphology 15:227-239.

Dozier, J. and Marks, D. 1987. Snow Mapping and Classification from Landsat Thematic Mapper Data. Annals of Glaciology 9:97-103.

Driedger, C.L. and Kennard, P.M. 1986. Ice Volumes on Cascade Volcanoes: Mount Rainier, Mount Hood, Three Sisters, and Mount Shasta. U.S. Geological Survey Professional Paper 1365.

Duguay, C.R. 1993. Modelling the Radiation Budget of Alpine Snowfields with Remotely Sensed Data: Model Formulation and Validation. Annals of Glaciology 17:288-294.

Ehlers, M. 1992. Remote Sensing and Geographic Information Systems: ImageIntegrated Geographic Informatio Systems. In Geographic Information Systems (GIS) and Mapping - Practices and Standards, ed. A.I. Johnson, D.B. Pettersson, and J.L. Fulton, pp.53-67. Philadelphia: American Society for Testing and Materials.

Eklundh, L. and Martensson, U. 1995. Rapid Generation of Digital Elevation Models from Topographic Maps. International Journal of Geographical Information Systems 9(3):329-340. 
Gao, J. 1995. Comparison of Sampling Schemes in Constructing DTMs from Topographic Maps. ITC Journal 1:18-22.

Garvin, J.B. and Williams, Jr., R.S. 1993. Geodetic Airborne Laser Altimetry of Breidamerkurjokull and Skeidararjokull, Iceland and Jakobshavs Isbrae, West Greenland. Annals of Glaciology 17:379-385.

Giordano, A. et al. 1994. A Conceptual Model of GIS-Based Spatial Analysis. Cartographica 31(4):44-57.

Goodchild, M., Haining, R., and Wise, S. 1992. Integrating GIS and Spatial Data Analysis: Problems and Possibilities. International Journal of Geographical Information Systems 6(5):407-423.

Goodchild, M.F. 1995. Sharing Imperfect Data. In Sharing Geographic Information, ed. H.J. Onsrud and G. Rushton, pp.413-426. New Brunswick, New Jersey: Rutgers, The State University of New Jersey.

Hall, D.K. et al. 1987. Characterization of the Snow-Ice Reflectance Zones on Glaciers Using Landsat Thematic Mapper Data. Annals of Glaciology 9:104108.

Hutter, K. 1983. Theoretical Glaciology. Dordrecht, Holland: D. Reidel Publishing Company.

Joughin, I. et al. 1996. Measurement of Ice-Sheet Topography Using Satellite-Radar Interferometry. Journal of Glaciology 42(140):10-22.

Keller, C.P. 1991. Time-Space Analysis and GIS. In GIS Applications in Natural Resources, ed. M. Heit and A. Shortreid, pp.141-144. Fort Collins, Colorada: GIS World, Inc.

Klein, A.G. and Isacks, B.L. 1996. Tracking Change in the Central Andes Mountains. GIS World 9(10):148-153.

Kuhn, T.S. 1996 [1962]. The Structure of Scientific Revolutions, Third Edition. Chicago: University of Chicago Press.

Kumler, M.P. 1994. An Intensive Comparison of Triangulated Irregular Networks (TINs) and Digital Elevation Models (DEMs). Cartographica 31(2):1-48. 
Langran, G. 1992. Time in Geographic Information Systems. London: Taylor and Francis.

Langran, G. and Chrisman, N.R. 1988. A Framework for Temporal Geographic Information. Cartographica 25(3):1-14.

Lanter, D.P. 1993. A Lineage Meta-Database Approach Toward Spatial Analytic Database Optimization. Cartography and Geographic Information Systems 20(2):112-121.

Lase, M.A. and MacAyeal, D.R. 1989. Numerical Models of Ice Shelf Flow: Ideal/Real. Annals of Glaciology 12:97-103.

Laurini, R. and Thompson, D. 1992. Fundamentals of Spatial Information Systems. London: Harcourt Brace Jovanovich.

Lawson, W. 1996. Structural Evolution of Variegated Glacier, Alaska, U.S.A., since 1948. Journal of Glaciology 42(141):261-270.

Lillesand, T.M. and Kiefer, R.W. 1994. Remote Sensing and Image Interpretation, Third Edition. New York: John Wiley and Sons, Inc.

Lindsay, R.R. and Rothrock, D. 1993. The Calculation of Surface Temperture and Albedo of Arctic Sea Ice from AVHRR. Annals of Glaciology 17:391-396.

Livingstone, D.N. 1992. The Geographical Tradition. Oxford: Blackwell Publishers Ltd.

Lorius, C., Jouzel, J., and Raunaud, D. 1992. The Ice Core Record: Past Archive of the Climate and Signpost to the Future. Philosophical Transactions of the Royal Society of London SERIES B: Biological Sciences 338(1285):227-233.

Mahoney, P., Carstensen, I.W. and Campbell, J.B. 1991. Effects of Technological Change On Relief Representation on USGS Topographic Maps. Cartographica 28(4):9-31.

McClung, D.M. and Tweedy, J. 1994. Numerical Avalanche Prediction: Kootenay Pass, British Columbia, Canada. Journal of Glaciology 40(135):350-358).

McCullagh, M.J. 1988. Terrain and Surface Modelling Systems: Theory and Practice. Photogrammetric Record 12(72):747-779. 
McGranaghan, M. 1993. A Cartographic View of Spatial Data Quality. Cartographica 30(2,3):8-19.

Moellering, H. 1991. Whither Analytical Cartography?. Cartography and Geographic Information Systems 18(1):7-9.

Monmonier, M.S. 1982. Computer Assisted Cartography. Englewood Cliffs, New Jersey: Prentice-Hall, Inc.

Mulvaney, R. and Wolff, E.W. 1994. Spatial Variability of the Major Chemistry of the Antarctic Ice Sheet. Annals of Glaciology 20:440-447.

Oerlemans, J. 1988. Simulation of Historic Glacier Variations with a Simple ClimateGlacier Model. Journal of Glaciology 34(118):333-341.

Oliver, M.A. and Webster, R. 1990. Kriging: A Method of Interpolation for Geographical Information Systems. International Journal of Geographical Information Systems 4(3):313-332.

Paterson, W.S.B. 1994 [1969]. The Physics of Glaciers, Third Edition. Tarrytown, New York: Elsevier Science Inc.

Peuker, T.K. and Chrisman, N. 1975. Cartographic Data Structures. The American Cartographer 2(1):55-69.

Peuquet, D.J. 1984. A Conceptual Framework and Comparison of Spatial Data Models. Cartographica 21(4):66-113.

Peuquet, D.J. and Duan, N. 1995. An Event-Based Spatiotemporal Data Model (ESTDM) for Temporal Analysis of Geographical Data. International Journal of Geogrpahical Information Systems 9(1):7-24.

Pitty, A.F., 1982. The Nature of Geomorphology. Methuen and Co. Ltd. London.

Raper, J.F. and Kelk, B. 1991. Three-Dimensional GIS. In Geogrpahical Information Systems: Principles and Applications, ed. D.J. Maguire, M.F. Goodchild, and D.W. Rhind, pp.299-317.

Reinhardt, W. and Rentcsh, H. 1986. Determination of Changes in Volume and Elevation of Glaciers Using Digital Elevation Models for the Vernagtferner, Otztal Alps, Austria. Annals of Glaciology 8:151-158. 
Richards, K.S. 1990. Introduction to Morphometry. In Geomorphological Techniques, Second Edition, ed. A. Goudie, pp.33-35. London: Unwin Hyman.

Robinson, D.A. 1993. Hemispheric Snow Cover from Satellites. Annals of Glaciology 17:367-371.

Selby, M.J. 1985. Earth's Changing Surface. Oxford: Oxford University Press.

Shi, J. and Dozier, J. 1993. Measurements of Snow and Glacier-Covered Area with Single Polarization SAR. Annals of Glaciology 17:72-76.

Sigurdsson, O. and Jonsson, T. 1995. Relation of Glacier Variations to Climate Changes in Iceland. Annals of Glaciology 21:263-270.

Simonett, D.S. 1988. Considerations on Integrating Remote Sensing and Geographic Infornation Systems. In Building Databases for Global Science, ed. H. Mounsey, and R.F. Tomlinson, pp.105-128. Philadelphia: Taylor and Francis, Inc.

Steiner, D.R. and Ehlers, M. 1990. Establishment of a Digital Database for the Study of Glacial Velocity in Antarctica. Technical Papers, 1990 ACSM-ASPRS Annual Convention: Image Processing / Remote Sensing 4:369-377.

Sterner, R. 1997. Color Landform Atlas of the United States. World Wide Web site: http://fermi.jhuapl.edu/states/states.html. Baltimore: Johns Hopkins University.

UNESCO/IASH 1970. Perennial Ice and Snow Masses: A Guide for Compilation and Assemblage of Data for a World Inventory. Paris: United Nations Educational, Scientific, and Cultural Organization.

Vitek, J.D., Giardino, J.R., and Fitzgerald, J.W. 1996. Mapping Geomorphology: A Journey from Paper Maps, Through Computer Mapping to GIS and Virtual Reality. Geomorphology 16:233-249.

Wankiewicz, A. 1993. Multi-Temporal Microwave Satellite Observation of Snowpacks. Annals of Glaciology 17:155-160.

Weibel, R. and Heller, M. 1991. Digital Terrain Modeling. In Geographical Information Systems: Principles and Applications, ed. D.J. Maguire, M.F. Goodchild, and D.W. Rhind, pp.269-297. Essex, England: Longman Scientific and Technical. 
Winther, J. 1993. Studies of Snow Surface Characteristics by Landsat TM in Dronning Maud Land, Antarctica. Annals of Glaciology 17:27-34.

Worboys, M.F. 1995. GIS: A Computing Perspective. London: Taylor and Francis.

Xiao, Q., Raafat, H., and Gauthier, D. 1989. A Temporal/Spatial Database Structure for Remotely Sensed Image Data Management Within GIS. GIS/LIS ' 89 Proceedings 1:116-123. 